\author{
Aus dem Fachbereich Medizin \\ der Johann Wolfgang Goethe-Universität \\ Frankfurt am Main
}

betreut am

Zentrum der Radiologie

Institut für Diagnostische und Interventionelle Radiologie

Direktor: Prof. Dr. Thomas Vogl

\title{
Die Wirkung der transarteriellen Chemoembolisation und der Mikrowellenablation auf die Kurzzeitdynamik von zirkulierenden Tumorzellen bei hepatozellulären Karzinompatienten
}

\author{
Dissertation \\ zur Erlangung des Doktorgrades der Zahnmedizin \\ des Fachbereichs Medizin \\ der Johann Wolfgang Goethe-Universität \\ Frankfurt am Main \\ vorgelegt von \\ Linda Jasmin Riegelbauer \\ aus Nürnberg \\ Frankfurt am Main, 2021
}


Dekan:

Prof. Dr. Stefan Zeuzem

Referent:

Prof. Dr. Thomas Vogl

Korreferent/in:

Tag der mündlichen Prüfung: 
Diese Arbeit ist

meiner Familie

gewidmet. 


\section{Inhaltsverzeichnis}

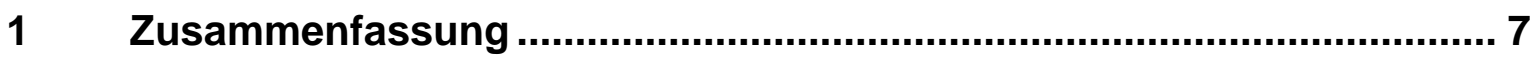

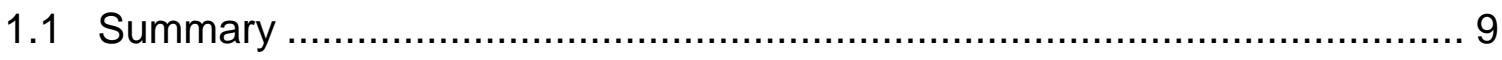

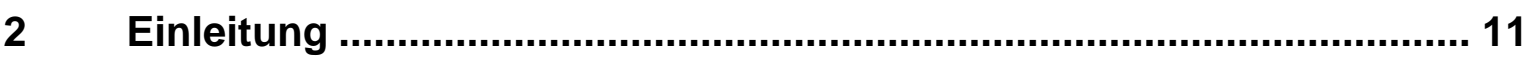

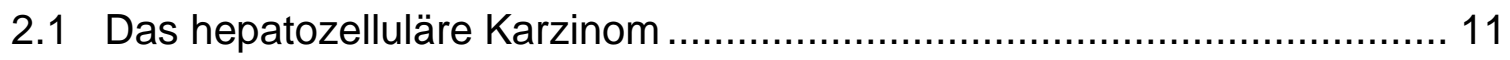

2.1.1 Epidemiologie, Prognose und Ätiologie ................................. 11

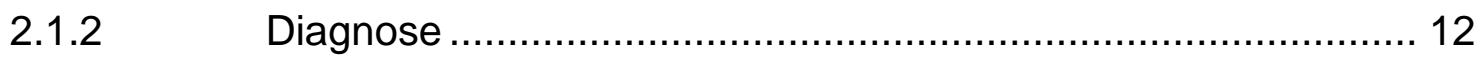

2.1.3 Klassifizierung und Therapie .............................................. 14

2.2 Radiologische Interventionen......................................................... 16

2.2.1 Transarterielle Chemoembolisation ....................................... 17

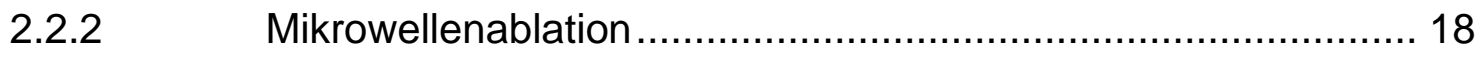

2.3 Zirkulierende Tumorzellen ........................................................... 19

2.3.1 Definition von zirkulierenden Tumorzellen............................... 19

2.3.2 Entstehung zirkulierender Tumorzellen .................................. 19

2.3.3 Unterscheidung von zirkulierenden Tumorzellen...................... 21

2.4 Isolation und Detektion von zirkulierenden Tumorzellen............................ 23

2.4.1 Detektion von zirkulierenden Tumorzellen mittels

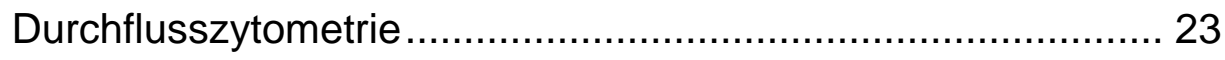

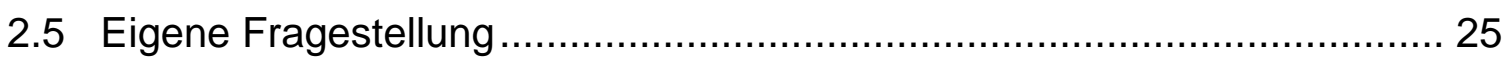

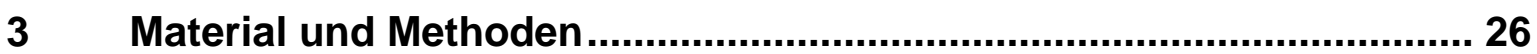

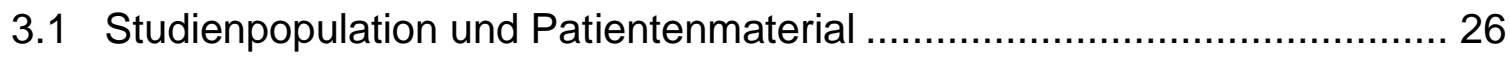

3.2 Datenquellen und Datenschutz ....................................................... 27

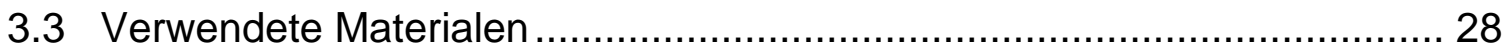

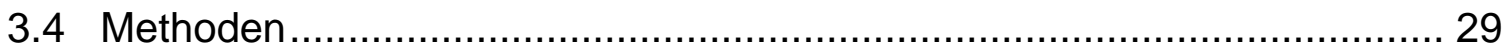

3.4.1 Angewendetes Verfahren zum Nachweis zirkulierender

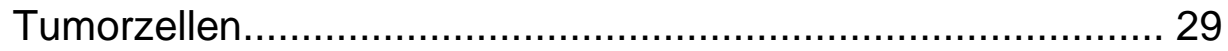

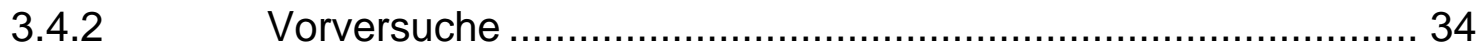

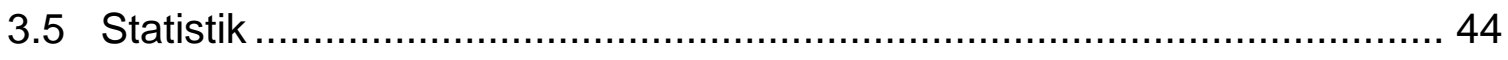

3.5.1 Wilcoxon-matched-pairs-Test............................................. 44

3.5.2 Wilcoxon-Mann-Whitney-Test ........................................... 45 
3.5.3 Rang-Korrelation: Spearman's Rho...................................... 46

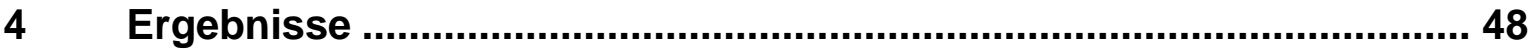

4.1 Anzahlen der zirkulierenden Tumorzellen ............................................ 51

4.1.1 CTC-Anzahlen der HCC-Patienten vor und nach TACE ........... 55

4.1.2 CTC-Anzahlen der HCC-Patienten vor und nach MWA ............ 56

4.1.3 CTC-Anzahlen bei TACE- und MWA-Patienten zusammen ...... 57

4.1.4 CTC-Anzahlen der gesunden Probanden und der TACE-

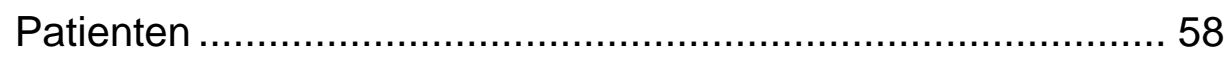

4.1.5 CTC-Anzahlen der gesunden Probanden und der MWA-

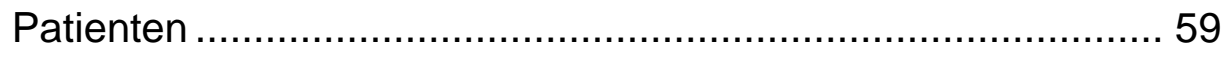

4.1.6 CTC-Anzahlen der gesunden Probanden und der TACE- und

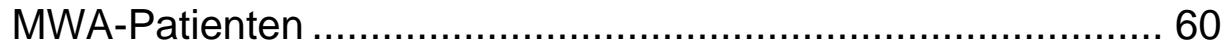

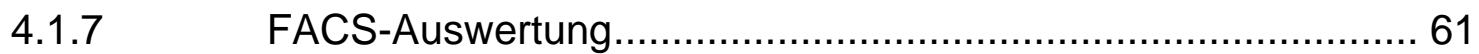

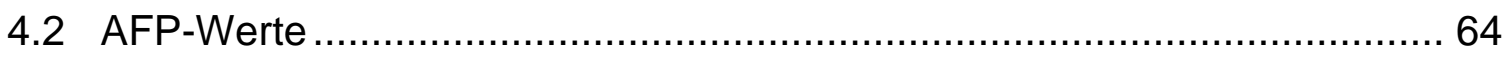

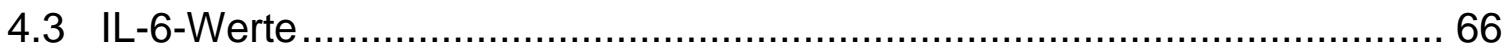

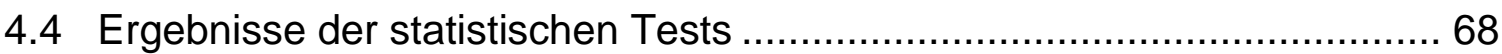

4.4.1 CTC-Anzahlen der HCC-Patienten vor und nach radiologischer Intervention im Vergleich.......................................................... 68

4.4.2 CTC-Anzahlen der gesunden Probanden und der HCC-Patienten

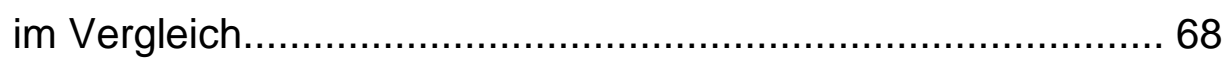

4.4.3 AFP- bzw. IL-6-Dynamik im Vergleich zur CTC-Dynamik .......... 69

4.5 Klinischer Verlauf nach radiologischer Intervention ................................. 70

5 Diskussion - Limitationen - Ausblick................................................... 73

5.1 Die Kurzzeitdynamik von zirkulierenden Tumorzellen bei transarterieller Chemoembolisation und Mikrowellenablation bei hepatozellulären Karzinompatienten

5.1.1 Tumorzellfreisetzung bei der Therapie des hepatozellulären

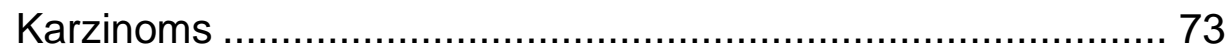

5.1.2 Gefäßarchitektur in Tumoren........................................... 74

5.1.3 Metastasierung durch CTCs................................................... 75

5.2 Unterschied der Anzahl zirkulierender Tumorzellen zwischen gesunden

Probanden und hepatozellulären Karzinompatienten 
5.2.1 Liquid Biopsy

5.3 Korrelation zwischen der Kurzzeitdynamik der CTCs und der des

AFP- Wertes als anerkannter klinischer Tumormarker .....

5.4 Korrelation zwischen der Kurzzeitdynamik der CTCs und der des IL-6-Werts als neu diskutierter Tumormarker

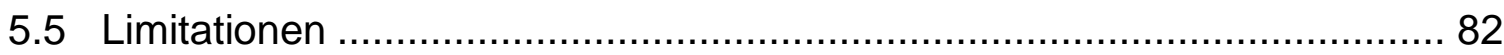

5.5.1 Blutproben-Gewinnung und Lagerung.................................. 82

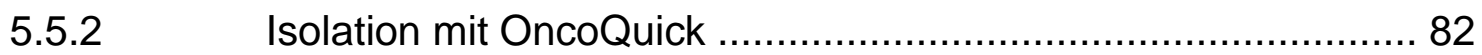

5.5.3 Detektion zirkulierender Tumorzellen ...................................... 83

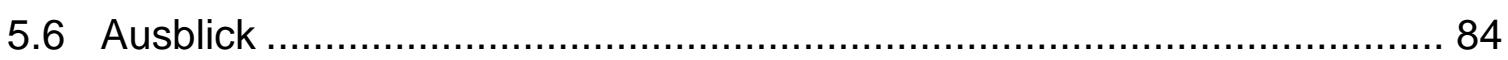

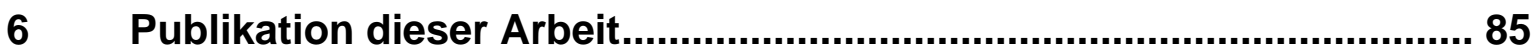

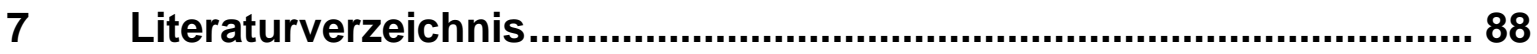

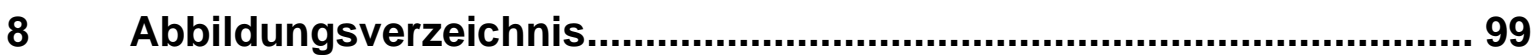

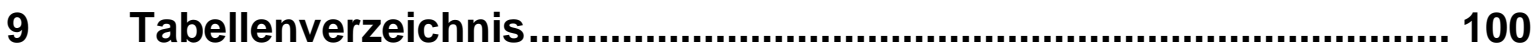

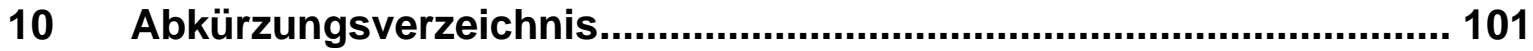

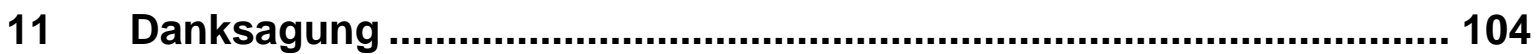

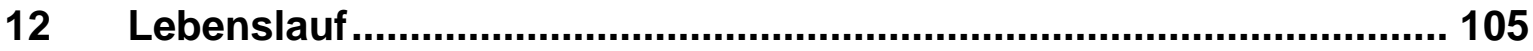

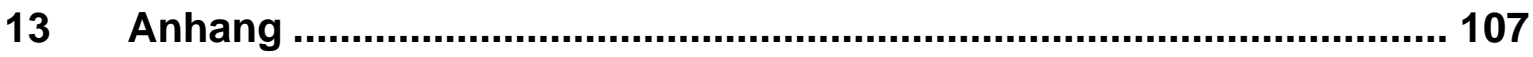

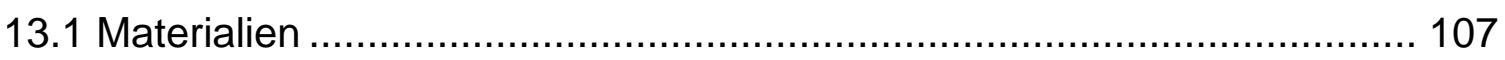

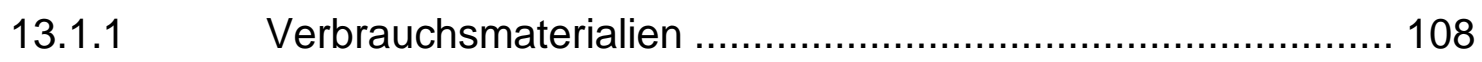

13.1.2 Chemikalien, Lösungen und Puffer ....................................... 109

13.1.3 HCC-Zelllinie HepG2 ................................................... 112

13.1.4 Zellmedium zur Kultivierung der HCC-Zelllinie HepG2 ............ 112

13.1.5 Einfriermedium zur Konservierung der HCC-Zelllinie HepG2.. 112

14 Schriftliche Erklärung.......................................................................... 113 


\section{Zusammenfassung}

Ziel der vorliegenden Arbeit war die Untersuchung der Kurzzeitdynamik zirkulierender Tumorzellen bei hepatozellulären Karzinompatienten, die erstmalig eine radiologische Intervention in Form einer transarteriellen Chemoembolisation oder einer Mikrowellenablation als Therapie erhielten. Dafür wurde in Vorversuchen eine neuartige Methode zur Isolation und Detektion von zirkulierenden Tumorzellen entwickelt.

Zugleich sollte ein potenzieller Einsatz dieser Methode als Screeningverfahren für hepatozelluläre Karzinompatienten mithilfe der Sensitivität und Spezifität überprüft werden. Darüber hinaus wurde eine mögliche Korrelation der Kurzzeitdynamik zirkulierender Tumorzellen sowohl mit der Kurzzeitdynamik des AFP-Wertes als anerkannten HCC-Tumormarker, als auch des IL-6-Wertes als aktuell diskutierten Tumormarker analysiert. Ferner wurde die Kurzzeitdynamik zirkulierender Tumorzellen mit dem klinischen Verlauf der Patienten verglichen.

Im Zeitraum von September 2017 bis Juni 2018 konnten Blutproben von 18 Patienten mit einem hepatozellulären Karzinom untersucht werden. Davon wurden zehn Patienten mittels Mikrowellenablation und acht Patienten mittels transarterieller Chemoembolisation behandelt. Daneben wurden Blutproben von 13 gesunden Probanden ausgewertet.

Methodisch wurden jeweils im Anschluss an die Gewinnung des Patientenblutes, vor und unmittelbar nach jeweiliger radiologischer Intervention, die zirkulierenden Tumorzellen aus dem Blut isoliert und die gewonnenen Zellen durch die Durchflusszytometrie nachgewiesen und quantifiziert. Als zirkulierende Tumorzellen wurden dabei jene Zellen betrachtet, die eine Negativität auf den Marker CD45 sowie eine Positivität auf die Marker ASGPR-1, CD146, CD274 und CD90 zeigten.

Durch den Vergleich der Proben vor und nach radiologischer Intervention konnte gezeigt werden, dass die Anzahlen zirkulierender Tumorzellen nach der radiologischen Intervention im Mittel niedriger sind als vor der Therapie. Die Anzahl zirkulierender Tumorzellen sank dabei im Schnitt bei den mit Mikrowellenablation behandelten Patienten stärker im Vergleich zu denen, die eine transarterielle Chemoembolisation erhielten. Dies bestätigte den klinischen Verlauf der 
Patientengruppen, da die Mortalität der Gruppe, die eine transarterielle Chemoembolisation erhielten deutlich höher war als bei den übrigen Patienten.

Als klinisch einsetzbare Screening-Methode im Sinne einer "Liquid Biopsy“ für das HCC müssen die Sensitivität und Spezifität weitergehend optimiert werden. Eine signifikante Korrelation zwischen der Kurzzeitdynamik der Anzahlen zirkulierender Tumorzellen und der Kurzzeitdynamik der AFP-Werte und der IL-6-Werte konnte nicht festgestellt werden.

Entgegen des erwarteten Trends, legte die angewendete Methode, durch das Absinken der zirkulierenden Tumorzellen, die positive Wirkung der transarteriellen Chemoembolisation und der Mikrowellenablation in hepatozellulären Karzinompatienten dar. 


\subsection{Summary}

The aim of this study was to investigate the short-term dynamics of circulating tumor cells in hepatocellular carcinoma patients who received transarterial chemoembolization or microwave ablation as radiological intervention for therapy for the first time. For this purpose, a novel method for isolation and detection of circulating tumor cells was developed in preliminary experiments.

At the same time, the potential use of this method as a screening procedure for hepatocellular carcinoma patients was to be examined using sensitivity and specificity. In addition, a possible correlation of the short-term dynamics of circulating tumor cells with the short-term dynamics of AFP as a recognized HCC tumor marker and IL-6 as a currently discussed tumor marker was analyzed. Furthermore, the short-term dynamics of circulating tumor cells were compared with the clinical course of the patients.

In the period from September 2017 to June 2018 blood samples of 18 patients with hepatocellular carcinoma were analyzed. Ten patients were treated by microwave ablation and eight patients by transarterial chemoembolization. In addition, blood samples from 13 healthy volunteers were evaluated.

Following the collection of the patient's blood, before and immediately after the respective radiological intervention, the circulating tumor cells were methodically isolated from the blood and the cells obtained were detected and quantified by flow

cytometry. Circulating tumor cells were considered to be those cells that showed a negativity for the marker CD45 and a positivity for the markers ASGPR-1, CD146, CD274 and CD90.

By comparing the samples before and after radiological intervention it could be shown that the number of circulating tumor cells after radiological intervention is on average lower than before therapy. On average, the number of circulating tumor cells decreased more in patients treated with microwave ablation compared to those who received transarterial chemoembolization. This confirmed the clinical course of the patient groups, as the mortality of the group receiving transarterial chemoembolization was higher than in the other patients. 
As a clinically applicable screening method in the sense of a "liquid biopsy" for HCC, sensitivity and specificity must be further optimized. A significant correlation between the short-term dynamics of circulating tumor cell counts and the short-term dynamics of AFP and IL-6 levels could not be established.

Contrary to the expected trend, the applied method, by decreasing circulating tumor cells, demonstrated the beneficial effect of transarterial chemoembolization and microwave ablation in hepatocellular carcinoma patients. 


\section{Einleitung}

\subsection{Das hepatozelluläre Karzinom}

\subsubsection{Epidemiologie, Prognose und Ätiologie}

Das hepatozelluläre Karzinom (engl. hepatocellular carcinoma, HCC) ist ein maligner Tumor der Leber, der von den Hepatozyten ausgeht. ${ }^{1}$ Mit einem Anteil von 70 - 85 \% der primären Leberkrebsarten, stellt das HCC weltweit den häufigsten Subtypen dar. ${ }^{2}$ Es ist die sechsthäufigste Tumorerkrankung und darüber hinaus die dritthäufigste tumorbedingte Todesursache weltweit. ${ }^{3}$ Jedes Jahr erkranken allein in Deutschland ca. sechs Männer und zwei Frauen pro 100.000 Einwohnern an einem HCC. ${ }^{3}$ Seit dem Jahr 1999 haben die altersstandardisierten Erkrankungsund Sterberaten bei beiden Geschlechtern in Deutschland zugenommen, wobei der Anstieg bei Männern deutlicher zu beobachten ist (s. Abbildung 1). ${ }^{4}$

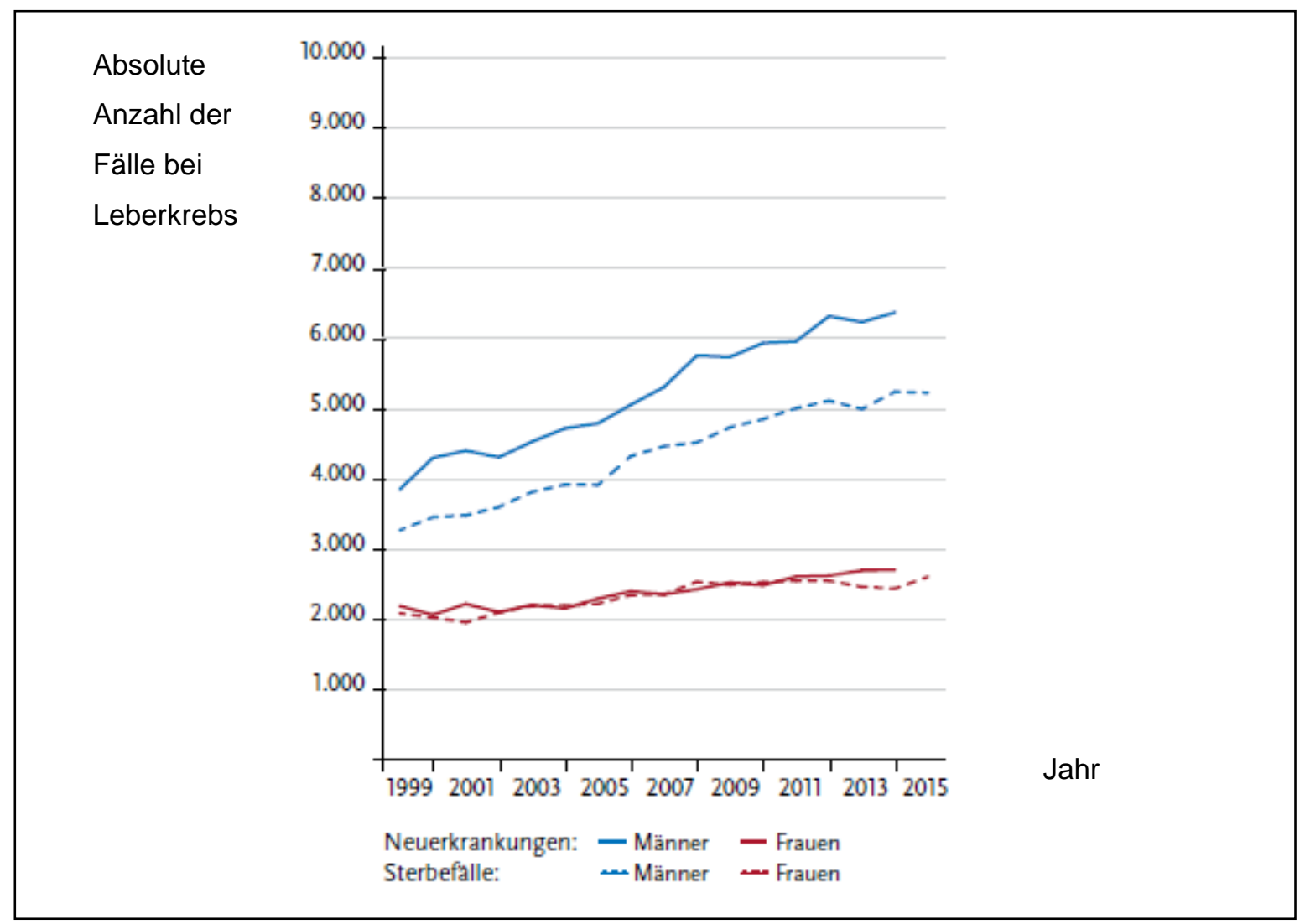

\section{Abbildung 1 - Erkrankungsrate Deutschland 1999 - 2015}

Anmerkung: Abbildung 3.6.1b aus dem Kapitel Leber (C22) „Krebs in Deutschland für 2013/2014. 11. Ausgabe. Robert Koch-Institut (Hrsg) und die Gesellschaft der epidemiologischen Krebsregister in Deutschland e.V. (Hrsg). Berlin, 2017“" ${ }^{5}$ 
Die relativen 5-Jahres-Überlebensraten von $14 \%$ bei Männern und $11 \%$ bei Frauen verdeutlichen die schlechte Langzeitprognose des HCCs. ${ }^{4}$ Die Haupttodesursache von HCC-Patienten stellt dabei nicht der Primärtumor dar, sondern dessen Metastasen, welche zum Teil erst nach Jahren in lebenswichtigen Organen auftreten. ${ }^{6}$ Innovationen im Bereich der HCC-Diagnostik und -Therapie ermöglichten in der letzten Dekade einen Wandel dieser Tumorerkrankung von einer nahezu sicheren Todesursache zu einer Krankheit, die in einem frühen Stadium entdeckt und behandelt werden kann. ${ }^{7}$

Über $90 \%$ aller malignen hepatozellulären Tumore entstehen auf dem Boden einer Leberzirrhose, wobei eine Zirrhose viraler Genese nach aktueller Datenlage mit dem höchsten Tumorrisiko verbunden ist. $^{8}$ Insgesamt verursachen Hepatitis-B-Infektionen $50 \%$ und Hepatitis-C-Infektionen $25 \%$ aller HCCs. ${ }^{8}$ Weitere Risikofaktoren für die Entstehung eines HCCs sind Alkoholabusus, eine nichtalkoholische Steatohepatitis (Fettleberhepatitis), das Pilzgift Aflatoxin B1 des Aspergillus flavus und Stoffwechselerkrankungen wie eine Hämochromatose oder ein Alpha-1-Antitrypsinmangel. ${ }^{4,9}$

\subsubsection{Diagnose}

Laut Leitlinie der Arbeitsgemeinschaft der Wissenschaftlichen Medizinischen Fachgesellschaften e.V. (AMWF) sollte Patienten mit erhöhtem HCC-Risiko eine Untersuchung zur Früherkennung eines HCCs angeraten werden, sofern diese von einer Therapie profitieren können. ${ }^{10}$ Zu dieser Risikogruppe zählen Patienten mit Leberzirrhose, chronischer Hepatitis-B-Infektion oder Steatohepatitis. ${ }^{10}$ Sowohl im Rahmen dieser Früherkennung als auch zur Verlaufsdiagnostik eines HCCs wird zum einen eine Sonografie der Leber durchgeführt und zum anderen der Alpha-Fetoprotein-Wert (AFP), ein Tumormarker, im Serum bestimmt. ${ }^{10}$

Als Tumormarker werden Proteine, Peptide oder andere biologische Substanzen bezeichnet, die direkt von Tumorzellen oder vom Körper als Reaktion auf einen Tumor gebildet werden. ${ }^{11}$ Der klinische Nutzen eines Tumormarkers hängt von seiner Spezifität und Sensitivität ab. ${ }^{11}$

Einen einzigen spezifischen HCC-Tumormarker zu definieren stellt sich bislang als sehr schwierig dar. ${ }^{12}$ Zum Einen gibt es zahlreiche und sehr unterschiedliche ätiologische Faktoren für die Entstehung eines HCCs (s.2.1.1), zum anderen kann 
ein HCC entweder von reifen Hepatozyten oder von Vorläuferzellen abstammen. ${ }^{13}$ Weiterhin durchläuft das HCC, wie andere Krebsarten auch, einen dynamischen Prozess, der die Morphologie und die molekularen Merkmale während der hepatozellulären Karzinogenese variieren lässt. ${ }^{13}$ Der ideale Tumormarker wäre spezifisch für das HCC und, zur Unterscheidung, bei prämalignen Lebererkrankungen (z.B. einer Leberzirrhose) nicht nachweisbar. ${ }^{14}$ Obwohl in zunehmendem Maße an der Entwicklung neuer Tumormarker geforscht wird, besteht nach wie vor eine weltweite Nachfrage nach weiteren Untersuchungen, ob bestimmte Tumormarker im klinischen Bereich eingesetzt werden können. ${ }^{12}$

\subsubsection{Alpha-Fetoprotein-Wert als Tumormarker}

Als Tumormarker des HCCs wurde das Alpha-Fetoprotein (AFP) als erster identifiziert. ${ }^{15}$ Trotz der Fülle von Tumormarkern, die für das HCC vorgeschlagen wurden, bleibt das AFP der meist verwendete. ${ }^{15,16}$

Als Tumormarker hat der AFP-Wert bei Patienten mit chronischer Lebererkrankung eine Sensitivität von $25-65 \%$ und eine Spezifität von $80-94 \% .^{17,18,19}$ Bei Erwachsenen stellt sich ein normaler Wert mit unter $15 \mu \mathrm{g} / \mathrm{l}$ AFP im Blut dar. ${ }^{8}$ Physiologisch erhöht ist das AFP, als embryonales Protein, lediglich bei Schwangeren. ${ }^{8}$

\subsubsection{Interleukin-6-Wert als Tumormarker}

Das entzündliche Zytokin Interleukin-6 (IL-6) wird in aktuellen Studien als potenzieller Tumormarker diskutiert, da er an der HCC-Entwicklung beteiligt zu sein scheint. ${ }^{20}$ 21, 22 Residente Lebermakrophagen, auch Kupffer-Zellen genannt, werden als die spezifischen tumor-assoziierten Makrophagen des HCCs angesehen und können verschiedene Zytokine - vor allem IL-6 - produzieren und damit eine Entzündungsreaktion und die Tumorentstehung fördern. ${ }^{23}$ Die molekularen Mechanismen und damit die genaue Rolle des IL-6 bei der Karzinogenese in der Leber sind jedoch noch ungeklärt. ${ }^{23,}{ }^{22}$ Studien zeigten allerdings, dass HCC-Patienten signifikant höhere IL-6-Spiegel aufweisen als gesunde Kontrollpersonen. ${ }^{20,}{ }^{24}$ Des Weiteren sind höhere IL6-Spiegel mit einer schlechteren Prognose verbunden. ${ }^{20}$ 


\subsubsection{Klassifizierung und Therapie}

Das makroskopische Erscheinungsbild eines HCCs kann vielfältig sein. ${ }^{8}$ Neben gut abgrenzbaren solitären, kommen multiple Tumore und solche mit einer diffusen Infiltration des Parenchyms vor. ${ }^{8}$

Zur Einteilung des HCCs hat sich in Deutschland die Barcelona Clinic Liver Cancer (BCLC) Klassifizierung etabliert. ${ }^{25}$ Die Einteilung der Patienten mit HCC erfolgt dabei in fünf verschiedene Stadien: sehr frühes, frühes, intermediäres, fortgeschrittenes Stadium sowie Endstadium. ${ }^{26}$ Dieses Klassifizierungssystem berücksichtigt verschiedene Kriterien wie die Tumorherdanzahl und -größe, die Einschränkung der Leberfunktion (Erhebung des Bilirubinwerts als Abbauprodukt der Leber) sowie das Vorliegen einer portalen Hypertension. ${ }^{25}$ Die BCLC-Einteilung dient als Grundlage für die Auswahl und Durchführung einer stadiengerechten HCC-Therapie mit kurativem oder palliativem Ansatz. ${ }^{25}$ Es existieren sowohl chirurgische, radiologische als auch antikörperbasierte Therapiemöglichkeiten. ${ }^{25}$ Abbildung 2 zeigt ein vereinfachtes Schema der BCLC-Einteilung

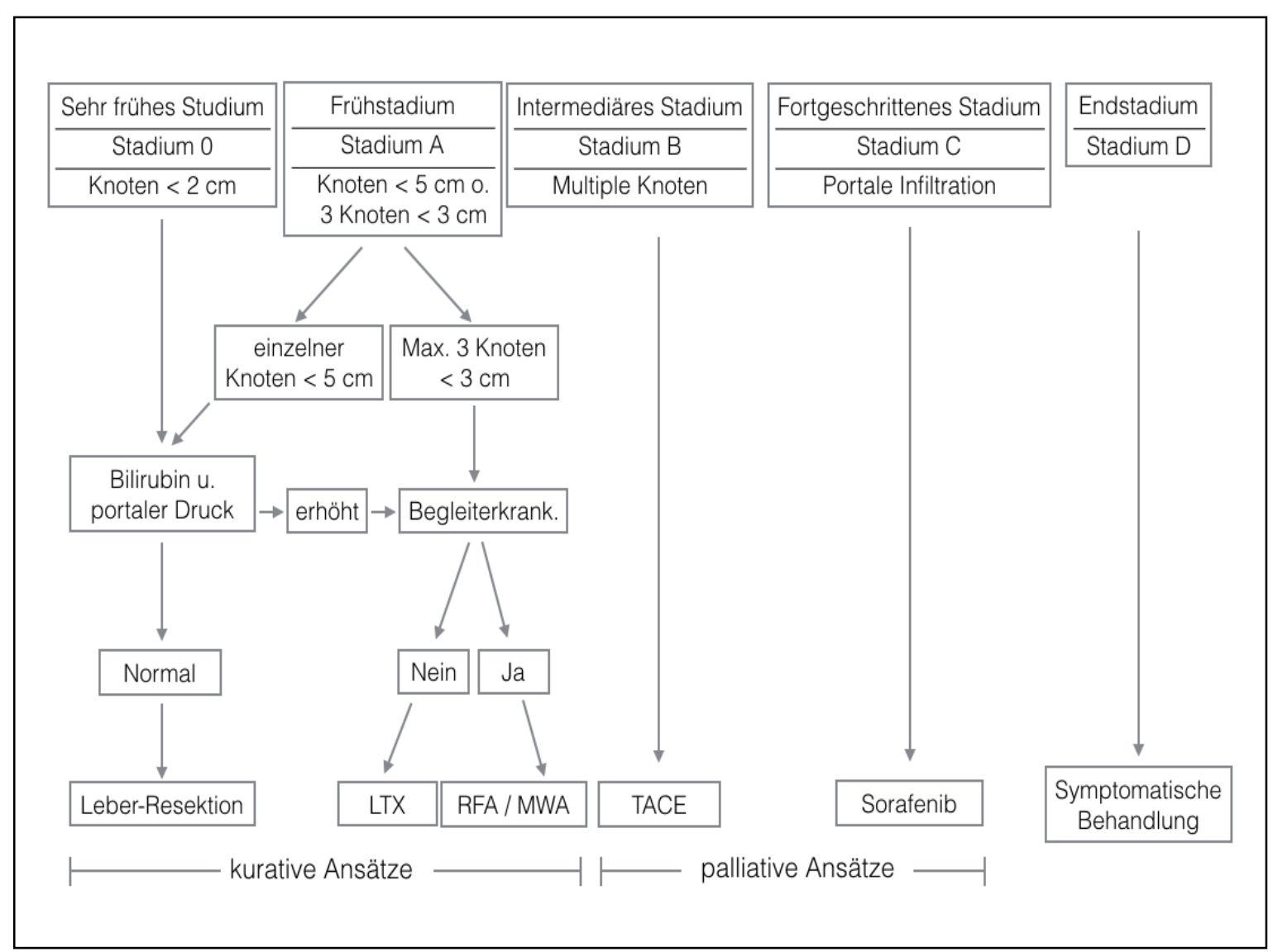

Abbildung 2 - BCLC-Klassifizierung des HCCs

Anmerkung: Abbildung 2 ist modifiziert nach dem Schema der BCLC-Arbeitsgruppe. ${ }^{7}$ 
Abk.: Begleiterkrank= Begleiterkrankungen, $\mathrm{LTX}=$ Lebertransplantation, $\mathrm{RFA}=$ Radiofrequenzablation, MWA = Mikrowellenablation, $\mathrm{TACE}=$ Transarterielle Chemoembolisation, $\mathrm{o} .=$ oder, $\mathrm{u} .=\mathrm{und}$

Zu den operativen Therapieansätzen zählen zum einen die Leberteilresektion mit dem Ziel einer vollständigen Entfernung des Tumors und zum anderen die Lebertransplantation, bei der eine erkrankte Leber durch eine gesunde Leber eines Spenders ersetzt werden kann. ${ }^{27}$ Die operativen Verfahren werden vor allem bei solitären HCC-Formen (Stadium 0 und A) empfohlen. ${ }^{7}$ Die radiologischen interventionellen Therapien, zu denen die Mikrowellenablation (MWA) und die Transarterielle Chemoembolisation (TACE) zählen, werden hingegen bei multiplen HCC-Herden (Stadium A und B) bevorzugt. ${ }^{7}$ Im fortgeschrittenen Stadium hat sich der monoklonale Antikörper Sorafenib als Therapiemöglichkeit etabliert. ${ }^{7}$ Dies ist ein systemischer, oraler Multikinase-Inhibitor mit antiangiogener und antiproliferativer Wirkung. ${ }^{28}$ Patienten im Endstadium werden lediglich symptomatisch behandelt. ${ }^{26}$ Auf die radiologischen, interventionellen Therapien wird in den folgenden Kapiteln genauer eingegangen. 


\subsection{Radiologische Interventionen}

Seit über 60 Jahren werden minimalinvasive Interventionen im Fachbereich Radiologie angewendet und ständig weiterentwickelt. ${ }^{29}$ Alleine im Jahr 2016 wurden in der Datenbank der Deutschen Gesellschaft für Interventionelle Radiologie und minimalinvasive Therapie (DeGIR) über 170.000 radiologische Interventionen in Deutschland dokumentiert. ${ }^{29}$

Im Rahmen der interventionellen Radiologie stehen zahlreiche Behandlungstechniken zur Verfügung. ${ }^{30}$ Die verschiedenen Techniken können unterschieden werden in die thermoablativen Verfahren, deren Wirkung auf thermischen Veränderungen beruht, und in die vaskulären Verfahren, die über eine Manipulation der Gefäße wirken. ${ }^{30}$ Die große Bandbreite der interventionellen radiologischen Therapieoptionen soll am Beispiel der Behandlung von Lungen- und Lebermetastasen in Tabelle 1 verdeutlicht werden.

Tabelle 1 - Behandlungstechniken interventioneller Radiologie

\begin{tabular}{|ll|}
\hline Einteilung & Therapien \\
\cline { 2 - 3 } thermoablativ & MWA (Mikrowellenablation) \\
& RFA (Radiofrequenzablation) \\
& LITT (Laserablation) \\
& IRE (Elektroporation) \\
& Kryotherapie \\
\cline { 2 - 3 } vaskulär & TACE (Transarterielle Chemoembolisation) \\
& TACP (Transarterielle Chemoperfusion) \\
& SIRT (selektive interne Radiotherapie) \\
& Chemosaturation
\end{tabular}

Anmerkung: Tabelle 1 ist erstellt aus Daten aus Vogl TJ, Panahi B, Fischer S, et al. Interventionelle Therapie von Lungen- und Lebermetastasen. Onkologe. 2014.

In der vorliegenden Studie wurden die radiologischen Therapieoptionen Mikrowellenablation (MWA) und Transarterielle Chemoembolisation (TACE) untersucht. Diese werden daher im Folgenden genauer erläutert. 


\subsubsection{Transarterielle Chemoembolisation}

Die Transarterielle Chemoembolisation (TACE) ist ein vaskulär basiertes Therapieverfahren der Radiologie und gilt bei HCC-Patienten mit BCLC Stadium B als Standardbehandlung. ${ }^{30,31}$ Dabei werden über einen Katheter Chemotherapeutika und Embolisationsmittel direkt in die arteriellen Gefäße des Karzinomgewebes appliziert. ${ }^{30}$ In Abbildung 3 ist das Therapieverfahren der TACE schematisch dargestellt.

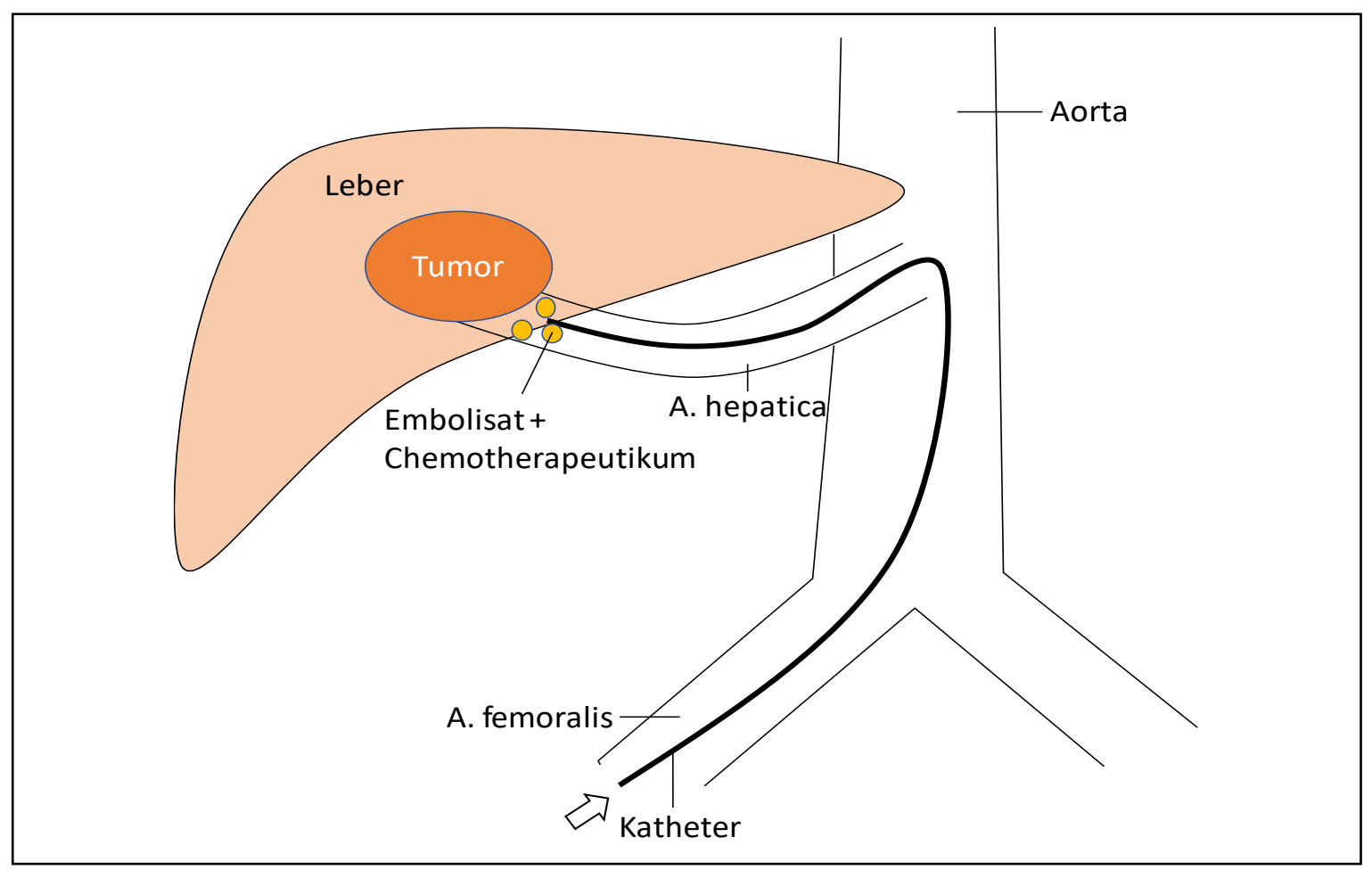

Abbildung 3 - Therapievefahren der Transarteriellen Chemoembolisation

Abk: A. = Arteria

Die TACE basiert auf zwei Therapieprinzipien: Zum einen führt das Embolisationsmittel zu einer lokalen Ischämie. ${ }^{30}$ Zum anderen ermöglicht es eine längere Wirkung und eine höhere Konzentration des parallel applizierten Chemotherapeutikums im Tumorgewebe (insb. im Vergleich zu einer systemischen Chemotherapie). ${ }^{30}$ Die gesunden Leberzellen werden dabei nur gering beeinträchtigt, da ihre Versorgung über die Portalvene bestehen bleibt. ${ }^{32}$ Als Chemotherapeutikum werden Zytostatika wie Cisplatin oder Mitomycin C verwendet. ${ }^{33}$ Als Embolisat und zugleich zur Darstellung und Lokalisation des HCCs dient das Röntgenkontrastmittel Lipiodol. ${ }^{33}$ 


\subsubsection{Mikrowellenablation}

Die Mikrowellenablation (MWA) gehört zu den thermoablativen Verfahren interventioneller, radiologischer Behandlungstechniken. ${ }^{30}$ Bei diesem Verfahren wird das Tumorgewebe durch Hitze zerstört. ${ }^{30} \mathrm{Nach}$ perkutanem, laparoskopischem oder offen chirurgischem Zugang wird der Tumor mittels radiologischer Kontrolle lokalisiert und in diesen eine Mikrowellensonde platziert. ${ }^{34}$ Die Sonde bzw. der integrierte Mikrowellengenerator emittiert elektromagnetische Wellen, die durch Wärmeerzeugung Gewebe zerstören. ${ }^{34}$ Diese Art der Wärmeentstehung wird als dielektrische Hysterese bezeichnet. Dabei versuchen polare Moleküle, wie Wasser, sich kontinuierlich nach dem angelegten elektromagnetischen Feld auszurichten, das seine Polarität Milliarden Male pro Sekunde wechselt (ca. 900 bis $2500 \mathrm{MHz}){ }^{34,35}$ Sobald die polaren Moleküle mit der Änderung der Feldausrichtung nicht mehr "mithalten" können, wird ein Teil der Mikrowellenenergie als Wärme frei. ${ }^{35}$ Vor allem Gewebe mit einem hohen Prozentsatz an Wasser, wie Tumore, sprechen deshalb auf diese Art der Gewebezerstörung stark an. ${ }^{36}$ In Abbildung 4 ist das Prinzip der MWA schematisch dargestellt.

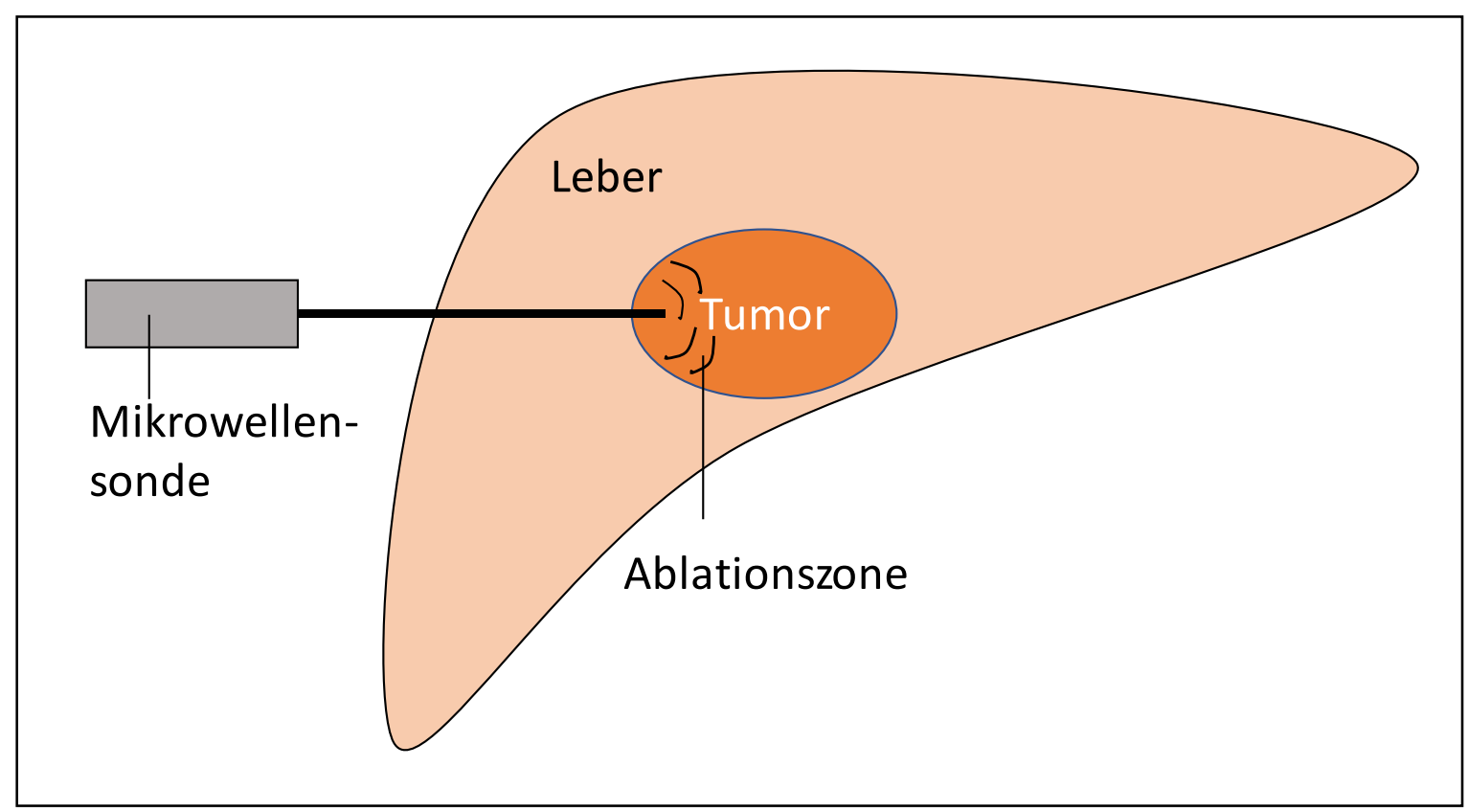

Abbildung 4 - Prinzip der Mikrowellenablation

Anmerkung: Als Ablationszone bezeichnet man das Gewebevolumen, das durch die emittierten Mikrowellen erhitzt wird. ${ }^{37}$ 


\subsection{Zirkulierende Tumorzellen}

\subsubsection{Definition von zirkulierenden Tumorzellen}

Bei zirkulierenden Tumorzellen (engl. circulating tumor cells; CTCs) handelt es sich um Tumorzellen, die sich vom Zellverband des Primärtumors oder dessen Metastasen lösen und sich systemisch über das Blut- oder Lymphsystem im Körper des Patienten ausbreiten können. ${ }^{37}$ Zirkulierende Tumorzellen wurden im Jahr 1869 erstmals im Blut von verstorbenen Tumor-Patienten gefunden. ${ }^{38}$

Tumorzellen werden kontinuierlich vom Tumorgewebe in das Blutsystem eines Patienten freigesetzt. ${ }^{39}$ Seit vielen Jahren ist bekannt, dass invasive diagnostische und therapeutische Eingriffe am Tumor, wie Biopsien oder Bestrahlung, zur iatrogenen Aussääung von Tumorzellen führen können. 40, 41, 42 Bereits durch äußere mechanische Manipulation des Tumors kann die Anzahl zirkulierender Tumorzellen bzw. ganzer zirkulierender Tumor-Zellverbände im Blut erhöht werden. ${ }^{39}$

In der letzten Dekade haben CTCs als potenzielle Tumormarker im Rahmen der Früherkennung enorme Aufmerksamkeit erfahren und sind derzeit Gegenstand der Grundlagenforschung. ${ }^{43}$ Ferner herrscht Konsens darüber, dass Informationen zu Vorkommen und Art von CTCs zusätzliche prognostische Informationen liefern können. ${ }^{44}$

Obwohl CTCs bereits in zahlreichen klinischen Studien untersucht wurden (aktuell lassen sich über 21.500 Publikationen zu CTCs auf PubMed finden [Stand:01/2019]), hat sich ihre Verwendung im klinischen Altag noch nicht etabliert..43,45 Unter anderem sind viele Fragen bezüglich der Detektion und Charakterisierung von CTCs noch ungeklärt. ${ }^{43}$

\subsubsection{Entstehung zirkulierender Tumorzellen}

Bei Tumorzellen kann eine sogenannte phänotypische Plastizität auftreten, welche lediglich bei embryonalen Zellen physiologisch ist. ${ }^{46}$ Dieser Begriff beschreibt die Tatsache, dass Zellen ihre phänotypischen Eigenschaften ändern können. ${ }^{46}$ Ein solcher Prozess findet bei der Metastasenbildung eines Primärtumors in Form der sogenannten epithelial-mesenchymalen Transition (EMT) statt: Verankerte Tumor-Epithelzellen gehen durch eine mehrstufige Dedifferenzierung in einen 
mesenchymalen Phänotypen über, sodass sich diese wie bewegliche Fibroblasten verhalten können. ${ }^{47}$ Auf zellulärer Ebene lässt sich dies beispielsweise durch die Herunterregulierung der E-Cadherin-Expression erklären. ${ }^{48}$ Das E-Cadherin ist normalerweise, als eines der wichtigsten Zelladhäsionsmoleküle, an der Epithelzelloberfläche lokalisiert und sorgt für einen festen Verbund der Epithelzellen. ${ }^{49}$ Als Folge der EMT kann die Emigration der Tumorzelle von der Epithelschicht stattfinden. ${ }^{50}$ Durch diesen Mechanismus kann sich die Tumorzelle aus dem Zellverband lösen und als zirkulierende Tumorzelle im Blutsystem des Menschen zu anderen Geweben wandern. ${ }^{50}$

Der beschriebene Vorgang der EMT ist reversibel. ${ }^{46}$ Die verlorenen epithelialen Merkmale können durch die sogenannte mesenchymal-epitheliale Transition (MET) wieder hergestellt werden. ${ }^{46}$ Bei Erreichen eines entfernten Gewebes kann sich die CTC somit erneut in eine Epithelzelle umwandeln und in einen gesunden Zellverband einnisten. ${ }^{46}$ Die Vorgänge der EMT und MET sind in Abbildung 5 zusammengefasst.

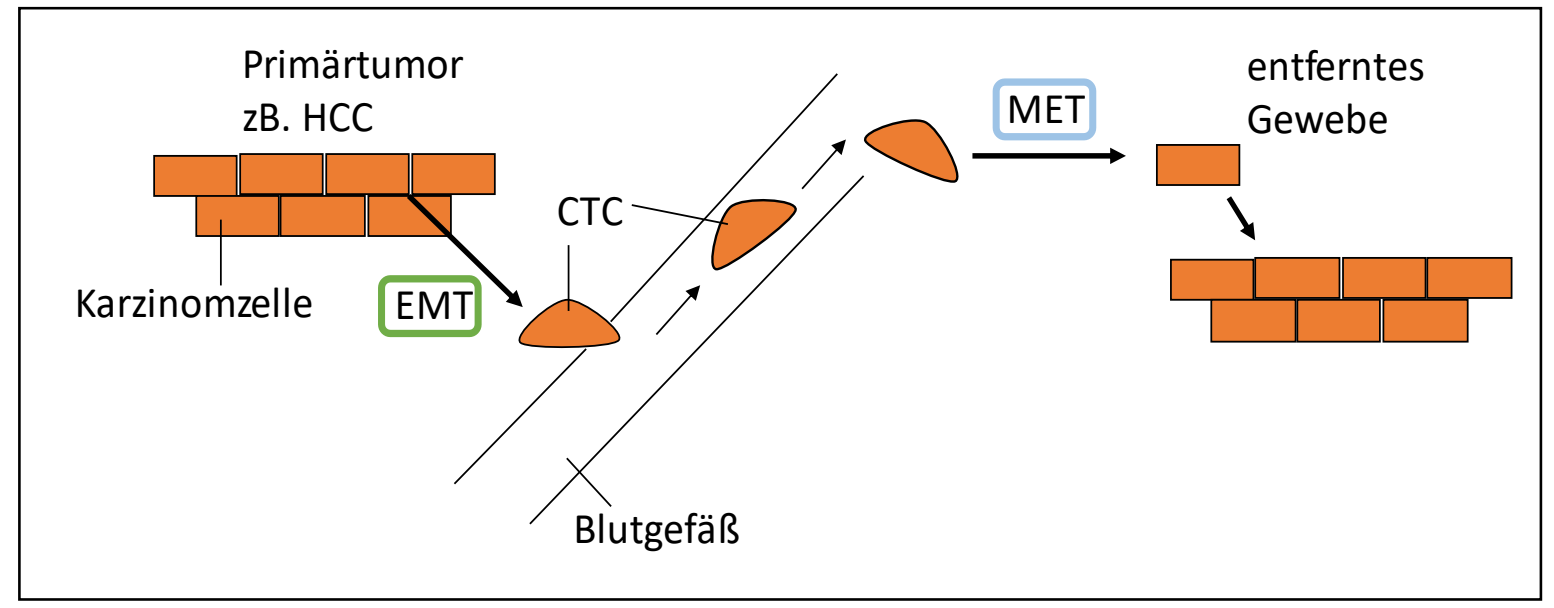

\section{Abbildung 5 - Mechanismus der EMT und MET}

Anmerkung: Abbildung ist angelehnt an die Abbildung von Moustakas A, Heldin C-H. aus Mechanisms of TGF $\beta$ Induced Epithelial-Mesenchymal Transition. J Clin Med. $2016{ }^{52}$

Abk: $\mathrm{EMT}=$ epithelial-mesenchymale Transition, $\mathrm{MET}=$ mesenchymal-epitheliale Transition, $\mathrm{HCC}=$ hepatozelluläres Karzinom, $\mathrm{CTC}=$ zirkulierende Tumorzelle

Die EMT und die MET sind im Wesentlichen für die metastatischen Vorgänge erforderlich und spielen damit offenbar eine entscheidende Rolle bei der intra- und extrahepatischen Metastasierung. ${ }^{47}$ 


\subsubsection{Unterscheidung von zirkulierenden Tumorzellen}

Verschiedene Studien zeigen, dass sich CTCs nach verschiedenen Merkmalen in unterschiedliche Subtypen einteilen lassen. ${ }^{51}$ Eine allgemeingültige Klassifikation von CTCs ist in der Literatur jedoch bis dato nicht zu finden.

In der hier vorliegenden Studie wurde sich insbesondere auf die so bezeichneten CTC-Subtypen der zirkulierenden Tumorstammzellen und der aggressiven zirkulierenden Tumorzellen fokussiert. Auf diese zwei Arten von CTCs wird in den folgenden Kapiteln näher eingegangen.

\subsubsection{Zirkulierende Tumorstammzellen}

Als Tumorstammzellen (engl. cancer stem cells, CSCs) werden Zelltypen eines Tumors bezeichnet, die die Fähigkeit besitzen, sich selbst zu erneuern und heterogene Linien von Zell-Nachkommen zu bilden. ${ }^{52}$ Nach derzeitigem wissenschaftlichen Kenntnisstand sind vor allem CSCs in der Lage, in peripheren Organen Metastasen zu bilden. ${ }^{53}$ Sowohl die langsame Zellzyklusprogression als auch die hohe Expression von Efflux-Pumpen (Strukturen, die Stoffe aus der Zelle heraus befördern können) macht Tumorstammzellen weniger empfindlich für Strahlen- und Chemotherapien. ${ }^{54}$ Es ist davon auszugehen, dass diverse Tumorarten derzeit nicht geheilt werden können, da die bislang eingesetzten Therapiemethoden die Tumorstammzellen nicht eliminieren können. ${ }^{54}$ CSCs entstammen nicht notwendigerweise aus einer Transformation gesunder Gewebestammzellen, sondern können auch "de novo" aus differenzierten Zellen entstehen. ${ }^{55,56}$

CSCs konnten bereits in einer Reihe von Malignomen nachgewiesen werden. ${ }^{57}$ Das Vorkommen dieser speziellen Art von CTCs scheint mit einer beträchtlich schlechteren Prognose für davon betroffenen Tumorpatienten verbunden zu sein. ${ }^{58}$

Als ein wichtiger Zellmarker für CSCs der Leber konnte das CD90-Protein identifiziert werden. ${ }^{59,} 60$ Maligne Zellen, die CD90 exprimieren, sind für die Entwicklung des Tumors maßgeblich verantwortlich. 59, 60 CD90 ist ein Glykoprotein, das hauptsächlich an Zell-Zell- und Zell-Matrix-Wechselwirkungen beteiligt ist. ${ }^{61}$ Insbesondere Zellen des Immunsystems, mesenchymale Stammzellen aus dem Knochenmark und hepatische Vorläuferzellen tragen dieses Protein physiologisch an ihrer Oberfläche. ${ }^{62,63}$ In aktuellen Studien konnte gezeigt werden, dass das 
CD90-Protein in $73 \%$ bis $92 \%$ der untersuchten HCC-Proben überexprimiert wird. ${ }^{60,64}$

\subsubsection{Aggressivität von zirkulierenden Tumorzellen}

Die Aggressivität und das postoperative Wiederauftreten eines hepatozellulären Karzinoms korreliert signifikant mit der Überexpression des „Programmed Death Liganden 1“ (PD-L1), der auch als CD274 bekannt ist. ${ }^{65}$ Der PD-L1, der auf verschiedenen Tumorzellen - aber auch Immunzellen exprimiert wird - spielt eine entscheidende Rolle bei der Resistenz des Tumors gegen das Immunsystem. ${ }^{66}$ Durch Bindung des korrespondierenden Rezeptors PD-1 inhibiert dieser Ligand aktivierte T-Lymphozyten, die normalerweise für die Eliminierung von entarteten Zellen zuständig sind.67,68 Die daraus folgende herabgesetzte Reaktion des Immunsystems führt zu einer Tumorprogression. ${ }^{69}$ Eine Überexpression von PD-L1 in Tumoren wie dem HCC, ist dementsprechend mit einem schlechteren klinischen Outcome verbunden. ${ }^{69}$ CTCs, die PD-L1 vermehrt an ihrer Oberfläche tragen, werden daher in dieser Studie als aggressive zirkulierende Tumorzellen benannt. In anderen Studien konnte der PD-L1 in 62\% der Proben von HCCs nachgewiesen werden. ${ }^{70}$ 


\subsection{Isolation und Detektion von zirkulierenden Tumorzellen}

Der Nachweis von CTCs ist mit hohen Anforderungen verbunden. ${ }^{71}$ Aufgrund der Tatsache, dass sie in sehr geringen Konzentrationen vorkommen (eine CTC auf ca. $10^{6}$ bis $10^{7}$ Leukozyten), erfordert die Identifikation und Charakterisierung dieser Zellen, eine extrem sensitive und spezifische analytische Methode. ${ }^{71,}{ }^{72}$ Für den Nachweis im Blut, müssen CTCs zuerst von den übrigen Blutzellen isoliert werden. ${ }^{72}$ Die möglichst reinen, gewonnenen Zellen können im Anschluss mittels Durchflusszytometrie dargestellt werden. ${ }^{72}$ Die Suche nach den optimalen Methoden und Durchführungen der Isolation und Detektion zirkulierender Tumorzellen ist derzeit noch Gegenstand der Forschung. ${ }^{72}$

\subsubsection{Detektion von zirkulierenden Tumorzellen mittels Durchflusszytometrie}

Die Methode der Wahl für die Detektion von Zellpopulationen ist die Durchflusszytometrie (engl. Fluorescence activated cell sorting, FACS). ${ }^{73}$ Dieses Verfahren benötigt die spezielle Gerätschaft eines Durchflusszytometers, das in Abbildung 6 dargestellt ist. ${ }^{73}$

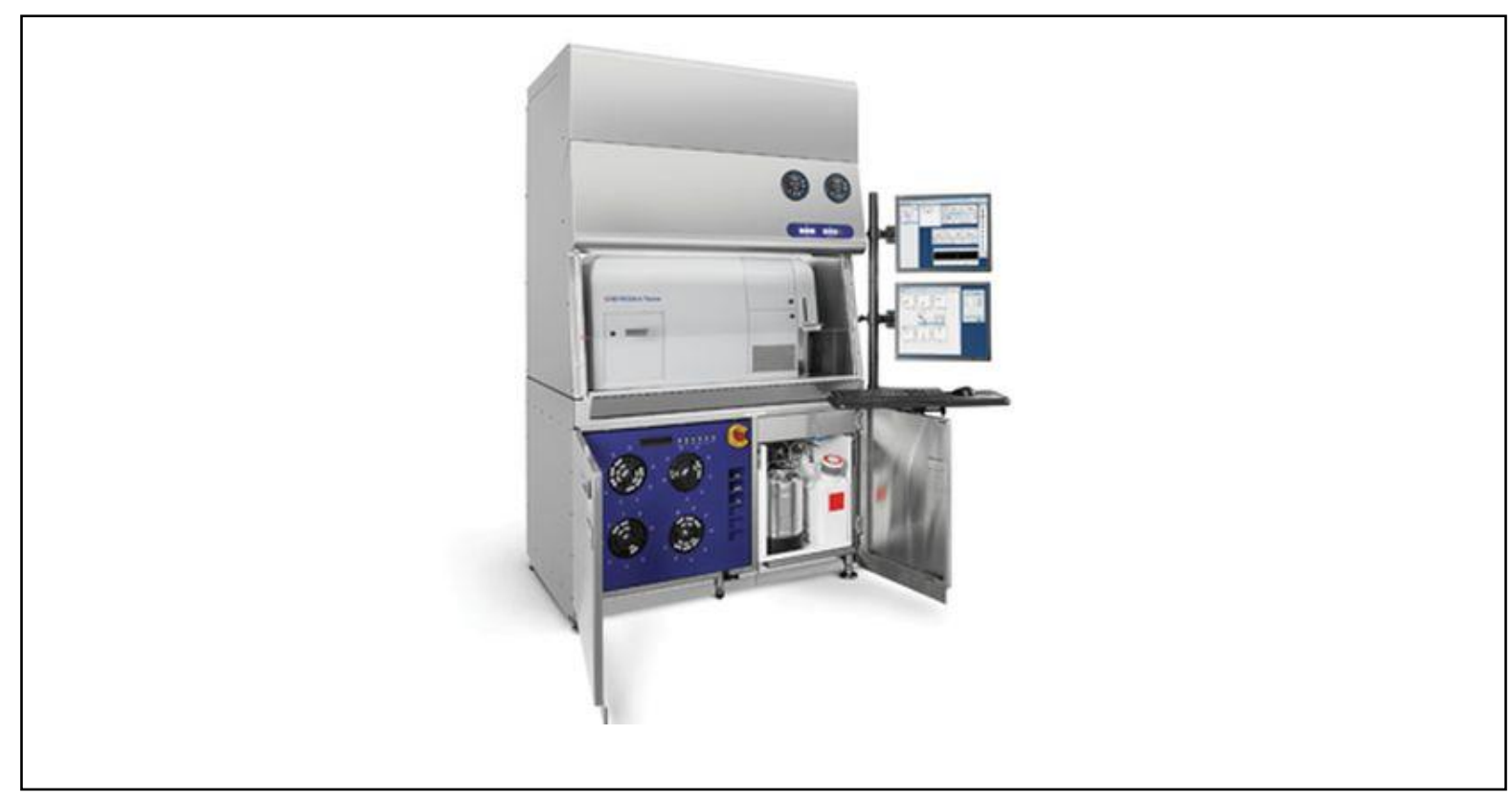

Abbildung 6 - Durchflusszytometer

Anmerkung: Bei dem verwendeten Durchflusszytometer handelt es sich um ein FACSAria ${ }^{\mathrm{TM}}$ Fusion Gerät der Firma BD Biosciences (San Jose, CA, USA) ${ }^{72}$ 
Um Tumorzellen mit Hilfe eines Durchflusszytometers darstellen zu können, werden sie nach der Isolation mit fluoreszenzmarkierten monoklonalen Antikörpern angefärbt. ${ }^{74}$ Letztere binden spezifische Oberflächenmarker der zu untersuchenden Zellpopulation. ${ }^{74}$

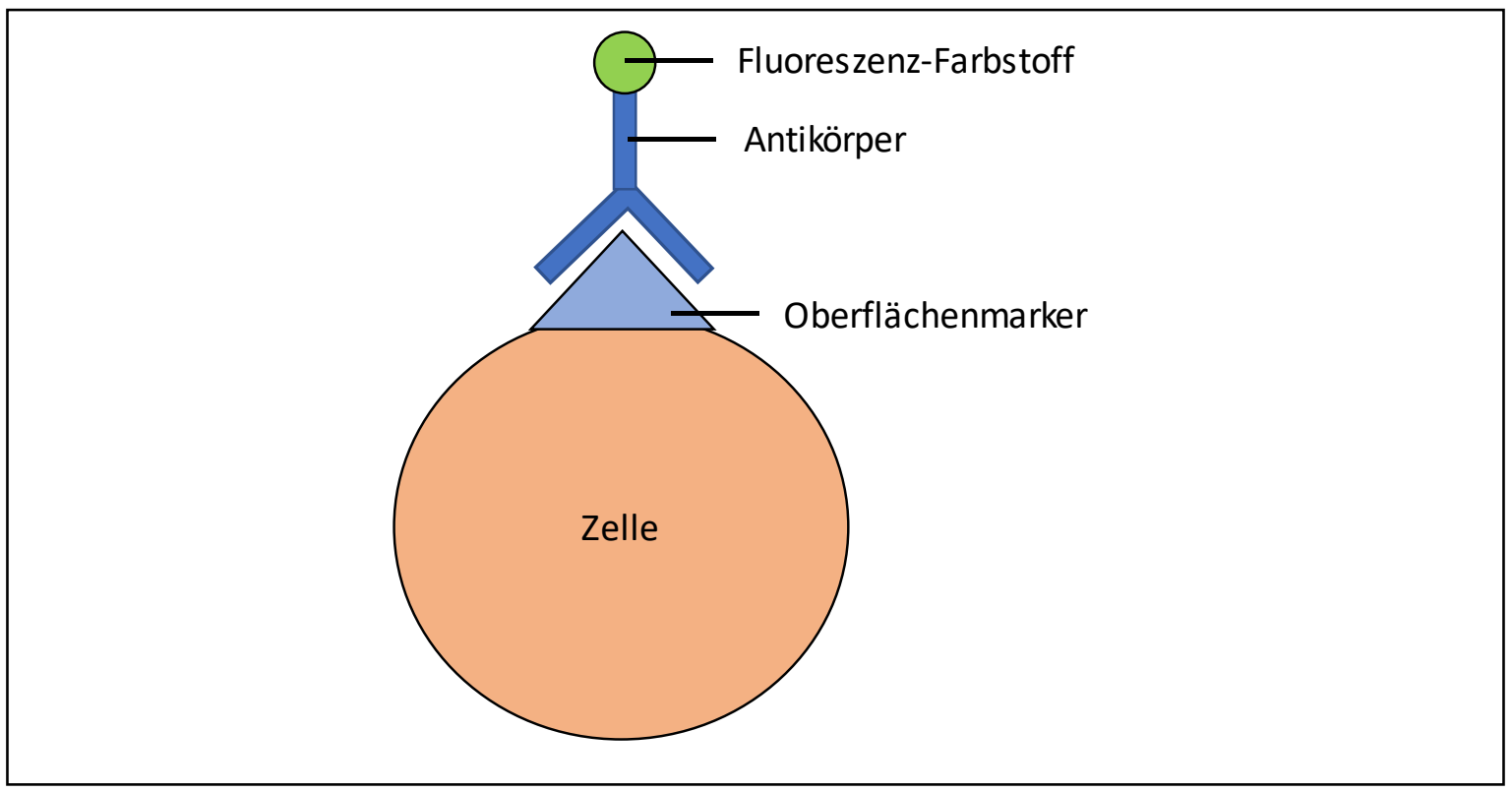

Abbildung 7 - Prinzip der Anfärbung mit fluoreszenzmarkierten Antikörpern

Anmerkung: Die Zelle könnte z.B. eine CTC sein. Die Oberflächenmarker könnten z.B. CD90 oder CD274 sein (s.o.).

Die markierten Zellen werden anschließend als Strom durch das Durchflusszytometer geleitet. ${ }^{75}$ Dabei registriert das Gerät die Fluoreszenzen der Antikörper. ${ }^{75}$ Basierend auf diesen Daten können die Zellen in der Auswertung nach Größe, Granularität und Oberflächenprofil unterschieden werden. ${ }^{75}$ So können die Anzahl eines bestimmten Zelltyps (z.B. CTCs) erfasst und verschiedene Zellpopulationen graphisch dargestellt werden. ${ }^{75}$

Damit hängt der Erfolg der Detektion von CTCs mittels FACS weitgehend von der Auswahl der Oberflächenmarker und der zugehörigen monoklonalen Antikörper $a b .{ }^{73}$ Zum angewendeten Verfahren sowie $z u$ den verwendeten Oberflächenmarkern und Antikörpern siehe Kapitel 3.4.1. 


\subsection{Eigene Fragestellung}

Auf Basis untersuchter Blutproben von HCC-Patienten, die sich einer radiologischen Intervention (TACE oder MWA) am Universitätsklinikum Frankfurt am Main zwischen September 2017 und Juni 2018 unterzogen haben, sollten im Rahmen dieser Studie folgende drei Fragen beantwortet werden:

1. Wie wirken sich die radiologischen Interventionen auf die Kurzzeitdynamik von zirkulierenden Tumorzellen bei hepatozellulären Karzinompatienten aus?

2. Wie hoch liegen die Sensitivität und Spezifität der CTC-Isolierung durch angewandte Methode in Hinsicht auf einen möglichen Einsatz als Screening-Methode für HCC-Patienten?

3. Besteht eine Korrelation zwischen der Kurzzeitdynamik der zirkulierenden Tumorzellen und der des Alpha-Fetoprotein-Wertes als anerkannter klinischer Tumormarker oder der des Interleukin-6-Wertes als neu diskutierten Tumormarker? 


\section{Material und Methoden}

Alle im Rahmen dieser Studie untersuchten Proben und verwendeten Materialien wurden im Forschungslabor des Zentrums der Chirurgie der Klinik für Allgemein-, Viszeral- und Transplantationschirurgie des Universitätsklinikums Frankfurt am Main verarbeitet.

\subsection{Studienpopulation und Patientenmaterial}

Grundlage dieser Arbeit waren Blutproben von 18 Patienten, die mit einem HCC im Universitätsklinikum Frankfurt am Main im Zeitraum September 2017 bis Juni 2018 vorstellig wurden und am Institut für "Diagnostische und Interventionelle Radiologie“ erstmalig eine TACE oder eine MWA als Therapiemaßnahme erhielten. Davon wurden acht Patienten mit einer TACE (Kollektiv A) und zehn Patienten mit einer MWA (Kollektiv B) behandelt. Allen Patienten wurde jeweils am Tag der Therapie vor und unmittelbar nach ( $<5$ min.) radiologischer Intervention venöses Blut aus einem peripheren Venenkatheter entnommen. Das Blut wurde in CellSave Preservative Tubes asserviert, die, laut Herstellerangaben, eine Lagerung des Blutes ohne Zelltod ermöglichten (bis zu zehn Tage). Das Blut in den Cellsave Tubes lagerte bis zum jeweils nächsten Tag bei Raumtemperatur, um dann für die FACS-Analyse verarbeitet zu werden.

An jedem Therapietag der Studie wurde einem gesunden Probanden (Kollektiv C) durch eine periphere Venenpunktion Blut entnommen und dieses ebenfalls in CellSave Preservative Tubes asserviert. Diese Vergleichsgruppe umfasste 16 Probanden.

Die demographischen Daten wie Alter und Geschlecht der Patienten sind in Tabelle 5, Tabelle 6 und Tabelle 7 (S. 43) dargestellt.

Die Ein- und Ausschlusskriterien der Studienpopulation sind in Tabelle 2 aufgelistet. 
Tabelle 2 - Ein- und Ausschlusskriterien der Studienpopulation

\begin{tabular}{|c|c|}
\hline \multirow[t]{2}{*}{ Patienten } & Ein- und Ausschlusskriterien \\
\hline & $\begin{array}{l}\text { - } \text { vorliegende HCC-Erkrankung } \\
\text { - } \quad \text { erstmalige Durchführung der entsprechenden } \\
\text { radiologischen Intervention } \\
\text { - Alter über } 18 \text { Jahre } \\
\text { - keine bekannte Infektionserkrankung } \\
\text { - keine bekannte Schwangerschaft }\end{array}$ \\
\hline \multirow[t]{2}{*}{ Probanden } & Ein- und Ausschlusskriterien \\
\hline & $\begin{array}{l}\text { - } \begin{array}{l}\text { Keine bekannten Erkrankungen der Leber } \\
\text { (chronische als auch akute) }\end{array} \\
\text { - } \text { kein Alkoholismus } \\
\text { - } \quad \text { keine bekannten Infektionserkrankungen (wie } \\
\text { Hepatitiden oder HIV etc.) } \\
\text { - keine bekannten Tumorerkrankungen } \\
\text { - keine vorliegende Schwangerschaft } \\
\text { - keine Adipositas }\end{array}$ \\
\hline
\end{tabular}

\subsection{Datenquellen und Datenschutz}

Demographische Daten der Patienten wie Alter, Geschlecht und Diagnosen sowie Labor- und Pathologiebefunde wurden aus der elektronischen Patientenakte „NICE“ des Universitätsklinikums Frankfurt am Main entnommen. Die Daten der gesunden Probanden wurden mündlich anamnestisch erhoben.

Bevor ein Patient in die Durchführung der Studie einbezogen wurde, musste er nach ausführlicher Aufklärung der Verwendung seines Blutes für Forschungszwecke zustimmen. Hierzu liegen die von den Patienten unterschriebenen „UCT Biobank Patientenaufklärungen \& Einverständniserklärungen“ vor. Ein positives Votum zur Durchführung dieser Studie wurde von der Ethikkomission des Fachbereichs Medizin am Universitätsklinikum der Goethe-Universität am 16.09.2016 erteilt (Nr: 321/16). 


\subsection{Verwendete Materialen}

Listen über sämtliche zur Studie verwendeten Verbrauchsmaterialien, Chemikalien, Lösungen, Puffer, Zelllinien und Zellmedien befinden sich im Anhang (s. 13.1). 


\subsection{Methoden}

\subsubsection{Angewendetes Verfahren zum Nachweis zirkulierender Tumorzellen}

Nach der Blut-Abnahme lagerte das Blut in Cellsave Preservative Tubes. Am Tag der Probenverarbeitung wurden die CTCs aus dem Blut zunächst isoliert, um anschließend detektiert werden zu können. Die Isolation fand im Forschungslabor des Zentrums der Chirurgie der Klinik für Allgemein-, Viszeral- und Transplantationschirurgie des Universitätsklinikums Frankfurt am Main statt. Die Detektion erfolgte mithilfe des BD FACSAria Fusion Durchflusszytometers des Flow Core Units (FCU) im Georg-Speyer-Haus am Universitätsklinikum Frankfurt am Main.

\subsubsection{Isolation von zirkulierenden Tumorzellen}

Die CTCs aus dem Blut der HCC-Patienten wurden mithilfe von OncoQuick Röhrchen der Firma greiner-bio one isoliert. Die Methode wurde basierend auf den Vorversuchen (s. 3.4.2.2) ausgewählt.

OncoQuick Röhrchen sind konische Zentrifugenröhrchen, die ein Dichte-Medium (oder Separationsmedium) unter einem Filter beinhalten. Zur Isolation wurde das Blut auf den Filter aufgebracht und anschließend zentrifugiert. Die Zentrifugalkraft trennt die Zellen aus einer Blutprobe in unterschiedliche Kompartimente des Röhrchens auf. Die zu eliminierenden Erythrozyten wandern beispielsweise Richtung Röhrchenboden durch den Filter hindurch, während sich die CTCs in Form einer Bande im oberen Bereich ansammeln. Dieses Prinzip der Auftrennung wird in Abbildung 8 schematisch dargestellt. 


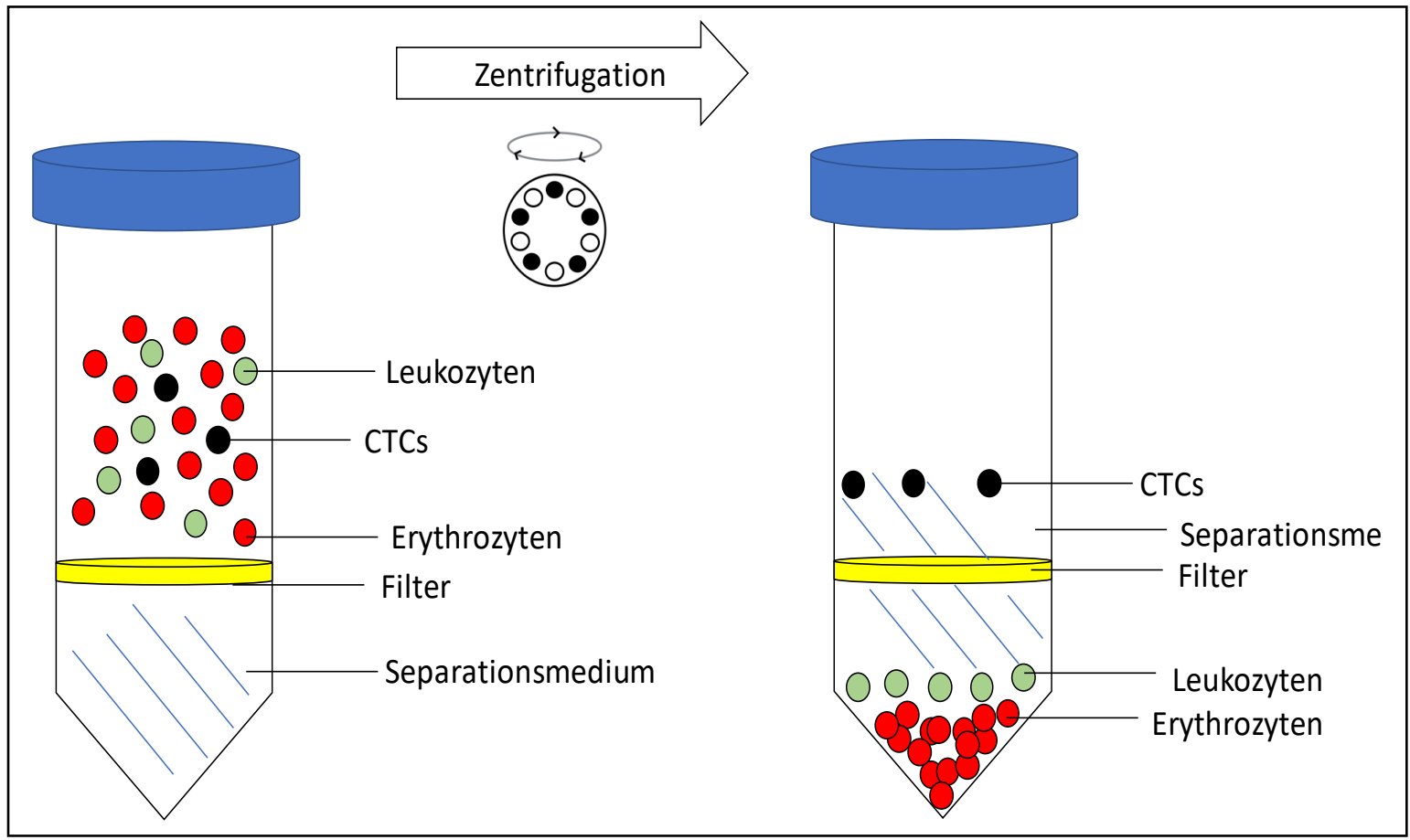

\section{Abbildung 8 - Prinzip der CTC-Isolation mit Oncoquick Röhrchen}

Anmerkung: Abbildung 8 ist angelehnt an die Abbildung aus dem OncoQuick® Informationsblatt der Firma greiner bio-one

Abk: CTCs $=$ zirkulierende Tumorzellen, Separationsme $=$ Separationsmedium

Der gesamte Ablauf der CTC-Isolation erfolgte exakt nach Angaben aus dem "Instruction Manuals“ für das OncoQuick des Herstellers. Die einzelnen Schritte sind in Abbildung 9 dargestellt und im Anschluss daran anhand der Nummerierung erläutert. 


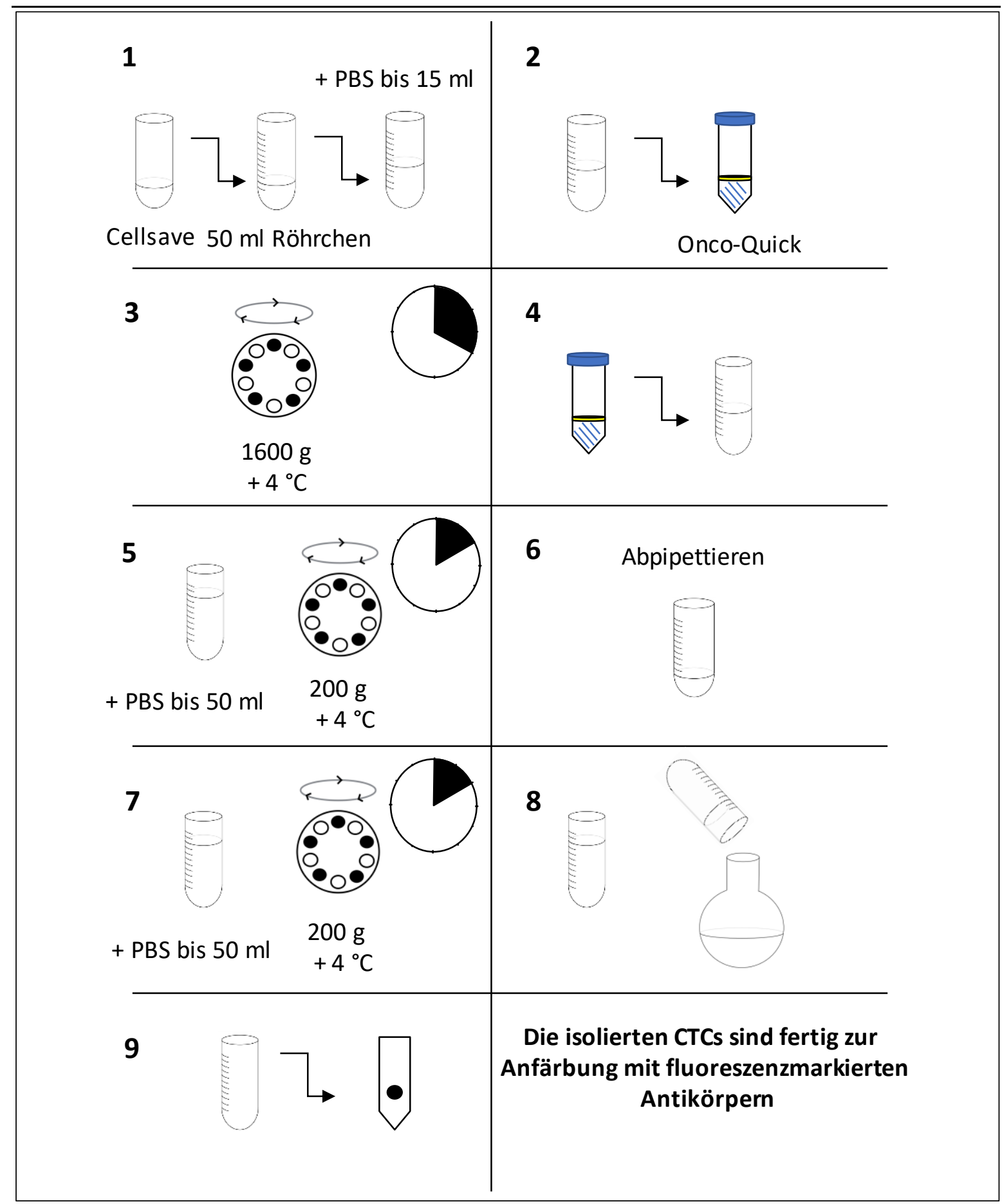

Abbildung 9 - Ablauf der CTC-Isolation

Abk: Cellsave $=$ Cellsave Preservative Tube; PBS $=$ Phosphate Buffered Saline (dt. phosphatgepufferte Salzlösung); CTCs= zirkulierende Tumorzellen

1 - 2 Zunächst wurde das Blut aus den Cellsave Preservative Tubes in $50 \mathrm{ml}$ Röhrchen transferiert und mit PBS (ohne $\mathrm{Ca}^{2+}$ und $\mathrm{Mg}^{2+}$ ) bis zur $15 \mathrm{ml}$ Marke aufgefüllt, um diese Lösung anschließend auf den Filter des OncoQuick Röhrchens zu übertragen. 
3 - Es erfolgte eine 20-minütige Zentrifugation dieses OncoQuick Röhrchens bei $1600 \mathrm{~g}$ und $+4{ }^{\circ} \mathrm{C}$. Die Beschleunigung sowie die Abbremsung der Zentrifuge wurden dabei, wie von greiner-bio one vorgegeben, jeweils auf die Stufe fünf (mittelstark) eingestellt.

Die im Anschluss verwendete Pipette und ein $50 \mathrm{ml}$ Röhrchen wurden mit dem FACS-Puffer befeuchtet, um das Binden der Tumorzellen an die Wände dieser Materialien zu minimieren. Dieser Schritt wurde auch als „pre-wetting“ bezeichnet.

4 - Der Überstand aus dem zentrifugierten Oncoquick Röhrchen wurde vorsichtig vollständig abpipettiert und mit der befeuchteten Pipette in das ebenso präparierte $50 \mathrm{ml}$ Röhrchen transferiert.

Die Wände des Oncoquick Röhrchens wurden nochmals mit $5 \mathrm{ml}$ FACS-Puffer durch ein sanftes Schwenken während des Pipettierens abgewaschen, um eventuell anhaftende Tumorzellen transferieren zu können. Danach wurden dieselben 5 ml FACS-Puffer zu den jeweiligen 50 ml Röhrchen hinzugefügt.

5 - Die erste Waschung der entstandenen Probe erfolgte durch Wiederauffüllen bis zur $50 \mathrm{ml}$ Marke mit FACS-Puffer und fünfmaliges Schwenken des Röhrchens. Danach wurden die Röhrchen für $10 \mathrm{~min}$ bei $200 \mathrm{~g}$ und $+4{ }^{\circ} \mathrm{C}$ zentrifugiert. Dabei wurden Beschleunigung und Abbremsung jeweils auf die höchste Stufe (neun) eingestellt.

6 - Von der in Schritt 5 gewaschenen Lösung wurden $45 \mathrm{ml}$ abpipettiert, sodass die Zellen am Boden des Röhrchens ungestört blieben.

7 - Für die zweite Waschung erfolgten ein erneutes Auffüllen desselben Röhrchens bis zur $50 \mathrm{ml}$ Marke mit FACS-Puffer und ein fünfmaliges Schwenken. Im Anschluss wurde das Röhrchen noch einmal für 10 min bei $200 \mathrm{~g}$ und $+4{ }^{\circ} \mathrm{C}$ zentrifugiert.

8 - Im Folgenden wurden die entstandenen Luftblasen an der Oberfläche der Probe mithilfe einer Pasteur-Pipette entfernt und das Röhrchen dekantiert.

9 - Zuletzt wurde die verbliebene Probe vorsichtig mithilfe der Pipette durchmischt und die komplette restliche Flüssigkeit (inklusive der verbliebenen Zellen am Boden des Röhrchens) in ein FACS-Röhrchen übertragen. 
Nach dem Dekantieren der Probe sind optimalerweise hauptsächlich CTCs am Boden des Röhrchens verblieben. Die noch innerhalb der Probe befindlichen Leukozyten konnten in der Durchflusszytometrie von den CTCs abgegrenzt werden.

\subsubsection{Detektion von zirkulierenden Tumorzellen mittels} Durchflusszytometrie

Die einzelnen Schritte zur Detektion der CTCs sind in Abbildung 10 dargestellt und werden analog dem vorherigen Kapitel anhand der Nummerierung erläutert.

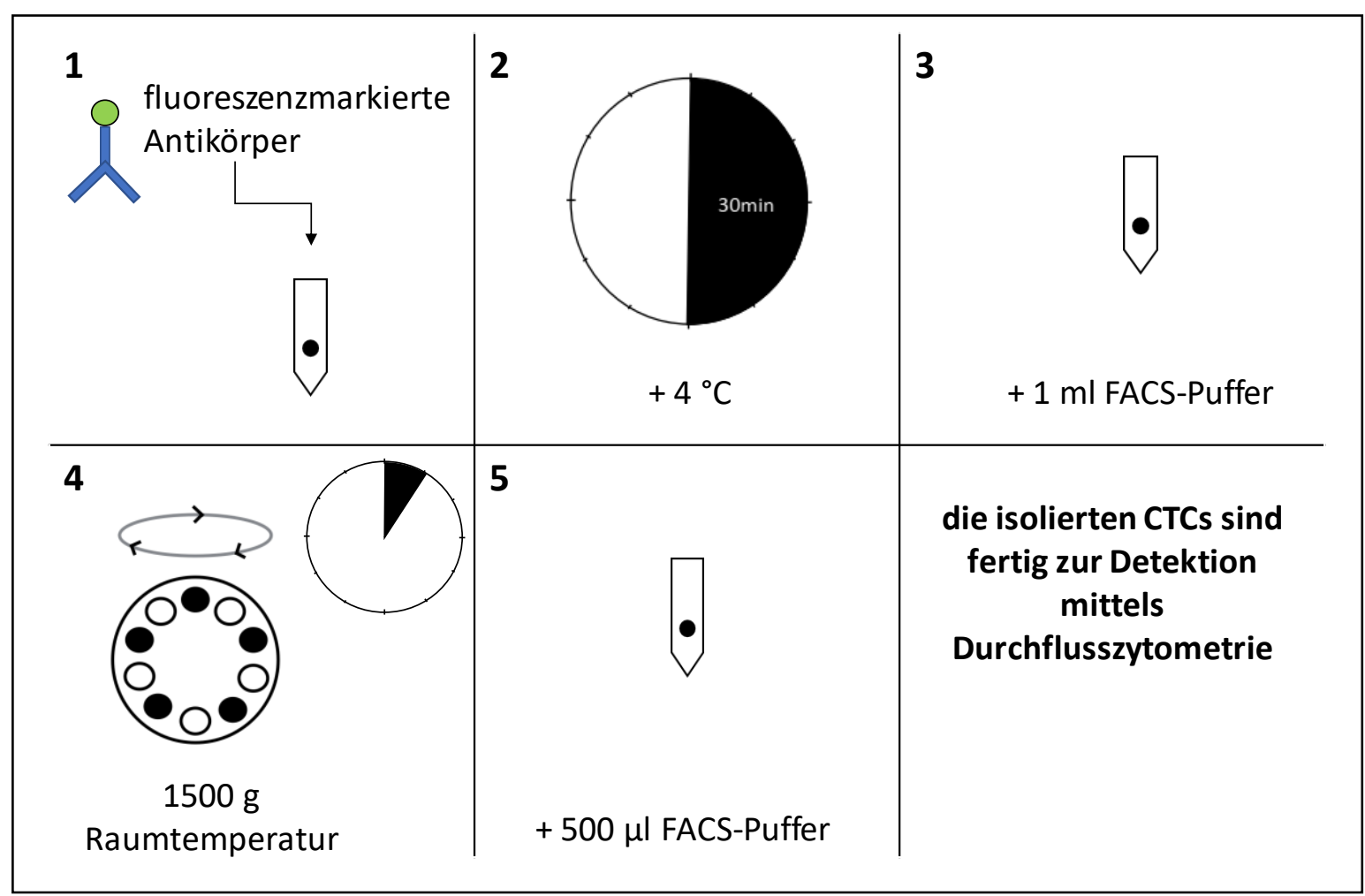

Abbildung 10 - Ablauf der CTC-Anfärbung mit fluoreszenzmarkierten Antikörpern

Abk: FACS= Fluorescence activated Cell Sorting; CTCs= zirkulierende Tumorzellen

1 - Unmittelbar nach Tumorzell-Isolation wurde die Flüssigkeit in den FACS-Tubes mit der Mischung aus den fluoreszenzmarkierten Antikörpern (s. 3.2.1.2) gefärbt.

2 - 4 Im Anschluss an eine 30-minütige Inkubation der Antikörper bei $+4^{\circ} \mathrm{C}$ im Dunkeln erfolgte ein Waschgang, um nicht gebundene Antikörper zu eliminieren. Dazu wurde einer Probe jeweils $1 \mathrm{ml}$ FACS-Puffer hinzugefügt, die anschließend für 5 min bei $1500 \mathrm{~g}$ und bei Raumtemperatur zentrifugiert wurde.

5 - Zuletzt wurden die Proben mit jeweils $500 \mu$ FACS-Puffer aufgefüllt. 
Zur Detektion der fluoreszierenden Antikörper und somit der Tumorzellen wurden die Proben mit dem BD FACSAria Fusion Durchflusszytometer des Flow Core Units (FCU) im Georg-Speyer-Haus am Universitätsklinikum Frankfurt am Main, gemessen, um im Anschluss mit der FACS Diva Software analysiert werden zu können. Aus technischen Gründen mussten einige Proben mit zusätzlichem FACS-Puffer verdünnt werden. Die genauen Werte und nachvollziehbaren Rechnungen zur Verdünnung der FACS-Proben befinden sich im Kapitel 4.1 auf Seite 51.

Die Zellen, die das Durchflusszytometer auf die Antikörper gegen CD146, ASGPR-1, CD90 und CD274 positiv erkannte und solche, die sich zusätzlich auf CD45 negativ darstellten, wurden als Tumorzellen kategorisiert.

\subsubsection{Bestimmung des AFP-Wertes und des IL-6-Wertes}

Bei der Abnahme jeder Blutprobe wurde zusätzlich zu den Cellsave Preservative Tubes ein Serum-Röhrchen mit Blut des Patienten entnommen. Dieses Röhrchen wurde unverzüglich nach Gewinnung der Probe in das Zentral-Labor des Universitätsklinikums in Frankfurt gegeben. Dort erfolgte die Auswertung der Proben. Die AFP- und IL-6-Werte konnten anschließend der elektronischen Patientenakte entnommen werden.

\subsubsection{Vorversuche}

Da zu Beginn der durchgeführten Arbeit bereits Untersuchungen der CTC-Dynamik in hepatozellulären Karzinompatienten bei Leberteilresektionen in derselben Arbeitsgruppe stattfanden, konnten die Ergebnisse daraus die Basis für die nachfolgenden Vorversuche bilden. Die Arbeitsgruppe entnahm Patienten Blutproben, isolierte die Tumorzellen aus diesen und stellte die Zellen sowohl mittels Durchflusszytometrie als auch durch Immunfluoreszenz-Mikroskopie dar. Die Ergebnisse zeigten, dass es möglich war, Tumorzellen von Patienten mit HCC auf diese Art nachzuweisen. Die vorangegangenen wissenschaftlichen Arbeiten der Arbeitsgruppe waren zum Zeitpunkt der vorliegenden Dissertation als wissenschaftliches Poster auf dem UCT Science Day 2017 in Frankfurt veröffentlicht. ${ }^{76}$ 


\subsubsection{Kultivierung und Lagerung der HepG2-Zelllinie}

Um das angewendete Versuchsprotokoll für die Isolation und Detektion von zirkulierenden Tumorzellen im Patientenblut erstellen und optimieren zu können, wurden entsprechende Vorversuche mit käuflich erworbenen Leberzellkarzinom-Zellen durchgeführt. Die Wahl fiel auf die HCC-Zellen der Linie HepG2 von der Firma CLS Services.

Die HepG2-Zellen wurden stets unter sterilen Bedingungen kultiviert und gelagert. Die Temperatur von $+37^{\circ} \mathrm{C}$ im Brutschrank wurde konstant gehalten, wobei eine mit Wasser gesättigte Atmosphäre bei einem Kohlenstoffdioxidgehalt von $5 \%$ herrschte. Sobald die Zellen in der Monolayer-Kultur zu ca. $80 \%$ konfluiert waren, wurden die Zellen in eine neue Zellkulturflasche passagiert, um ein Absterben der Zellkultur zu verhindern. Hierzu wurden die Zellen, nach dem Abkippen des alten Mediums, mit $10 \mathrm{ml}$ Phosphatgepufferter Salzlösung (PBS) (ohne $\mathrm{Ca}^{2+}$ und $\mathrm{Mg}^{2+}$ ) gewaschen und die am Boden der Zellkulturflasche adhärenten Zellen mittels $10 \mathrm{ml}$ Accutase gelöst. Im Anschluss konnten die HepG2-Zellen mit dem hergestellen Zelledium zur Kultivierung (s.13.1.4) resuspendiert und in einer neuen Kulturflasche ausgesät werden.

Für die Langzeitlagerung der Zelllinie wurden die HepG2-Zellen ebenfalls, wie oben beschrieben, abgelöst, um sie für 5 min bei $385 \mathrm{~g}$ und $+4{ }^{\circ} \mathrm{C}$ zu zentrifugieren. Anschließend wurde das entstandene Zellpellet im zuvor präparierten Einfriermedium resuspendiert. Von dieser Zellsuspension wurde jeweils $1 \mathrm{ml}$ in ein Kryoröhrchen pipettiert und in die Einfrierbox deponiert, die, laut Herstellerangaben, eine exakte Kühlrate von $-1^{\circ} \mathrm{C}$ pro Minute sicher stellte. ${ }^{77}$ Die Box lagerte im Anschluss eine Nacht lang bei $-80^{\circ} \mathrm{C}$. Am Folgetag erfolgte die Überführung der Kryoröhrchen in flüssigen Stickstoff bei $-196{ }^{\circ} \mathrm{C}$.

Bei Bedarf konnten die kryokonservierten Tumorzellen bei $+37^{\circ} \mathrm{C}$ aufgetaut und dann wiederum in einer Zellkulturflasche in $20 \mathrm{ml}$ Zellmedium resuspendiert werden. Nach Zentrifugation bei $385 \mathrm{~g}$ für $5 \mathrm{~min}$ bei $+4^{\circ} \mathrm{C}$ wurde das Zellpellet mit $15 \mathrm{ml}$ Medium versetzt und in eine neue Zellkulturflasche gegeben, die dann im Brutschrank inkubierte.

Alle zur Kontrolle verwendeten Zellen wurden unter Zuhilfenahme des MycoProbe $^{\mathrm{TM}}$ - Mycoplasma Detection Kits regelmäßig auf Mykoplasmen getestet. 
Bei Verwendung der Zellen wurde ein C-Chip benutzt, um die genaue Zellanzahl bestimmen zu können.

\subsubsection{Etablierung der optimalen Isolationsmethode von zirkulierenden Tumorzellen}

Zur Etablierung der Isolationsmethode mit der ergiebigsten Ausbeute an zirkulierenden Tumorzellen wurden vier verschiedene Verfahren verglichen.

Eine der in den folgenden vier Absätzen kurz beschriebenen Methoden wurde ausgewählt. Die Produktdatenblätter und Protokolle über das genaue Verfahren sind auf den jeweiligen Internetseiten der Firmen Miltenyi Biotec $\mathrm{GmbH}$, Stemmcell Technologies und Greiner Bio-One GmbH zu finden.

Bei der ersten zur Auswahl stehenden Methode handelte es sich um das Tumor Isolation Kit von Miltenyi Biotec (TIK), bei dem zunächst die Erythrozyten lysiert wurden. Nach mehrmaligem Waschen konnten Nicht-Tumorzellen mit magnetischen Beats markiert werden. Durch den Vorgang des sogenannten magentischen Sortierens der Zellen (magnetic cell sorting, MACS) wurden die zurückgebliebenen Tumorzellen aufgefangen.

Die zweite zur Verfügung stehende Methode nannte sich RosetteSep ${ }^{\mathrm{TM}}$ CTC Enrichment Cocktail Containing Anti-CD36 von Stemcell Technologies. Bei dieser Methode wurden sowohl Erythrozyten durch Glycophorin A als auch andere Zellen im Blut negativ isoliert, d.h. an Anti-CD2, 16, 19, 36, 38, 45, 66 gebunden, um daraufhin mit einem Dichte-Gradienten nach unterschiedlicher Dichte aufgetrennt zu werden.

Bei der dritten Methode mit dem Namen EasySep ${ }^{\mathrm{TM}}$ Human CD45 Depletion Kit, sollten laut Firma (Stemcell Technologies) mit tetramerischen AntikörperKomplexen CD45, 66 und Glycophorin A an Erythrozyten durch Zentrifugation mit einem Dichte-Gradienten die Zellen nach Dichte aufgetrennt werden und so die Tumorzellen isoliert werden.

Ausgewählt und in den Versuchen verwendet wurde schließlich die vierte Methode mit der Bezeichnung OncoQuick Röhrchen von greiner-bio one. Die Funktionsweise dazu wurde in Kapitel 3.4 erklärt. Der genaue Ablauf der Isolation wurde in Abbildung 8 veranschaulicht. 
Zur Simulation von vorhandenen CTCs im Blut wurden für die Vorversuche der CTC-Isolation Tumorzellen der HepG2-Zelllinie (s. 3.4.2.1) nach Abkippen des alten Mediums mit $10 \mathrm{ml}$ Phosphatgepufferter Salzlösung (PBS) (ohne $\mathrm{Ca}^{2+}$ und $\mathrm{Mg}^{2+}$ ) gewaschen und die am Boden der Zellkulturflasche verbliebenen Zellen mittels $10 \mathrm{ml}$ Accutase abgelöst. Die Anzahl dieser Zellen wurde mithilfe der Trypan-BlauFärbung bestimmt. So konnte Blut eines gesunden Probanden mit einer bestimmten Zahl von Tumorzellen angereichert werden. Daraufhin wurden die Isolationsmethoden auf ihre Ausbeute hin getestet und je nach Anzahl der wiedergefundenen Tumorzellen bewertet.

\section{Vorversuch 1: TIK vs. OncoQuick im Immunfluoreszenz-Mikroskop}

Ziel dieses Vorversuches war es, mit dem in der Arbeitsgruppe vorher verwendeten TIK (s.o.) als auch mit dem Isolationsverfahren mittels OncoQuick-Röhrchen visuell die Möglichkeit der CTC-Isolation, die Bestimmung der Menge an aus Blut isolierten CTCs und die Sichtbarkeit unter dem Immunfluoreszenz-Mikroskop zu überprüfen. Außerdem wurde analysiert, ob das TIK und das OncoQuick Verfahren eine gleiche oder unterschiedliche CTC-Ausbeute hervorbringen. Dazu wurden jeweils zwei Blutproben eines gesunden Probandens mit 300 Tumorzellen und zwei Blutproben mit 30 Tumorzellen angereichert und anschließend dem TIK und dem OncoQuick Verfahren unterzogen. Die isolierten Zellen wurden auf einem Objektträger gebracht und mit Antikörpern angefärbt. Anschließend erfolgte die Auswertung unter dem Immunfluoreszenz-Mikroskop.

In Abbildung 11 sind beispielhaft Fotos der gefundenen CTCs unter dem Immunfluoreszenz-Mikroskop zu sehen. 

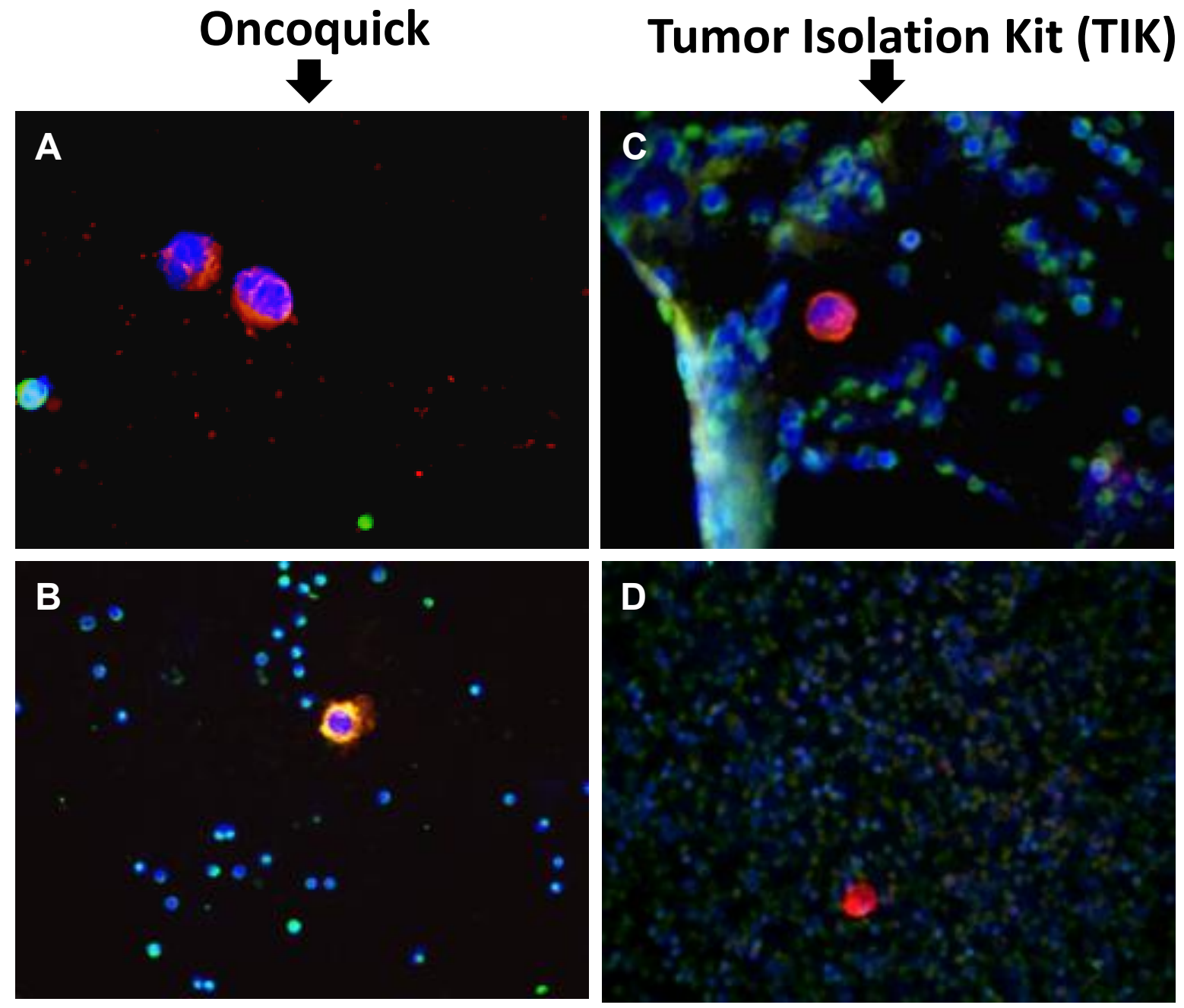

Abbildung 11 - CTCs im Immunfluoreszenz-Mikroskop

Anmerkung: CD45- CD146+ ASGPR+Zellen mittels Oncoquick bei 40-facher Vergrößerung(A) und 20-facher Vergrößerung (B). CD45- CD146+ ASGPR+Zellen mittels TIK Verfahren bei 40-facher Vergrößerung (C) und 20-facher Vergrößerung (D).

\section{Ergebnis Vorversuch 1:}

Es konnten CTCs mit den untersuchten Isolationsmethoden isoliert werden und mit Antikörpern unter dem Immunfluoreszenz-Mikroskop sichtbar gemacht werden. Die Zähl-Ergebnisse des Vorversuchs 1 sind in Tabelle 3 zusammengefasst. 
Tabelle 3 - Ergebnisse des Vorversuchs 1

\begin{tabular}{|ll|}
\hline $\begin{array}{l}\text { Anzahl } \\
\text { zugefügter } \\
\text { Tumorzellen }\end{array}$ & $\begin{array}{l}\text { Anzahl der Tumorzellen, die wiedergefunden wurden } \\
\text { OncoQuick }\end{array}$ \\
\cline { 2 - 2 } 300 & 202 \\
30 & 15 \\
300 & TIK \\
30 & 35 \\
\hline
\end{tabular}

\section{Fazit Vorversuch 1:}

- Das Ergebnis mit TIK ergab kein eindeutiges Bild, da viele Erythrozyten übrig geblieben waren $\rightarrow$ Überdeckung der Tumorzellen im Mikroskopbild.

- Mit OncoQuick konnten in den Proben mit 300 Zellen deutlich mehr Tumorzellen als beim TIK wiedergefunden werden.

- OncoQuick war das Verfahren mit weniger Versuchsschritten und daher mit weniger Fehlerquellen.

Vorversuch 2-5:

Blutproben, die mit unterschiedlichen Tumorzellanzahlen angereichert waren, wurden den vier zu untersuchenden Isolationsmethoden (s.o.) unterzogen. Mithilfe des Durchflusszytometers wurde daraufhin die Zellausbeute der jeweiligen Methoden bestimmt.

Es ergaben sich folgende Ergebnisse der Vorversuche 2-5:

- Im Durchflusszytometer wurden zwei Populationen von vermuteten CTCs gefunden. Eine Population zeigte einen höheren Ausschlag auf den ASGPR-Antikörper als die andere. Die zwei Populationen wurden je nach Höhe des Ausschlags „ASGPR-low“ und „ASGPR-high“ benannt. Als wiedergefundene CTCs wurden fortan die ASGPR-high-Zellen gezählt, da 
ASGPR-1 ein leberspezifischer Membranrezeptor ist. ${ }^{78}$ (Erklärung s. 3.4.2.3)

- Als Isolationsmethode mit der größten CTC-Ausbeute und mit den geringsten Fehlerquellen stellte sich das OncoQuick Röhrchen von der Firma greiner bio-one heraus.

\section{Fazit Vorversuche 2-5:}

Aus oben genannten Gründen fiel die Wahl für die optimale Isolationsmethode auf das OncoQuick Röhrchen.

\subsubsection{Etablierung der optimalen Detektionsmethode}

Zur Etablierung der optimalen Detektionsmethode war eine Analyse der Antikörper-Zusammensetzung erforderlich. Dazu fiel die Wahl auf monoklonale Antikörper, die bereits an einen fluoreszierenden Farbstoff gekoppelt waren.

Zum Nachweis von entarteten Hepatozyten wurden Anti-Asialoglykoproteinrezeptor-1-Antikörper (Anti-ASGPR-1-Antikörper) verwendet, da ASGPR-1 ein spezifischer Rezeptor von Leberzellmembranen ist. ${ }^{78}$ Der Antikörper war an Phycoerythrin (PE) als fluoreszierenden Farbstoff gebunden.

Um hepatozelluläre Karzinomzellen zu identifizieren wurden Anti-CD146-Antikörper (auch Melanoma Cell Adhesion Molecule, MCAM genannt) eingesetzt, die an den fluoreszierenden Farbstoff Allophycocyanin (APC) gekoppelt waren. Dieser Antikörper wurde intendiert ausgewählt, da neueste Studien zeigten, dass CD146 vor allem in Membranen von hepatozellulären Karzinomzellen überexprimiert wurde und dagegen in gesunden Hepatozyten nicht vorhanden war. ${ }^{79}$ Außerdem schien das Potenzial der epithelial-mesenchymalen-Transition (EMT) mit erhöhter CD146-Expression signifikant anzusteigen. ${ }^{79}$ Dies ließ vermuten, dass gerade diese Zellen als CTCs im peripheren Blut nachweisbar sein können.

Zur Differenzierung von zirkulierenden malignen Tumorstammzellen (circulating cancer stemm cells $=$ CSCs) wurden Anti-CD90-Antikörper eingesetzt (s. 2.3.3.1). Als fluoreszierender Farbstoff wurden vom Hersteller Peridinin-Chlorophyll-Proteine über Cyanin5.5-Moleküle, an die Antikörper konjugiert (PerCP/Cy5.5). 
Der Marker für die sogenannten aggressiven zirkulierenden Tumorzellen waren Anti-CD274-Antikörper (s. 2.3.3.2). Dazu wurde sich bei der Auswahl für Antikörper entschieden, die an den Farbstoff BV421 gebunden waren.

Zur Absicherung der Unterscheidung der Tumorzellen von Leukozyten wurden Anti-CD45-Antikörper verwendet, die mit Fluoresceinisothiocyanat (FITC) gekoppelt waren, da CD45 als das allgemeine Leukozyten-Antigen bekannt war. ${ }^{80}$

Vor dem Einsatz an Patientenproben wurde die optimale Menge der hinzugefügten Antikörper für die Durchflusszytometrie durch Titration bestimmt. Dazu wurden Tumorzellen aus der HepG2-Zelllinie entnommen und mit der Mischung aus oben genannten Antikörpern inkubiert. Im Anschluss konnte mit dem Durchflusszytometer ein Nachweis der Tumorzellen mit unterschiedlichen Antikörpermengen stattfinden und so die optimalen Konzentrationen ermittelt werden. Die zur CTC-Detektion verwendete Antikörper-Zusammensetzung ist in Tabelle 4 zusammengefasst.

Tabelle 4 - verwendete Antikörper-Zusammensetzung

Antikörper

Farbstoff

Menge $[\mu l]$ pro Probe

Anti-ASGPR-1

PE

10

Anti-CD146

APC

5

Anti-CD274

BV421

10

Anti-CD90

PerCP/Cy5.5

10

Anti-CD45

FITC

10 
Vorversuch 6: Anfärben mit den ausgewählten Antikörpern

Aus der HepG2-Zelllinien-Kultur wurden Tumorzellen mit $10 \mathrm{ml}$ Accutase abgelöst, gewaschen und mit der ausgewählten Antikörper-Zusammensetzung angefärbt. Dabei zeigten 96,2 \% der HepG2-Zellen eine Negativität auf Anti-CD45-Antikörper, wovon 91,5 \% eine Positivität auf Anti-ASGPR1- und den Anti-CD146-Antikörper aufwiesen. Von dieser Population waren wiederum 69,9\% CD274 positiv, was sie als aggressive Tumorzelle einstufen ließ. Zu 7,4\% hatten die Tumorzellen sowohl aggressive als auch Tumorstammzell-Eigenschaften (CD 274 positiv und CD90 positiv). (Erklärung s. 2.4.1) In Abbildung 12 ist die FACS-Auswertung des Vorversuchs 6 dargestellt.

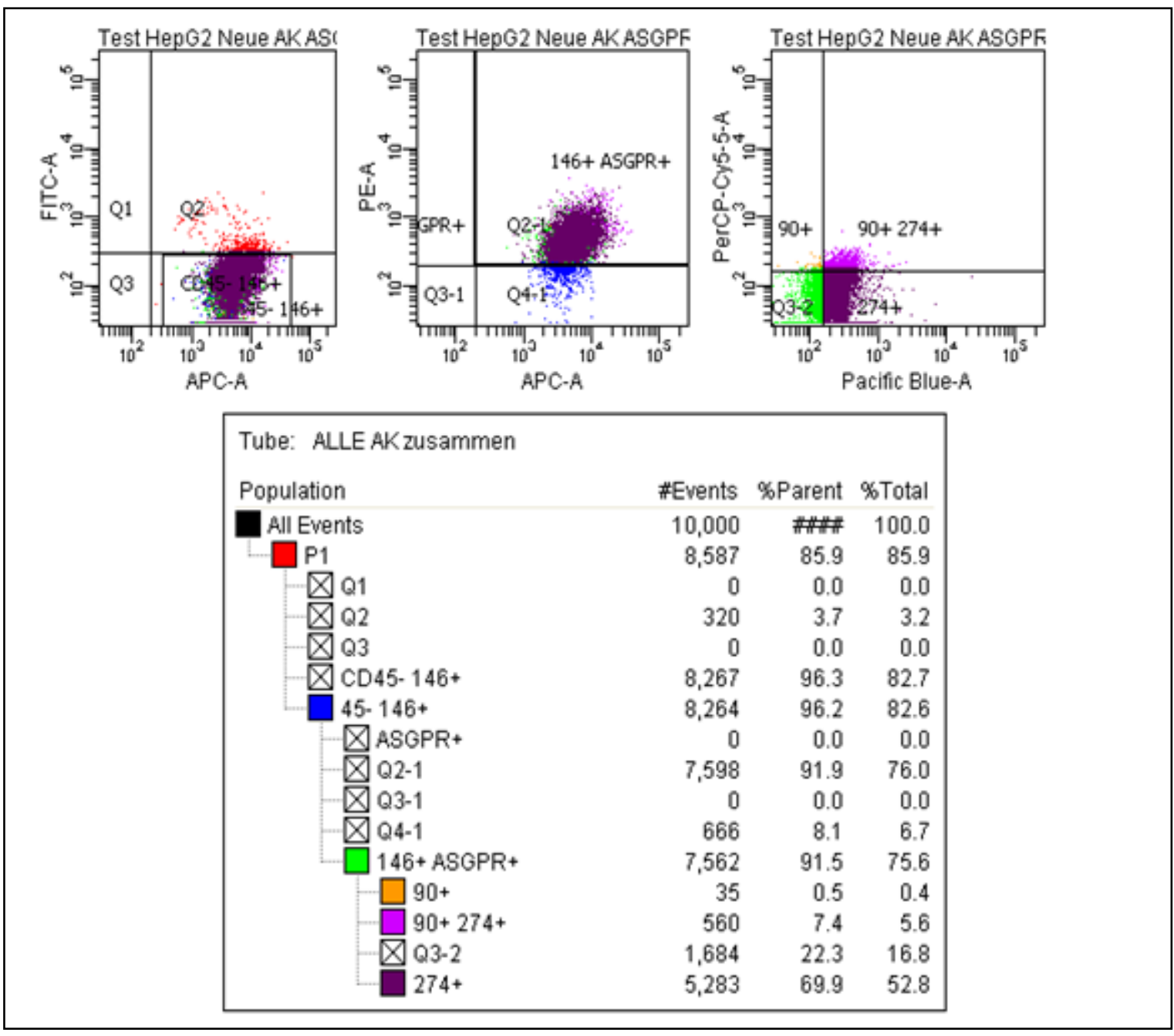

Abbildung 12 - Ergebnisse der Durchflusszytometrie: HepG2-Zellen mit AntikörperMischung 
Im Vorversuch 7 wurden die Antikörper-Mengen schließlich titriert. D.h. die optimale Menge der hinzugefügten Antikörper wurde so austariert, dass der optimale Ausschlag des Zytometers stattfinden konnte und das Zytometer für alle nachfolgenden Versuche standardisiert eingestellt werden konnte. Die genauen Mengenangaben dazu sind in Tabelle 4 angegeben. 


\subsection{Statistik}

Die statistische Auswertung wurde mit dem BiAS.- (Biometrische Analyse von Stichproben) Programm für Windows (Version 11.09) erstellt mit freundlicher Unterstützung von Herrn Dr. Hanns Ackermann des Fachbereichs Medizin der Goethe-Universität Frankfurt am Main.

\subsubsection{Wilcoxon-matched-pairs-Test}

Um die erste Frage dieser wissenschaftlichen Arbeit nach der Wirkung der radiologischen Interventionen auf die Kurzzeitdynamik von CTCs bei HCC-Patienten zu beantworten, wurden die Mediane der Anzahlen der CTCs vor und nach den Therapieverfahren TACE und MWA in einem Wilcoxon-matched-pairs Test miteinander verglichen. Dieser Test ist auch unter dem Namen WilcoxonVorzeichenrangtest bekannt.

Der Vorzeichenrangtest von Wilcoxon (1945) ist ein nicht-parametrischer Test zum Vergleich zweier Gruppen mit einem quantitativen Zielkriterium. ${ }^{81,82}$ Durch den Vergleich der beiden Mediane wird geprüft, ob sich zwei abhängige Stichproben in ihrer zentralen Tendenz unterscheiden. ${ }^{82,} 83$ In dieser Dissertation entsprechen die zwei abhängigen Stichproben jeweils den Anzahlen zirkulierender Tumorzellen vor $\left(\tilde{x}_{1}\right)$ und nach radiologischer Intervention $\left(\tilde{x}_{2}\right)$.

Die Nullhypothese lautet:

$$
H_{0}: \tilde{x}_{1} \neq \tilde{x}_{2}
$$

Dies stellt die Annahme dar, dass ein Unterschied zwischen den Anzahlen zirkulierender Tumorzellen vor einer radiologischen Intervention im Vergleich zu nach einer radiologischen Intervention besteht.

Die Alternativhypothese lautet:

$$
H_{1}: \tilde{x}_{1}=\tilde{x}_{2}
$$

Dies stellt die Annahme dar, dass sich die Anzahlen der zirkulierenden Tumorzellen vor und nach einer radiologischen Intervention nicht unterscheiden. 
Der Wert der Effektstärke lässt auf das Ausmaß der Wirkung der radiologischen Intervention schließen. ${ }^{83}$

Der $p$-Wert quantifiziert die Wahrscheinlichkeit, dass das gefundene Testergebnis zustande kommt, wenn in Wirklichkeit die Nullhypothese richtig ist. ${ }^{83}$ D.h. der p-Wert ist die Wahrscheinlichkeit dafür, dass das Testergebnis ein reiner Zufallsbefund ist. ${ }^{83}$ Wenn $p$ kleiner ist als das zuvor festgelegte Signifikanzniveau, wird die Alternativhypothese angenommen. Der p-Wert drückt lediglich aus, ob ein statistisch signifikanter Unterschied existiert. Er enthält jedoch keine Informationen über die Größe dieses Unterschieds. In dieser Arbeit wurde das Signifikanzniveau von 0,05 festgelegt. Das bedeutet etwas ist signifikant, wenn der $p$-Wert kleiner gleich 0,05 beträgt.

Die Wahrscheinlichkeit eines Tests, eine richtige Alternativhypothese als solche zu erkennen quantifiziert die so genannte „power" oder auch Teststärke genannt. ${ }^{83}$

\subsubsection{Wilcoxon-Mann-Whitney-Test}

Der Wilcoxon-Mann-Whitney-Test wurde angewendet, um die zweite Fragestellung dieser Dissertation nach dem Nachweis eines Unterschieds in der CTC-Anzahl zwischen HCC-Patienten und den gesunden Probanden mittels der angewendeten Methoden zu beantworten.

Um die zweite Fragestellung dieser Dissertation zu beantworten, nämlich welcher Unterschied der CTC-Anzahl mit angewendeter Methode zwischen HCC-Patienten und den gesunden Probanden nachgewiesen werden kann, wurde der Wilcoxon-Mann-Whitney-Test angewendet.

Der Wilcoxon-Mann-Whitney-Test, auch Mann-Whitney-U-Test genannt, ist ein nicht-parametrischer Test, der Daten aus zwei unabhängigen Stichproben hinsichtlich ihrer zentralen Tendenz vergleicht. ${ }^{84}$ Dieser Test, der von Mann und Whitney 1947 entwickelt wurde, erwartet Daten aus zwei unabhängigen Zufallsstichproben, bei denen pro Fall ein Messwert vorliegt. 82,84

Der Wilcoxon-Mann-Whitney-Test prüft die Nullhypothese $H_{0}$, dass zwei zu vergleichende Stichproben aus homomer verteilten Populationen mit identischem Medianwert stammen. ${ }^{82}$ Population 1 waren hierbei die CTC-Anzahlen bei 
gesunden Probanden, wobei die Population 2 die CTC-Anzahlen der an HCC erkrankten Personen darstellte.

Wird der Wilcoxon-Mann-Whitney-Test signifikant ( $p$-Wert $<0,05)$, ist davon auszugehen, dass sich die Mediane der zugrunde liegenden Populationen unterscheiden und sich so die Alternativhypothese $H_{1}$ bewahrheitet. ${ }^{82} H_{1}$ steht dafür, dass sich die CTC-Anzahlen bei Erkrankten und Gesunden unterscheiden würden, da die Populationen unterschiedliche Medianwerte hätten.

Für die Interpretation des Testergebnisses haben Mann und Whitney den sog. relativen Effekt vorgeschlagen, mit dem geschätzt werden kann, mit welcher Wahrscheinlichkeit die Werte in der Population 1 kleiner sind als die Werte in der Population $2 .{ }^{82}$ Ist $\mathrm{P}>0,5$ besteht eine stochastische Tendenz zu kleineren Werten in der Population 1 im Vergleich zur Population 2 und für $P<0,5$ sind die Werte in der Population 1 der Tendenz nach größer. ${ }^{82}$ Der P-Wert ist ein Schätzwert, der stichprobenbedingten Schwankungen unterliegt. ${ }^{82}$

Somit ist der relative Effekt, auch Mann-Whitney-Schätzer genannt, die Wahrscheinlichkeit, dass ein Wert aus Population 1 (Gesunde) kleiner ist als ein Wert aus Population 2 (HCC-Patienten).

\subsubsection{Rang-Korrelation: Spearman's Rho}

Zur Beantwortung der dritten Fragestellung dieser Dissertation, ob eine Korrelation zwischen der Kurzzeitdynamik der CTCs und der des AFP-Werts besteht, wurde die Rang-Korrelation mit der Bezeichnung Spearman's Korrelationskoeffizient „rho“, verwendet.

Der Korrelationskoeffizient nach Spearman (von 1904) ist ein Maß für die Stärke eines monotonen Zusammenhangs. ${ }^{83} \mathrm{Er}$ wird auch als Rangkorrelation bezeichnet, da er auf den Rangzahlen der Beobachtungswerte (xi, yi) basiert. ${ }^{83}$

Um diesen Koeffizienten zu berechnen, werden alle x-Werte (hier die Differenz der prä- und post- CTC-Anzahlen) sortiert und mit Rangzahlen versehen. ${ }^{83}$ Der kleinste Wert erhält den Rang 1, der größte den Rang n. Mit den Daten des y-Merkmals (hier die Differenz der prä- und post- AFP- bzw. IL-6-Werte) verfährt man ebenso. Jeder Beobachtungseinheit wird also eine Rangzahl für das x-Merkmal und eine für das 
y-Merkmal zugeordnet. Die Differenz dieser beiden Rangzahlen sei d i. Aus diesen Differenzen wird der Spearman'sche Korrelationskoeffizient berechnet. ${ }^{83}$

Der Korrelationskoeffizient nach Spearman rho erstreckt sich zwischen den Werten minus eins und plus eins. Rho nimmt den maximalen Betrag eins an, wenn der Zusammenhang streng monoton ist. Dies bedeutet es korreliert. Ein positives Vorzeichen symbolisiert einen gleichsinnigen, ein negatives Vorzeichen einen gegensinnigen Zusammenhang. Rho $=0$ bedeutet, dass kein monotoner Zusammenhang nachweisbar ist. ${ }^{83}$ 


\section{Ergebnisse}

Die Angaben der Patienten und Probanden über Geschlecht, Alter, BCLC-Stadium und das Datum der Therapie sind in folgenden Tabellen (Tabelle 5, Tabelle 6 und Tabelle 7) aufgelistet.

Tabelle 5 Kollektiv A - Patienten, die eine TACE erhielten

\begin{tabular}{ccccc}
\hline $\begin{array}{c}\text { Patienten- } \\
\text { Nr. }\end{array}$ & Geschlecht & $\begin{array}{c}\text { Alter bei } \\
\text { Therapie } \\
\text { in Jahren }\end{array}$ & $\begin{array}{c}\text { Datum der Therapie } \\
\text { = Datum der Blutentnahme }\end{array}$ & $\begin{array}{c}\text { BCLC- } \\
\text { Stadium }\end{array}$ \\
\hline TACE 1 & $\mathrm{m}$ & 63 & 18.09 .2017 & $\mathrm{~A}$ \\
TACE 2 & $\mathrm{m}$ & 67 & 27.09 .2017 & $\mathrm{~B}$ \\
TACE 3 & $\mathrm{m}$ & 73 & 28.09 .2017 & $\mathrm{~A}$ \\
TACE 4 & $\mathrm{w}$ & 57 & 04.10 .2017 & $\mathrm{~B}$ \\
TACE 5 & $\mathrm{m}$ & 68 & 10.10 .2017 & $\mathrm{~B}$ \\
TACE 6 & $\mathrm{m}$ & 73 & 07.12 .2017 & $\mathrm{~B}$ \\
TACE 7 & $\mathrm{m}$ & 54 & 13.02 .2018 & $\mathrm{~A}$ \\
TACE 8 & $\mathrm{w}$ & 58 & 14.02 .2018 & $\mathrm{~B}$ \\
\hline
\end{tabular}

Anmerkung: $m$ = männlich, w weiblich 
Tabelle 6 Kollektiv B - Patienten, die eine MWA erhielten

\begin{tabular}{|c|c|c|c|c|}
\hline $\begin{array}{c}\text { Patienten- } \\
\mathrm{Nr} .\end{array}$ & Geschlecht & $\begin{array}{l}\text { Alter bei } \\
\text { Therapie } \\
\text { in Jahren }\end{array}$ & $\begin{array}{l}\text { Datum der Therapie } \\
\text { = Datum der } \\
\text { Blutentnahmen }\end{array}$ & $\begin{array}{l}\text { BCLC- } \\
\text { Stadium }\end{array}$ \\
\hline MWA 1 & $m$ & 73 & 17.10 .2017 & $B$ \\
\hline MWA 2 & $\mathrm{~m}$ & 47 & 23.10.2017 & C \\
\hline MWA 3 & $\mathrm{~m}$ & 60 & 23.10.2017 & A \\
\hline MWA 4 & $\mathrm{~m}$ & 79 & 23.10.2017 & B \\
\hline MWA 5 & $\mathrm{~m}$ & 73 & 16.11 .2017 & B \\
\hline MWA 6 & w & 58 & 16.01 .2018 & B \\
\hline MWA 7 & w & 59 & 07.05 .2018 & B \\
\hline MWA 8 & w & 69 & 07.05 .2018 & A \\
\hline MWA 9 & $\mathrm{~m}$ & 61 & 17.05 .2018 & B \\
\hline MWA10 & $\mathrm{m}$ & 70 & 14.06 .2018 & B \\
\hline
\end{tabular}

Anmerkung: $m$ = männlich, $w$ weiblich 
Tabelle 7 Kollektiv C - gesunde Probanden

\begin{tabular}{|c|c|c|c|}
\hline Proband & Geschlecht & $\begin{array}{c}\text { Alter bei } \\
\text { Blutentnahme in } \\
\text { Jahren }\end{array}$ & Datum der Blutabnahme \\
\hline HD 1 & $\mathrm{w}$ & 25 & 20.09 .2017 \\
\hline HD 2 & $\mathrm{~m}$ & 26 & 27.09 .2017 \\
\hline HD 4 & w & 21 & 04.10 .2017 \\
\hline HD 5 & w & 28 & 10.10 .2017 \\
\hline HD 7 & w & 32 & 17.10 .2017 \\
\hline HD 8 & w & 28 & 23.10.2017 \\
\hline HD 10 & $\mathrm{~m}$ & 25 & 16.10 .2017 \\
\hline HD 13 & $\mathrm{~m}$ & 27 & 07.12 .2018 \\
\hline HD 19 & $\mathrm{~m}$ & 26 & 16.01 .2018 \\
\hline HD 24 & $\mathrm{~m}$ & 23 & 13.02 .2018 \\
\hline HD 28 & w & 30 & 14.02.2018 \\
\hline HD31_1 & w & 25 & 07.05 .2018 \\
\hline HD 9_3 & w & 26 & 14.06 .2018 \\
\hline
\end{tabular}

Anmerkung: $m=$ männlich, $w=$ weiblich, $\mathrm{HD}=$ Healthy Donor (dt.: gesunder Proband) 


\subsection{Anzahlen der zirkulierenden Tumorzellen}

Die Anzahlen der gefundenen CTCs sind in Tabelle 8, Tabelle 9 und Tabelle 10 ersichtlich.

Das eingesetzte Blut-Volumen $(v)$ bemisst sich auf Werte zwischen 2,5 und 21,5 ml. Die Anzahl der CTCs ist in den Tabellen als Variable $x$ angegeben. $x$ beinhaltet die Anzahlen der gefundenen Zellen, die CD45 negativ, ASGPR positiv, CD146 positiv, CD274 positiv und CD90 positiv sind. Diese Zellen wurden, wie oben beschrieben, als CTCs bezeichnet.

Die Probe im FACS-Röhrchen musste meist aus technischen Gründen verdünnt werden, da das Durchflusszytometer wegen der Genauigkeit nur mit einer bestimmten Geschwindigkeit Flüssigkeit aus den FACS-Röhrchen aufnehmen sollte. Das verwendete FACS Ariall Fusion Durchflusszytometer hat dabei eine maximale Erfassungsrate von 70.000 „events“ pro Sekunde. 85 Die „events“ sind dabei Zellen, die, wie oben beschrieben, nach unterschiedlichen Parametern einer Zell-Population zugeordnet werden können.

Wenn die Anzahl der Zellen im FACS-Röhrchen, die pro Sekunde durch das FACS Ariall aufgenommen werden, diese Grenze überschreiten, muss die Probe individuell mit FACS-Puffer verdünnt werden. Der Wert in der dritten Spalte der nachfolgenden Tabellen ist das Volumen, auf das die Probe verdünnt wurde und wurde mit $y$ benannt.

Da aus technischen Gründen nicht immer die gesamte Probe eingelesen werden konnte, wurde ein Rest $r$ im FACS-Röhrchen übriggelassen. Aus diesen Werten ließ sich der Verdünnungsfaktor oder engl. "dilution“ - Faktor (Dil.faktor), errechnen nach der Formel:

$$
\text { Dil. faktor }=\frac{y}{(y-r)} .
$$

Mithilfe dieses Dil.faktors lässt sich die Anzahl der CTCs pro ml Blut ermitteln:

$$
\text { CTCs pro ml Blut }=\frac{x \times \text { Dil.faktor }}{v} \text {. }
$$


Ergebnisse

Tabelle 8 - Ergebnisse prä-op

\begin{tabular}{|c|c|c|c|c|c|c|}
\hline Patient & $\begin{array}{c}\text { Volumen } \\
\text { einges. (v) } \\
\text { [ml] }\end{array}$ & $\begin{array}{l}\text { Anzahl } \\
\text { CTCs } \\
\text { total }(x)\end{array}$ & $\begin{array}{l}\text { Verdünnt } \\
\text { auf (y) [ml] }\end{array}$ & $\begin{array}{c}\text { Rest }(r) \\
{[\mathrm{ml}]}\end{array}$ & Dil.faktor & $\begin{array}{c}\text { CTCs pro } \\
\text { ml Blut } \\
\text { prä-op }\end{array}$ \\
\hline MWA 1 & 8,5 & 5 & 2,00 & 0,05 & 1,03 & 0,6 \\
\hline MWA 2 & 8,0 & 13 & 2,10 & 0,05 & 1,02 & 1,7 \\
\hline MWA 3 & 8,0 & 29 & 2,10 & 0,05 & 1,02 & 3,7 \\
\hline MWA 4 & 8,0 & 13 & 2,10 & 0,05 & 1,02 & 1,7 \\
\hline MWA 5 & 3,5 & 1 & 0,25 & 0,00 & 1,00 & 0,3 \\
\hline MWA 6 & 2,5 & 1 & 1,50 & 0,10 & 1,07 & 0,4 \\
\hline MWA 7 & 6,0 & 0 & 1,50 & 0,05 & 1,03 & 0,0 \\
\hline MWA 8 & 6,0 & 0 & 1,50 & 1,00 & 3,00 & 0,0 \\
\hline MWA 9 & 6,0 & 47 & 1,50 & 0,15 & 1,11 & 8,7 \\
\hline MWA10 & 5,0 & 0 & 7,00 & 6,00 & 7,00 & 0,0 \\
\hline TACE 1 & 21,0 & 2 & 1,40 & 0,20 & 1,17 & 0,1 \\
\hline TACE 2 & 7,5 & 4 & 1,40 & 0,35 & 1,33 & 0,7 \\
\hline TACE 3 & 4,0 & 3 & 1,40 & 0,20 & 1,17 & 0,9 \\
\hline TACE 4 & 7,0 & 3 & 1,40 & 0,20 & 1,17 & 0,5 \\
\hline TACE 5 & 11,2 & 6 & 1,40 & 0,10 & 1,08 & 0,6 \\
\hline TACE 6 & 8,0 & 2 & 1,40 & 0,35 & 1,33 & 0,3 \\
\hline TACE 7 & 6,5 & 10 & 1,40 & 0,28 & 1,25 & 1,9 \\
\hline TACE 8 & 6,0 & 0 & 1,30 & 0,10 & 1,08 & 0,0 \\
\hline
\end{tabular}


Ergebnisse

Tabelle 9 - Ergebnisse post-op

\begin{tabular}{|c|c|c|c|c|c|c|}
\hline Patient & $\begin{array}{c}\text { Volumen } \\
\text { einges. (v) } \\
\text { [ml] }\end{array}$ & $\begin{array}{l}\text { Anzahl } \\
\text { CTCs } \\
\text { total }\end{array}$ & $\begin{array}{l}\text { Verdünnt } \\
\text { auf [ml] }\end{array}$ & Rest [ml] & Dil.faktor & $\begin{array}{c}\text { CTCs pro } \\
\text { ml Blut } \\
\text { post-op }\end{array}$ \\
\hline MWA 1 & 9,0 & 4 & 2,00 & 0,05 & 1,03 & 0,5 \\
\hline MWA 2 & 10,0 & 8 & 2,10 & 0,05 & 1,02 & 0,8 \\
\hline MWA 3 & 8,0 & 15 & 2,10 & 0,05 & 1,02 & 1,9 \\
\hline MWA 4 & 6,0 & 8 & 2,10 & 0,05 & 1,02 & 1,4 \\
\hline MWA 5 & 4,5 & 0 & 0,25 & 0,00 & 1,00 & 0,0 \\
\hline MWA 6 & 2,5 & 1 & 1,50 & 0,10 & 1,07 & 0,4 \\
\hline MWA 7 & 6,0 & 0 & 1,40 & 1,00 & 3,50 & 0,0 \\
\hline MWA 8 & 6,0 & 0 & 1,50 & 1,20 & 5,00 & 0,0 \\
\hline MWA 9 & 6,0 & 44 & 1,50 & 0,15 & 1,11 & 8,1 \\
\hline MWA10 & 5,0 & 0 & 1,50 & 0,20 & 1,15 & 0,0 \\
\hline TACE 1 & 20,5 & 9 & 1,40 & 0,20 & 1,17 & 0,5 \\
\hline TACE 2 & 12,0 & 12 & 1,40 & 0,20 & 1,17 & 1,2 \\
\hline TACE 3 & 10,0 & 2 & 1,40 & 0,20 & 1,17 & 0,2 \\
\hline TACE 4 & 7,0 & 0 & 1,40 & 0,20 & 1,17 & 0,0 \\
\hline TACE 5 & 11,5 & 5 & 1,40 & 0,10 & 1,08 & 0,5 \\
\hline TACE 6 & 8,0 & 5 & 1,40 & 0,35 & 1,33 & 0,8 \\
\hline TACE 7 & 7,5 & 2 & 1,40 & 0,28 & 1,25 & 0,3 \\
\hline TACE 8 & 6,0 & 0 & 1,30 & 0,05 & 1,04 & 0,0 \\
\hline
\end{tabular}


Tabelle 10 - Ergebnisse HDs

\begin{tabular}{|c|c|c|c|c|c|c|}
\hline Proband & $\begin{array}{c}\text { Volumen } \\
\text { einges. (v) } \\
\text { [ml] }\end{array}$ & $\begin{array}{l}\text { Anzahl } \\
\text { CTCs } \\
\text { total }\end{array}$ & $\begin{array}{l}\text { Verdünnt } \\
\text { auf [ml] }\end{array}$ & Rest [ml] & Dil.faktor & $\begin{array}{c}\text { CTCs pro } \\
\text { ml Blut }\end{array}$ \\
\hline$\overline{\mathrm{HD} 1}$ & 7,5 & 7 & 1,40 & 0,20 & 1,17 & 1,1 \\
\hline HD 2 & 15,0 & 16 & 1,40 & 0,05 & 1,04 & 1,1 \\
\hline HD 4 & 5,0 & 0 & 1,40 & 0,20 & 1,17 & 0,0 \\
\hline HD 5 & 5,0 & 0 & 1,40 & 0,20 & 1,17 & 0,0 \\
\hline HD 7 & 8,5 & 9 & 2,00 & 0,05 & 1,03 & 1,1 \\
\hline HD 8 & 10,5 & 12 & 2,00 & 0,05 & 1,03 & 1,2 \\
\hline HD 10 & 9,0 & 0 & 0,25 & 0,00 & 1,00 & 0,0 \\
\hline HD 13 & 9,0 & 10 & 1,40 & 0,10 & 1,08 & 1,2 \\
\hline HD 19 & 4,9 & 0 & 1,50 & 0,15 & 1,11 & 0,0 \\
\hline HD 24 & 7,5 & 5 & 1,40 & 0,28 & 1,25 & 0,8 \\
\hline HD 28 & 6,0 & 1 & 1,50 & 0,10 & 1,07 & 0,2 \\
\hline HD31_1 & 10,0 & 1 & 1,50 & 0,40 & 1,36 & 0,1 \\
\hline HD 9_3 & 5,0 & 0 & 1,50 & 0,10 & 1,07 & 0,0 \\
\hline
\end{tabular}

Anmerkung: $\mathrm{HD}=$ Healthy Donor $=$ gesunder Proband ohne HCC

Aus den obigen Ergebnissen konnten die Mittelwerte und die jeweiligen Standardabweichungen berechnet werden. In den nachfolgenden Kapiteln sind diese Mittelwerte und Standardabweichungen der jeweiligen Ergebnisse bei TACE (Abbildung 13), bei MWA (Abbildung 14) und bei beiden Gruppen zusammen vor und nach radiologischer Intervention (Abbildung 15) als Balkendiagramme dargestellt. Darauffolgend sind die Ergebnisse der gesunden Probanden im Vergleich zu denen der TACE-Patienten (Abbildung 16), im Vergleich zu denen der 
MWA-Patienten (Abbildung 17) und im Vergleich $z u$ beiden radiologischen Interventionen (Abbildung 18) grafisch dargestellt.

\subsubsection{CTC-Anzahlen der HCC-Patienten vor und nach TACE}

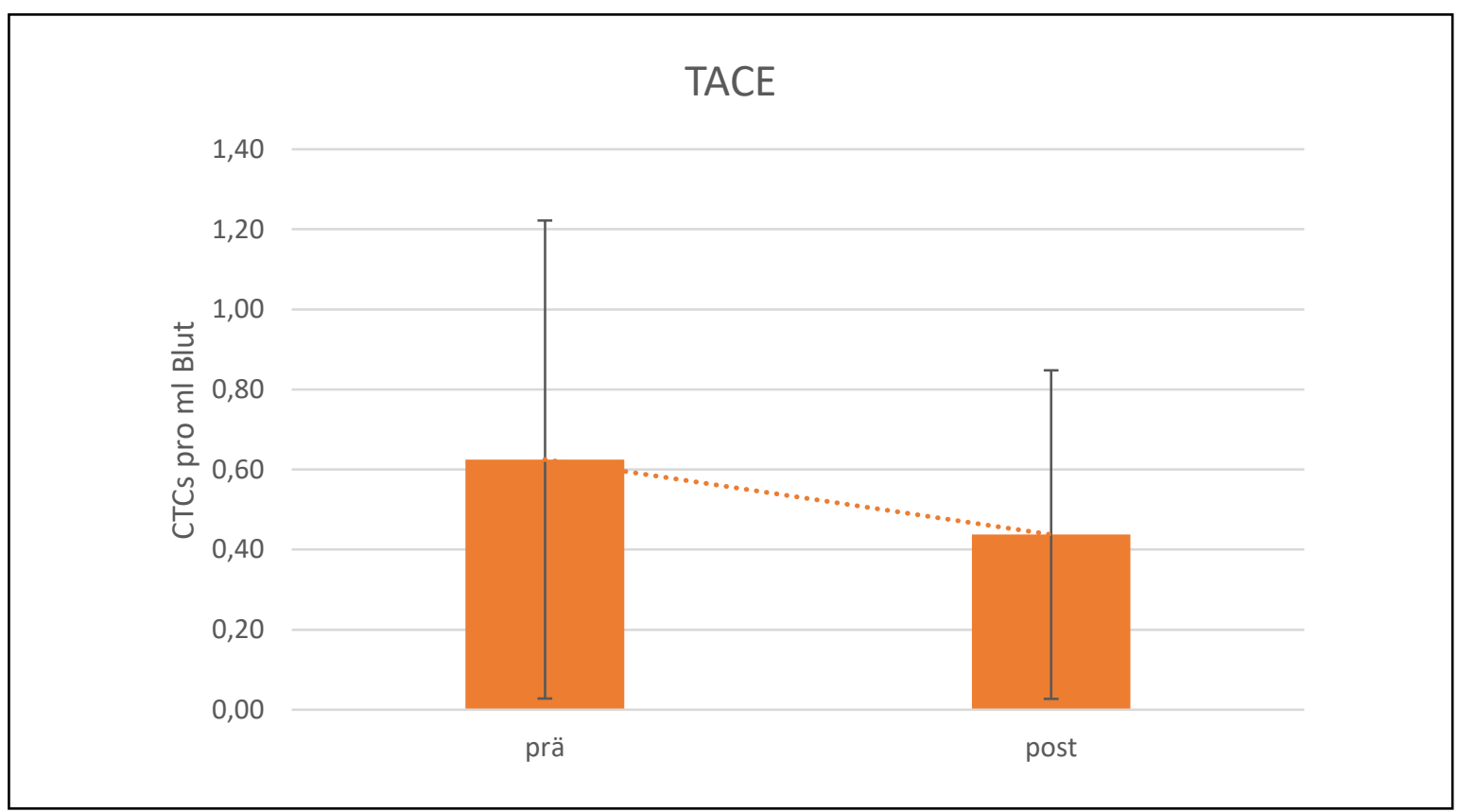

Abbildung 13 - Ergebnisse der CTC-Anzahlen bei TACE im Vergleich

Anmerkung:

prä = CTC-Anzahlen der HCC-Patienten vor radiologischer Intervention post = CTC-Anzahlen der HCC-Patienten nach radiologischer Intervention

Die Balken zeigen die Mittelwerte mit den entsprechenden Standardabweichungen der CTC-Anzahlen. Die gepunktete Linie zeigt den Trend der CTC-Kurzzeitdynamik.

Der Mittelwert der CTC-Anzahlen der TACE-Patienten vor der radiologischen Intervention betrug 0,6 CTCs pro ml Blut. Nach der Durchführung der TACE war ein Mittelwert von 0,4 CTCs pro ml Blut zu verzeichnen. Im Vergleich zu den Proben der TACE-Patienten vor der Therapie lagen die Ergebnisse darausfolgend um 0,2 CTCs pro ml Blut niedriger. Die Standardabweichungen betrugen bei den Proben vor TACE 0,6 und bei den Proben nach TACE 0,4 CTCs pro ml Blut. 


\subsubsection{CTC-Anzahlen der HCC-Patienten vor und nach MWA}

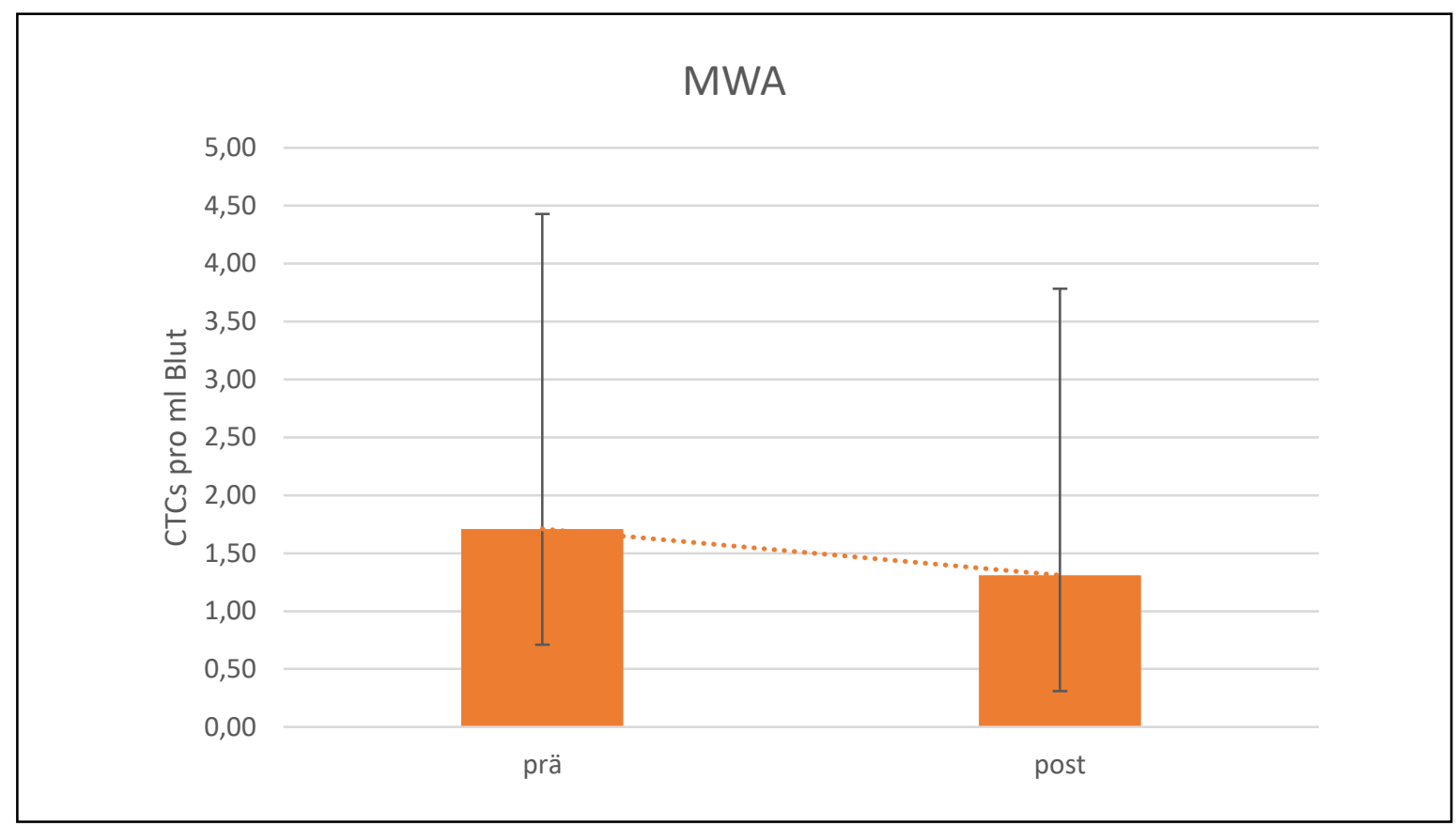

Abbildung 14 - Ergebnisse der CTC-Anzahlen bei MWA im Vergleich

Anmerkung:

prä = CTC-Anzahlen der HCC-Patienten vor radiologischer Intervention post $=$ CTC-Anzahlen der HCC-Patienten nach radiologischer Intervention Die Balken zeigen die Mittelwerte mit den entsprechenden Standardabweichungen der CTC-Anzahlen. Die gepunktete Linie zeigt den Trend der CTC-Kurzzeitdynamik.

Die Mittelwerte betrugen für die Proben vor MWA 1,7 und nach MWA 1,3 CTCs pro ml Blut. Aus dem Vergleich ergab sich auch hier ein Absinken der detektierten CTCs nach Durchführung der radiologischen Intervention. Bei der Therapie mit MWA sank dieser Wert um 0,4. Die Standardabweichungen beliefen sich bei den Proben vor MWA auf 2,7 und bei den Proben nach MWA auf 2,5 CTCs pro ml Blut. 


\subsubsection{CTC-Anzahlen bei TACE- und MWA-Patienten zusammen}

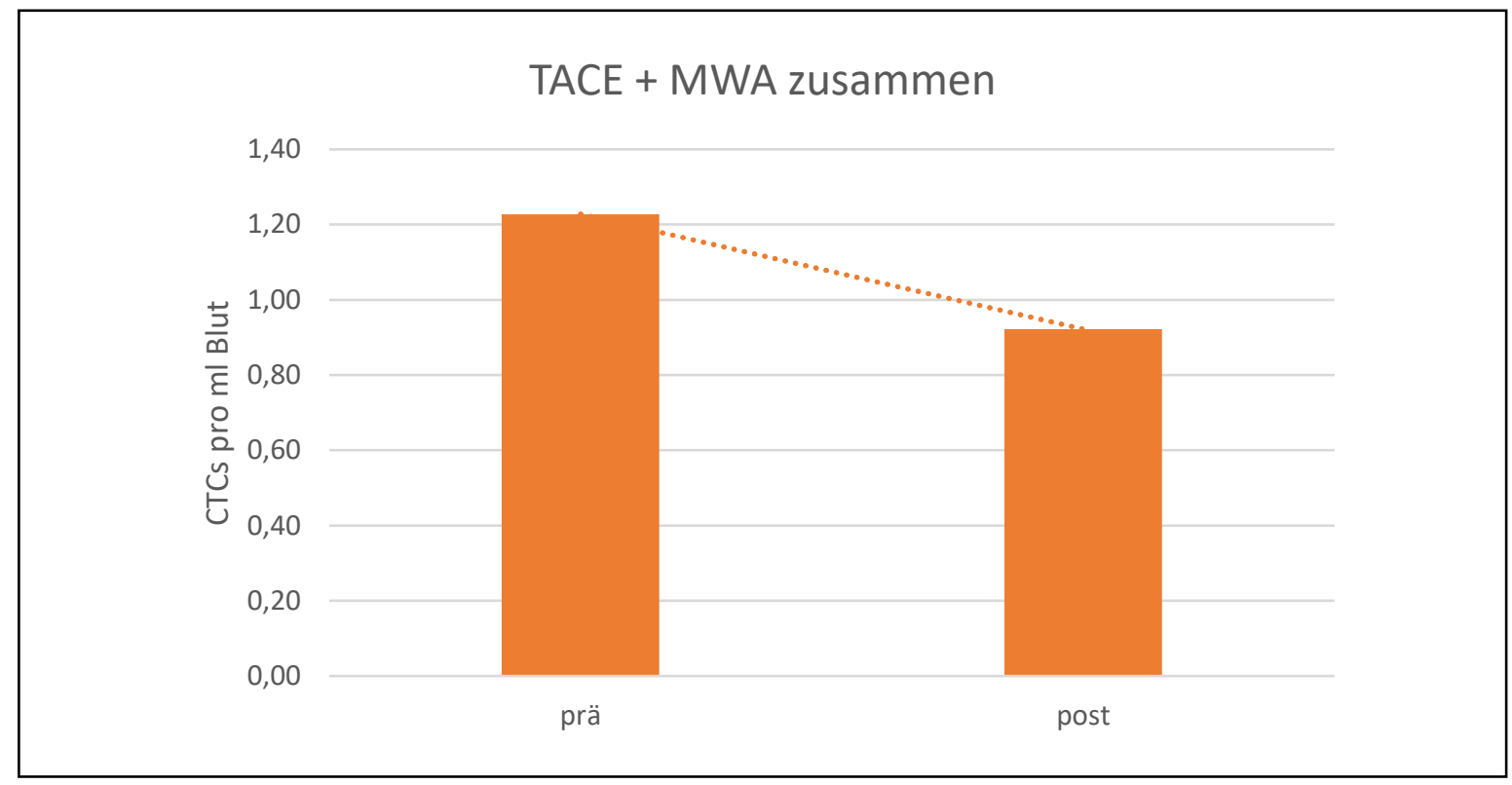

Abbildung 15 - Ergebnisse der CTC-Anzahlen bei TACE und MWA

Anmerkung:

prä = CTC-Anzahlen der HCC-Patienten vor radiologischer Intervention

post $=$ CTC-Anzahlen der HCC-Patienten nach radiologischer Intervention

Die Balken zeigen die Mittelwerte der CTC-Anzahlen.

Die gepunktete Linie zeigt den Trend der CTC-Kurzzeitdynamik.

Bei allen HCC-Patienten vor radiologischer Therapie zusammen ergab sich ein Mittelwert von 1,2 CTCs pro ml Blut. Nach der Therapie lag der Mittelwert aller eingeschlossener Patienten bei 0,9 CTCs pro ml Blut. Insgesamt ließ sich ein Sinken der CTC-Anzahl bei den HCC-Patienten nach radiologischer Intervention von 0,3 CTCs pro ml Blut verzeichnen.

In Kapitel 4.4 folgt das Ergebnis der statistischen Auswertung dieser CTC-Anzahlen. 


\subsubsection{CTC-Anzahlen der gesunden Probanden und der TACE-Patienten}

Für den Vergleich der CTC-Anzahlen der gesunden Probanden mit denen der TACE- bzw. MWA-Patienten, wurden die Werte ausschließlich vor der Therapie berücksichtigt. Die CTC-Anzahlen nach der Therapie fanden keine Berücksichtigung in nachfolgenden Ergebnissen.

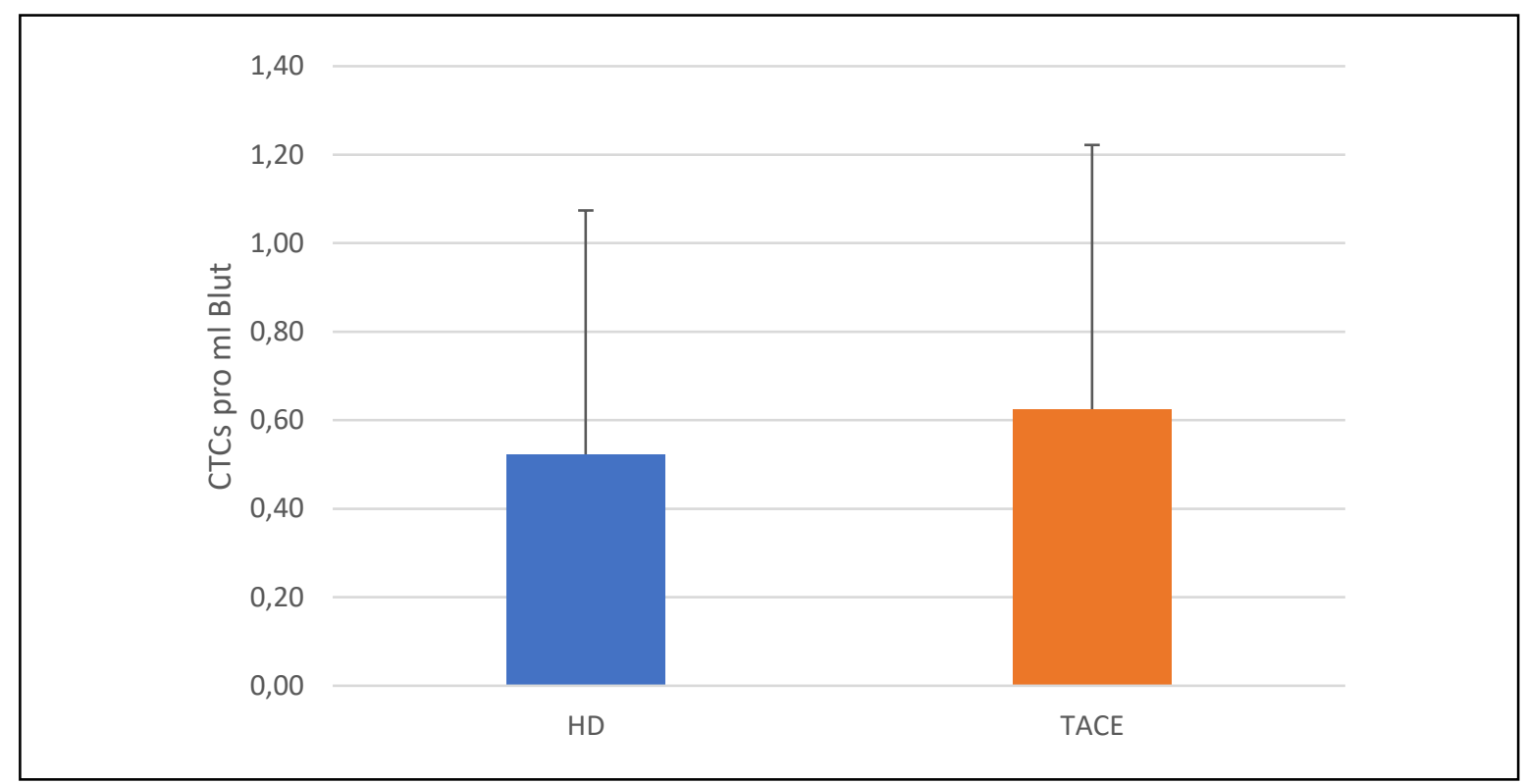

\section{Abbildung 16 - HDs vs. TACE-Patienten}

Anmerkung:

$\mathrm{HD}=\mathrm{CTC}-$ Anzahlen der gesunden Probanden

TACE = CTC-Anzahlen der HCC-Patienten vor radiologischer Intervention

Die Balken zeigen die Mittelwerte mit den entsprechenden Standardabweichungen der CTC-Anzahlen.

Der Mittelwert der CTC-Anzahl bei den gesunden Probanden betrug 0,52 Zellen pro ml Blut. Bei den HCC-Patienten, die eine TACE als Therapie erhielten, betrug der Wert 0,63 Zellen pro ml Blut. Die Standardabweichungen lagen bei 0,55 Zellen bei den gesunden Probanden und bei 0,6 Zellen pro ml Blut bei den TACE-Patienten. 


\subsubsection{CTC-Anzahlen der gesunden Probanden und der MWA-Patienten}

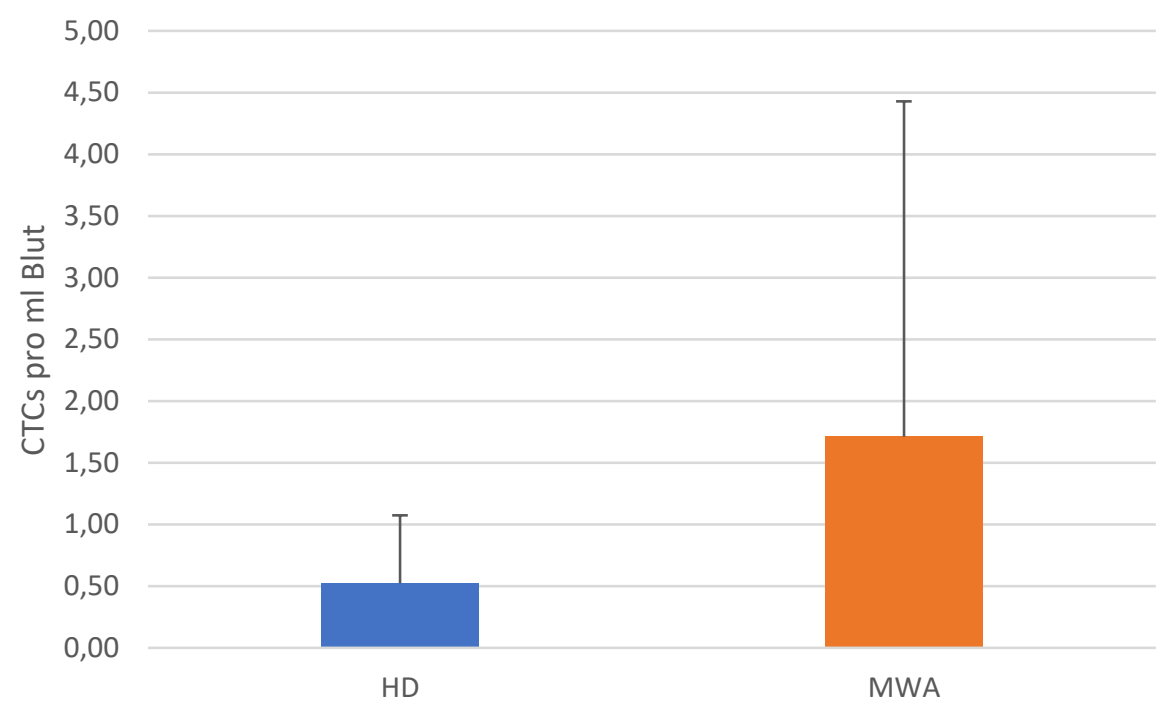

Abbildung 17 - HDs vs. MWA-Patienten

Anmerkung:

$\mathrm{HD}=\mathrm{CTC}-$ Anzahlen der gesunden Probanden

MWA = CTC-Anzahlen der HCC-Patienten vor radiologischer Intervention

Die Balken zeigen die Mittelwerte mit den entsprechenden Standardabweichungen der CTC-Anzahlen.

Die Anzahl der detektierten CTCs bei den gesunden Patienten lag im Mittel bei 0,52 und bei den HCC-Patienten, die eine MWA erhielten, bei 1,71 pro ml Blut. Die Standardabweichungen für diese Werte lagen bei den gesunden Probanden bei 0,55 und bei den MWA-Patienten bei 2,72 CTCs pro ml Blut. 


\subsubsection{CTC-Anzahlen der gesunden Probanden und der TACE- und MWA-Patienten}

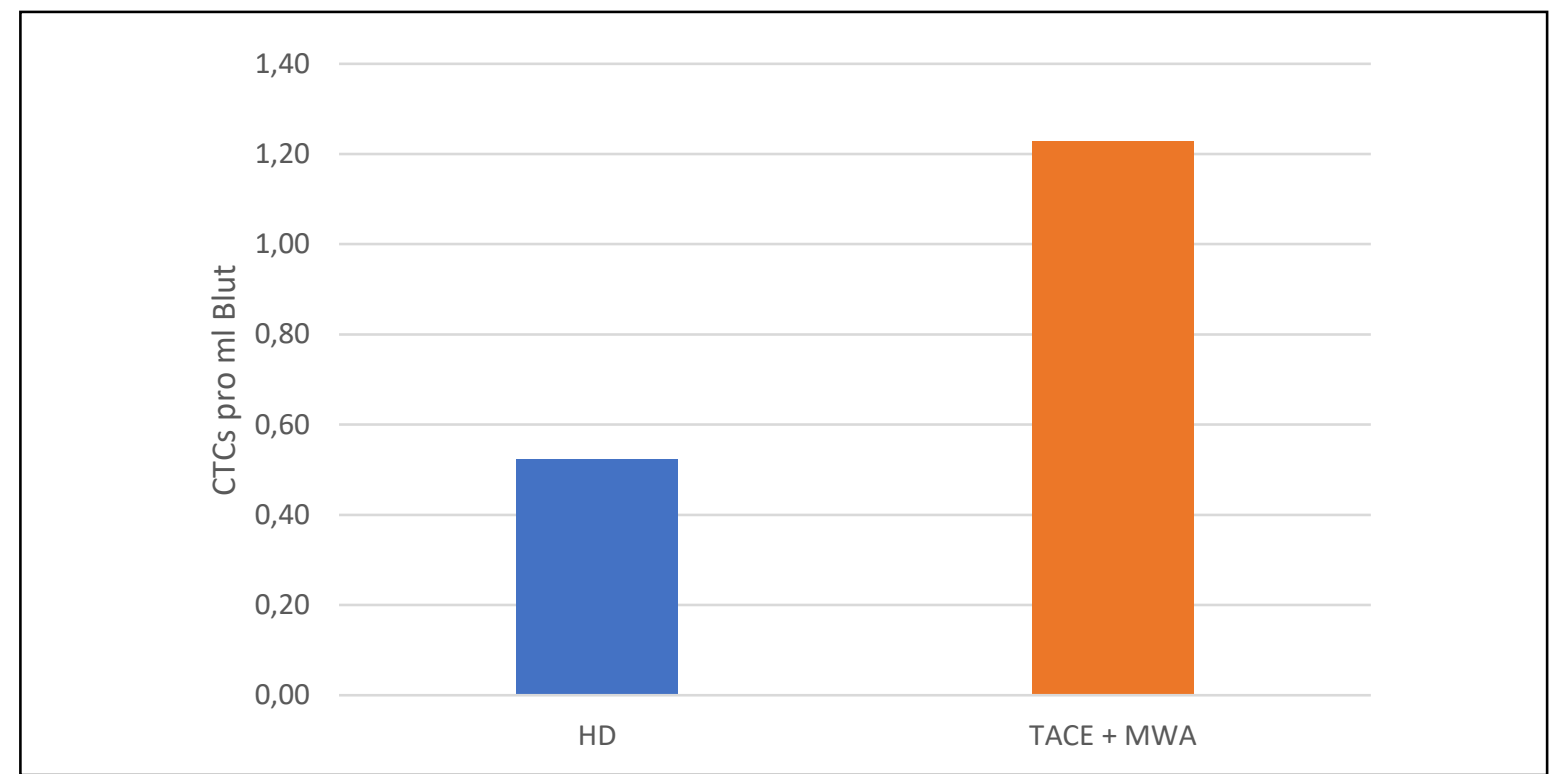

Abbildung 18 - HDs vs. TACE- und MWA-Patienten

Anmerkung:

$\mathrm{HD}=\mathrm{CTC}-$ Anzahlen der gesunden Probanden

TACE + MWA = CTC-Anzahlen der HCC-Patienten vor radiologischer Intervention

Die Balken zeigen die Mittelwerte der CTC-Anzahlen.

Mit einem Mittelwert von 0,52 CTCs pro $\mathrm{ml}$ Blut zeigten sich die gesunden Probanden, wohingegen die erkrankten HCC-Patienten vor der radiologischen Therapie im Mittel 1,23 CTCs pro ml Blut aufwiesen. Die Standardabweichungen berechneten sich für die gesunden Probanden auf 0,55 und bei den HCC-Patienten auf 2,09 Zellen pro ml Blut. 


\subsubsection{FACS-Auswertung}

An dieser Stelle soll eine Auswertung mit dem FACS und entsprechender Software beispielhaft an einer HCC-Patientenprobe (TACE5 prä-op) gezeigt werden. Aus Gründen der Übersicht wurde auf eine bildliche Darstellung aller Patienten-Auswertungen verzichtet.

Bei einem Gate (dt. Rahmen) handelt es sich um einen Ausschnitt von gefundenen Zellen, der markiert wird. Die Zellen in diesem Gate können dann in einem neuen Diagramm nach weiteren Parametern untersucht werden. In Abbildung 19 ist zu sehen wie um die CD45-negative und die CD146-positive Population das zweite Gate gelegt wurde. Zuvor wurden durch das erste Gate bereits diejenigen Zellen ausgewählt, die CD45 negativ und CD146 positiv waren.

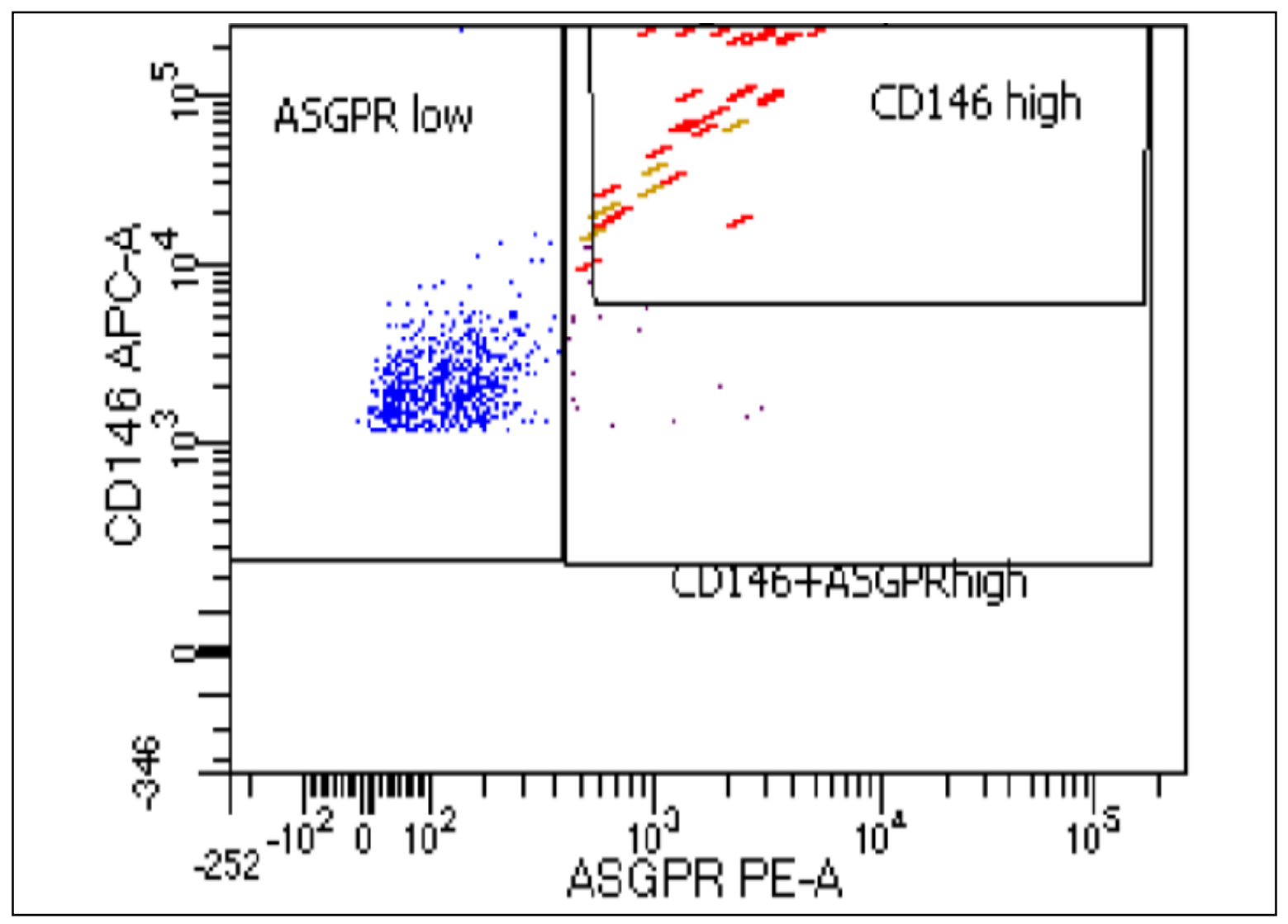

Abbildung 19 - FACS-Auswertung, zweites Gate

In Abbildung 19 ist erkennbar, dass die CD45 negativen und CD146 positiven Zellen nun zusätzlich nach ASGPR-1 analysiert wurden. Das Kästchen rechts oben mit den roten und gelben Punkten stellt das dritte Gate dar, das weitergehend untersucht wurde (s. Abbildung 20). Die blauen Punkte in Abbildung 19 sind die 
CD146 positive Population, die eine schwache ASGPR-1-Expression zeigt (ASGPR-low) (s. 3.4.2.3).

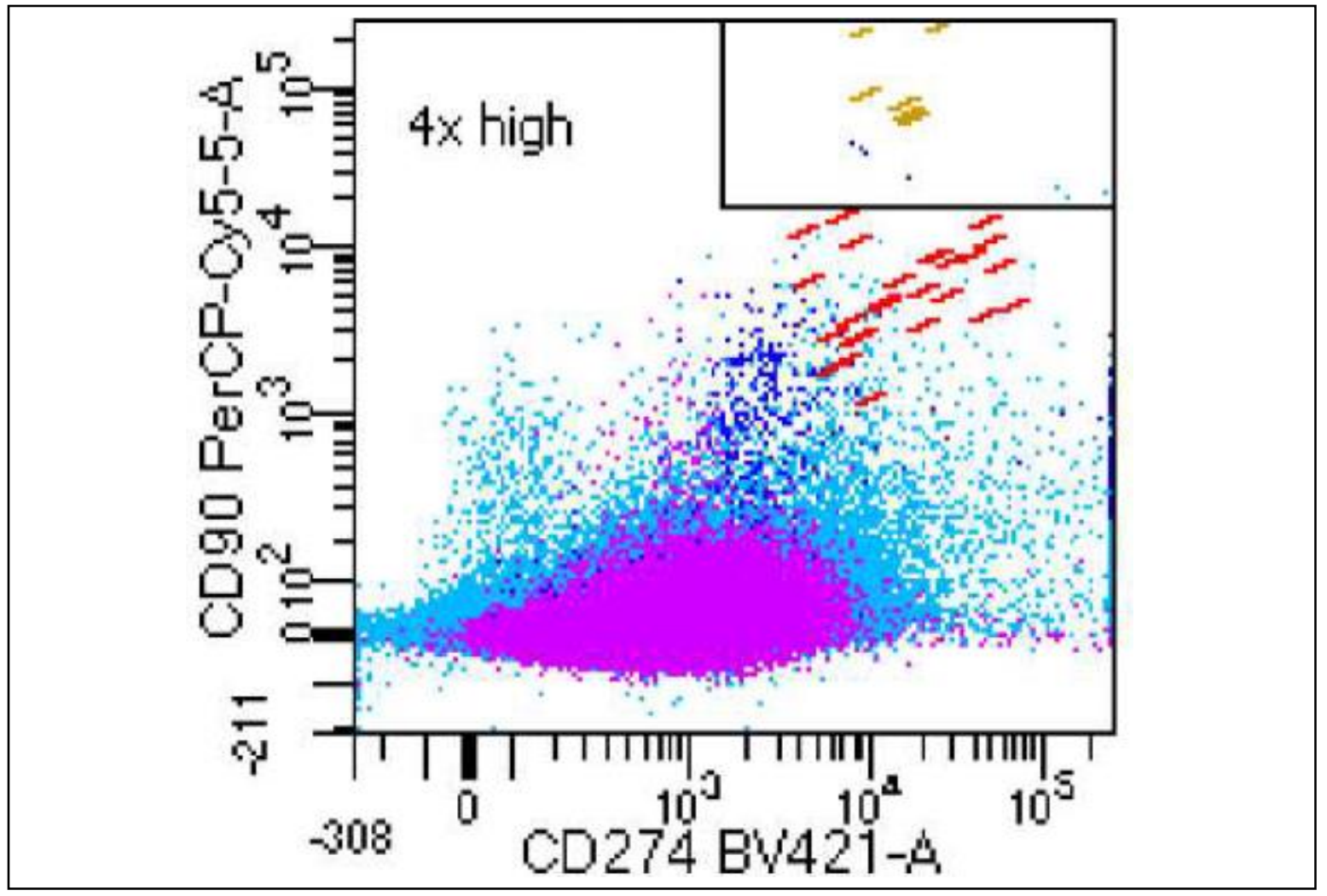

Abbildung 20 - FACS-Auswertung, drittes Gate

Entsprechend der Achsenbeschriftung ist zu sehen, dass die CD45 negativen, CD146 und ASGPR-1 positiven Zellen hier weiterhin nach CD90- und CD274-Positivität unterschieden wurden.

Das Kästchen oben rechts in der Ecke enthält die ausgewählte Population, die auch als CD90 und CD274 positiv galten. Es können sechs Zellen gezählt werden (sechs gelbe Punkte). Das sind in dieser Analyse die Zellen, die als CTCs bezeichnet wurden, da sie allen festgelegten Kriterien nachkamen. Die tabellarisch dargestellte Analyse der Software in Abbildung 21 bestätigt diese Zählung. 


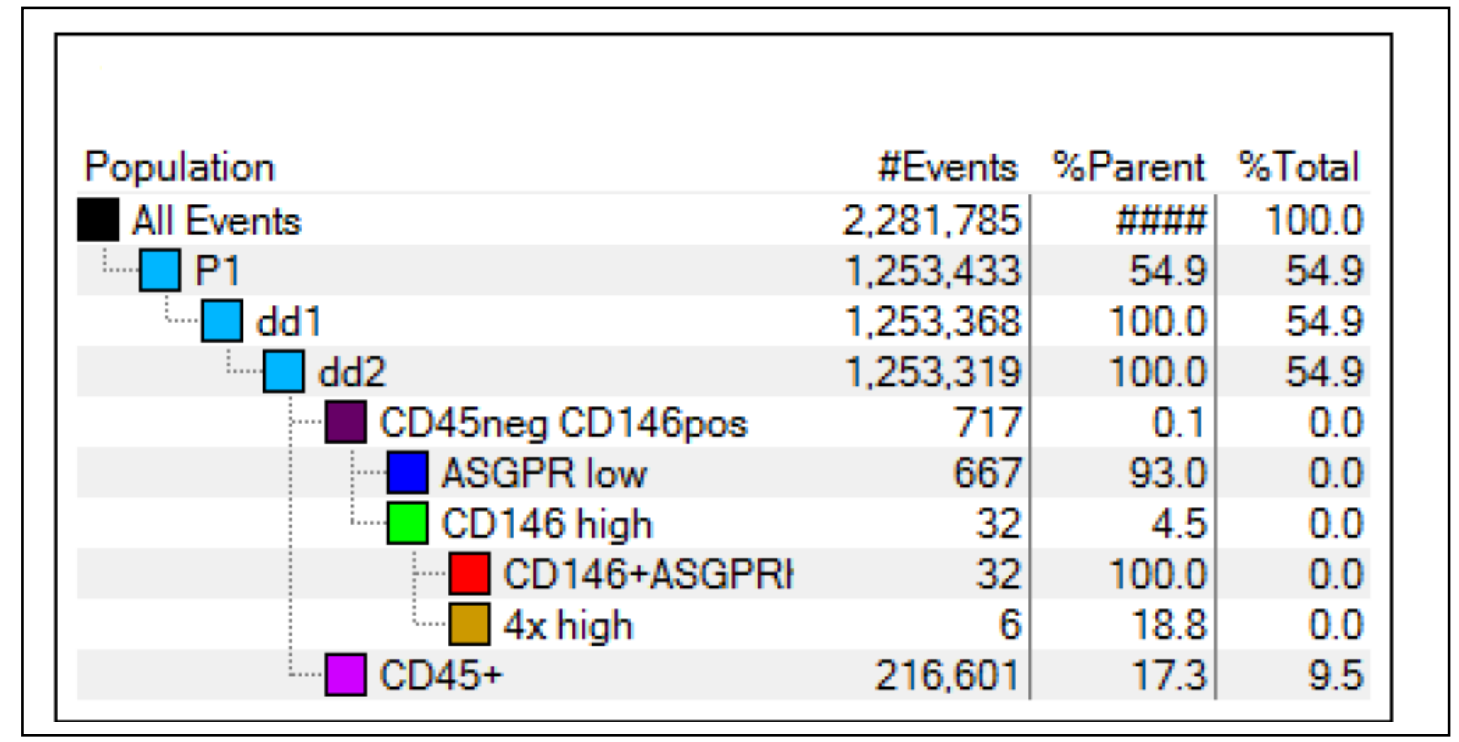

Abbildung 21 - FACS-Auswertung Tabelle TACE5 prä-op

Anm: „4x high“ bedeutet, dass alle vier Marker (CD146, ASGPR-1, CD274 und CD90) hoch genug ausgeprägt waren, als dass sie in dieses endgültige Gate der gezählten CTCs einbezogen wurden. 


\subsection{AFP-Werte}

In Tabelle 11 sind die Ergebnisse der AFP-Werte vor und nach Therapie zu sehen. Auch die Differenz der AFP-Werte und die Differenz der CTC-Anzahlen sind dargestellt. Die Differenz errechnet sich jeweils aus dem AFP-Wert prä-op minus dem AFP-Wert post-op bzw. der CTC-Anzahl prä-op minus der CTC-Anzahl post-op (s. Tabelle 8 und Tabelle 9).

Tabelle 11 - AFP-Werte und Differenzen der AFP-Werte und CTC-Anzahlen

\begin{tabular}{|c|c|c|c|c|}
\hline Patient & $\begin{array}{l}\text { AFP-Wert } \\
\text { prä-op }\end{array}$ & $\begin{array}{l}\text { AFP-Wert } \\
\text { post-op }\end{array}$ & $\begin{array}{c}\text { Differenz } \\
\text { der AFP-Werte }\end{array}$ & $\begin{array}{c}\text { Differenz } \\
\text { der CTC-Anzahlen }\end{array}$ \\
\hline MWA 1 & 3,3 & 3,2 & $-0,1$ & $-0,1$ \\
\hline MWA 2 & 2,3 & 3,1 & $+0,8$ & $-0,8$ \\
\hline MWA 3 & 5,2 & 4,7 & $-0,5$ & $-1,8$ \\
\hline MWA 4 & 2,4 & 0,6 & $-1,8$ & $-0,3$ \\
\hline MWA 5 & 4,6 & 4,4 & $-0,2$ & $-0,3$ \\
\hline MWA 6 & 13 & 11,8 & $-1,2$ & 0,0 \\
\hline MWA 7 & 4,8 & 4,5 & $-0,3$ & 0,0 \\
\hline MWA 8 & 4 & 5,4 & $+1,4$ & 0,0 \\
\hline MWA 9 & 1833 & 1496 & -337 & $-0,6$ \\
\hline MWA10 & 8,3 & 9,7 & $+1,4$ & 0,0 \\
\hline TACE 1 & 0 & 33 & +33 & 0,4 \\
\hline TACE 2 & 155,4 & 151,1 & $-4,3$ & 0,5 \\
\hline TACE 3 & 228,7 & 256,6 & $+27,9$ & $-0,6$ \\
\hline TACE 4 & 4,1 & 4,4 & $+0,3$ & $-0,5$ \\
\hline
\end{tabular}


Ergebnisse

$\begin{array}{ccccc}\text { TACE } 5 & 3,8 & 3,4 & -0,4 & -0,1 \\ \text { TACE } 6 & 6,7 & 6,1 & -0,6 & 0,5 \\ \text { TACE } 7 & 2 & 1,9 & -0,1 & -1,6 \\ \text { TACE } 8 & 60500 & 60500 & 0,0 & 0,0\end{array}$




\subsection{IL-6-Werte}

In Tabelle 12 sind sowohl die Ergebnisse der IL-6-Werte vor und nach Therapie als auch die Differenzen der IL-6-Werte und der CTC-Anzahlen aufgeführt. Die Differenz errechnet sich, ebenso wie im Kapitel zuvor, jeweils aus dem IL-6-Wert prä-op minus dem IL-6-Wert post-op bzw. der CTC-Anzahl prä-op minus der CTC-Anzahl post-op (s. Tabelle 8 und Tabelle 9).

Tabelle 12 - IL-6-Werte und Differenzen der IL-6-Werte und CTC-Anzahlen

\begin{tabular}{|c|c|c|c|c|}
\hline Patient & $\begin{array}{l}\text { IL-6-Wert } \\
\text { prä-op }\end{array}$ & $\begin{array}{l}\text { IL-6-Wert } \\
\text { post-op }\end{array}$ & $\begin{array}{c}\text { Differenz } \\
\text { der IL-6-Werte }\end{array}$ & $\begin{array}{c}\text { Differenz } \\
\text { der CTC-Anzahlen }\end{array}$ \\
\hline MWA 1 & 9,9 & 7 & $-2,9$ & $-0,1$ \\
\hline MWA 2 & 5,6 & 7,7 & $+2,1$ & $-0,8$ \\
\hline MWA 3 & 12,7 & 11,9 & $-0,8$ & $-1,8$ \\
\hline MWA 4 & 13,8 & 20,7 & $+6,9$ & $-0,3$ \\
\hline MWA 5 & 14,1 & 15,9 & $+1,76$ & $-0,3$ \\
\hline MWA 6 & 10,7 & 8,7 & -2 & 0,0 \\
\hline MWA 7 & 7,4 & 7,4 & 0,0 & 0,0 \\
\hline MWA 8 & 48,5 & 5,7 & $-42,8$ & 0,0 \\
\hline MWA 9 & 5,5 & 5,4 & $-0,1$ & $-0,6$ \\
\hline MWA10 & 39,5 & 18,8 & $-20,7$ & 0,0 \\
\hline TACE 1 & 5,4 & 5,4 & 0,0 & 0,4 \\
\hline TACE 2 & 16,2 & 44,2 & +28 & 0,5 \\
\hline TACE 3 & 21,3 & 28,3 & +7 & $-0,6$ \\
\hline TACE 4 & 5,3 & 7,4 & $+2,1$ & $-0,5$ \\
\hline
\end{tabular}


Ergebnisse

\begin{tabular}{ccccc} 
TACE 5 & 6,3 & 9,7 & $+3,4$ & $-0,1$ \\
TACE 6 & 20,1 & 28,5 & $+8,4$ & 0,5 \\
TACE 7 & 5,8 & 6,7 & $+0,9$ & $-1,6$ \\
TACE 8 & 18,7 & 19,8 & $+1,1$ & 0,0 \\
\hline
\end{tabular}




\subsection{Ergebnisse der statistischen Tests}

\subsubsection{CTC-Anzahlen der HCC-Patienten vor und nach radiologischer Intervention im Vergleich}

Um die erste Fragestellung dieser Arbeit, nach der Kurzzeitdynamik zirkulierender Tumorzellen vor und nach radiologischer Intervention, beantworten zu können wurde der Wilcoxon-matched-pairs-Test mit den CTC-Anzahlen der HCC-Patienten vor und nach radiologischer Intervention (TACE und MWA zusammen) durchgeführt (s. 3.5.1).

Dieser Test ergab eine Effektstärke von 0,3566, was einen statistisch „mittleren Unterschied" nach Therapie im Vergleich zu vor Therapie bedeutet. Der $p$-Wert für diesen Test nahm einen Wert von 0,08 an.

\subsubsection{CTC-Anzahlen der gesunden Probanden und der HCC-Patienten im Vergleich}

Der Wilcoxon-Mann-Whitney-Test (s. 3.5.2), der für die Beantwortung der zweiten Fragestellung, nach der Optimierung der Methodik zur CTC-Isolation und Detektion, Verwendung fand, wurde drei Mal angewandt.

\subsubsection{Gesunde Probanden vs. TACE-Patienten}

Die Effektstärke $R$ nach Rosenthal von $R=0,08$ zeigt einen sehr geringen Unterschied zwischen den CTC-Anzahlen der gesunden Probanden und denen der HCC-Patienten vor einer Therapie mit TACE. Der $p$-Wert für diesen Wert liegt bei $p=0,75$. Dies kann keine Signifikanz der Ergebnisse nachweisen. Der MannWhitney-Schätzer $P=0.56$ stellt die Wahrscheinlichkeit dar, dass der Wert bei den gesunden Probanden niedriger ist als bei den erkrankten HCC-Patienten. Ein Wert von $>0,5$ zeigt einen schwachen Trend, dass dies der Fall ist.

\subsubsection{Gesunde Probanden vs. MWA-Patienten}

Die hier berechnete Effektstärke $R$ beträgt 0,21 und bedeutet einen geringen Unterschied zwischen den CTC-Anzahlen der gesunden Probanden und denen der HCC-Patienten vor einer Therapie mit MWA. Auch hier konnte keine Signifikanz nachgewiesen werden, da der $p$-Wert mit $p=0.38$ dafür $z u$ hoch liegt. Der Mann-Whitney-Schätzer $\mathrm{P}=0.62$ zeigt eine höhere Wahrscheinlichkeit, dass 
die gesunden Probanden eine niedrigere CTC-Anzahl aufweisen als die erkrankten Patienten als in obiger Auswertung.

\subsubsection{Gesunde Probanden vs. TACE- und MWA-Patienten zusammen}

Auch die Ergebnisse dieses statistischen Tests zeigten einen geringen Unterschied von $\mathrm{R}=0,15$ zwischen den gesunden Probanden und den prä-Ergebnissen der HCC-Patienten. Mit einem $p$-Wert von $p=0,44$ ist hier ebenfalls keine statistische Signifikanz zu sehen.

Mit einem Mann-Whitney-Schätzer $P=0.59$ kann, ebenso wie in den Kapiteln zuvor beschrieben, ein schwacher Trend für die Wahrscheinlichkeit, dass die gesunden Probanden geringere CTC-Anzahlen entnommen werden, diese ist allerdings als gering zu bezeichnen.

\subsubsection{Sensitivität und Spezifität}

Weiterhin sollten die Testgütekriterien der Sensitivität und der Spezifität des angewendeten Screeningverfahrens zur CTC-Detektion ermittelt werden. Mithilfe des Vierfelder-Tests ließen sich eine Sensitivität von 0.778 und eine Spezifität von 0.385 berechnen. 86

\subsubsection{AFP- bzw. IL-6-Dynamik im Vergleich zur CTC-Dynamik}

Um die dritte Fragestellung nach dem Zusammenhang zwischen der Differenz der CTC-Anzahlen und der AFP- bzw. IL-6-Werte, vor und nach Therapie, zu beantworten, wurde jeweils der Spearmen's Korrelationskoeffizient rho bestimmt (s. 3.5.3). Die statistische Auswertung dieser Ergebnisse ergab für die Korrelation der Differenz der AFP-Werte und der Differenz der CTC-Anzahlen einen negativen Wert für den Korrelationskoeffizienten rho $=-0,030860$. Der $p$-Wert für diesen Test lag bei 0,901814 .

Der Korrelationskoeffizient bei gleichem Test mit den Differenzen der IL-6-Werte und der Differenz der CTC-Anzahlen lag bei einem Wert von rho $=0.032361 \mathrm{mit}$ einem $p$-Wert von 0.901814 .

Die Interpretationen der oben beschriebenen Ergebnisse befinden sich im folgenden Kapitel 5. 


\subsection{Klinischer Verlauf nach radiologischer Intervention}

Im Anschluss an die Untersuchung des Blutes der Patienten wurden die Daten zur Kontrolle des klinischen Verlaufs der Patienten im November 2019 erhoben. Der Zeitraum bis zur klinischen Verlaufskontrolle beträgt somit post-op zwischen 1,4 und 2,2 Jahren. Die nachfolgende Tabelle 13 stellt die zuletzt erhobenen Diagnosen bzw. Zustände der Patienten dar.

Insgesamt konnte bei zwei Patienten von einer „Heilung“ ausgegangen werden. Als "geheilt" wurden jene Patienten bezeichnet, die eine Tumorregression oder keine Tumorprogression, keine Lokalrezidive bzw. keine Fernmetastasen aufzeigten. Ein Patient aus der Gruppe der MWA-Patienten und ein TACE-Patient wurden daher als geheilt eingestuft.

Mit „Rezidiv“ gekennzeichnete Patienten waren am Leben, doch wiesen im Verlauf entweder eine Tumorprogression oder Lokalrezidive intrahepatisch auf. Dies lag bei sieben der MWA-Patienten und bei drei TACE-Patienten vor. Nur ein Patient zeigte eine Fernmetastase (TACE3; nicht in der Tabelle verzeichnet), dieser Patient und zwei weitere TACE-Patienten verstarben bis zum angegebenen Zeitpunkt der Verlaufskontrolle.

Um zu überprüfen, ob die Differenzen der CTC-Anzahlen mit dem klinischen Verlauf der Patienten übereinstimmen, wurde folgende Bewertung angewandt: Als positiv korrelierend wurde ein Absinken der CTC-Anzahl bei einer Heilung der Patienten anerkannt (zur genaueren Erklärung s. 5.1.1). Ebenso wurde verfahren bei einem Anstieg der CTC-Anzahlen bei Auftreten von Rezidiven oder bei Versterben der Patienten. Blieb die CTC-Anzahl gleich, wurde die CTC-Anzahl prä-op genauer betrachtet. Waren die CTCs sowohl prä als auch post-op bei einem Wert von 0,0 und der Patient zeigte eine Heilung, wies das auf eine Korellation hin. Zeigte ein solcher Patient jedoch ein Rezidiv oder verstarb, war es mit "nein“ = keine Korrelation zu bewerten. Waren dagegen bei einem Patienten, bei dem die CTC-Anzahl gleichblieb, bereits prä-op CTCs im Blut zu finden, und er zeigte in der Kontrolle Rezidive auf oder verstarb, wurde dies als positive Korrelation gewertet.

Die Ergebnisse zeigen somit, dass bei fünf der 18 untersuchten Patienten eine Korrelation zwischen der CTC-Differenz und dem klinischen Verlauf besteht. Bei 
zehn Patienten, konnte dies nicht nachgewiesen werden. Es kann also gesagt werden, dass sich das in den vorherigen Kapiteln erläuterte Absinken der CTC-Anzahl nach der Therapie im klinischen Verlauf teilweise bestätigt.

Werden die Gruppen der MWA- und TACE-Patienten einzeln betrachtet, ist zu verzeichnen, dass das klinische Outcome der TACE-Patienten schlechter ist als bei den MWA-Patienten, bei denen keine Todesfälle nach Therapie verzeichnet werden konnten. Dieser klinische Verlauf korreliert mit den CTC-Differenzen. Bei einem stärkeren Absinken der CTC-Anzahlen bei den MWA-Patienten (0,4 CTCs) überlebten mehr Individuen im Vergleich zu den TACE-Patienten (0,2 CTCs), bei denen drei Patienten verstarben.

Um eine signifikante Aussage treffen zu können und einen klinischen Verlauf anhand der CTC-Differenz vorhersagen zu können, bleiben weitere Studien mit einem größeren Patientenkollektiv abzuwarten.

Die Verwendung der CTC-Bestimmung zur Diagnostik oder als "Liquid Biopsy"-Methode wird in Kapitel 5.2 genauer erörtert und als solche diskutiert. 
Ergebnisse

Tabelle 13 - klinischer Verlauf

\begin{tabular}{|c|c|c|c|c|}
\hline Patient & Klinischer Verlauf & $\begin{array}{c}\text { CTCs pro ml Blut } \\
\text { prä-op }\end{array}$ & $\begin{array}{c}\text { Differenz } \\
\text { der CTC-Anzahlen }\end{array}$ & $\begin{array}{l}\text { Korrelation von } \\
\text { CTC-Differenz und } \\
\text { klinischem Verlauf }\end{array}$ \\
\hline MWA 1 & k.A. & 0,6 & $-0,1$ & k.A. \\
\hline MWA 2 & Rezidiv & 1,7 & $-0,8$ & nein \\
\hline MWA 3 & Rezidiv & 3,7 & $-1,8$ & nein \\
\hline MWA 4 & Rezidiv & 1,7 & $-0,3$ & nein \\
\hline MWA 5 & Rezidiv & 0,3 & $-0,3$ & nein \\
\hline MWA 6 & Rezidiv & 0,4 & 0,0 & ja \\
\hline MWA 7 & Heilung & 0,0 & 0,0 & ja \\
\hline MWA 8 & Rezidiv & 0,0 & 0,0 & nein \\
\hline MWA 9 & k.A. & 8,7 & $-0,6$ & k.A. \\
\hline MWA10 & Rezidiv & 0,0 & 0,0 & nein \\
\hline TACE 1 & k.A. & 0,1 & 0,4 & k.A. \\
\hline TACE 2 & verstorben & 0,7 & 0,5 & ja \\
\hline TACE 3 & verstorben & 0,9 & $-0,6$ & nein \\
\hline TACE 4 & Rezidiv & 0,5 & $-0,5$ & nein \\
\hline TACE 5 & Heilung & 0,6 & $-0,1$ & ja \\
\hline TACE 6 & Rezidiv & 0,3 & 0,5 & ja \\
\hline TACE 7 & Rezidiv & 1,9 & $-1,6$ & nein \\
\hline TACE 8 & verstorben & 0,0 & 0,0 & nein \\
\hline
\end{tabular}

Anmerkung: Die Erklärungen der Tabelle befinden sich im Flusstext auf S. 70. 


\section{Diskussion - Limitationen - Ausblick}

\subsection{Die Kurzzeitdynamik von zirkulierenden Tumorzellen bei transarterieller Chemoembolisation und Mikrowellenablation bei hepatozellulären Karzinompatienten}

Zur Diskussion steht in dieser Dissertation der Unterschied der CTC-Anzahlen der HCC-Patienten vor und nach der Therapie als Kurzzeitdynamik von CTCs für die Therapiemethoden der TACE und der MWA. Die Ergebnisse zeigen, dass die CTC-Anzahlen nach durchgeführter TACE bzw. MWA im Mittel um 0,3 CTCs pro ml Blut im Vergleich zu vor der Therapie sanken. Dies ist statistisch ein „mittlerer Unterschied“. Der statistische Test ergab einen $p$-Wert von $p=0,08$. Die Wahrscheinlichkeit, dass das Ergebnis kein Zufall ist beträgt somit 99,2\% und ist daher zwar nicht signifikant, jedoch hoch.

Ein Absinken der CTC-Anzahl wurde vor der Durchführung dieser Studie nicht als Ergebnis erwartet. Es wurde eher ein kurzfristiger Anstieg der CTC-Anzahl nach Einsetzen der radiologischen Interventionen angenommen. Diese Annahme basierte zum einen auf der Tumorzellfreisetzung bei der Therapie des HCCs und zum anderen auf der Gefäßarchitektur in Tumoren. Diese Gründe werden in folgenden Kapiteln näher erläutert.

\subsubsection{Tumorzellfreisetzung bei der Therapie des hepatozellulären Karzinoms}

Wie in Kapitel 2.3.1 beschrieben, können Eingriffe am Tumor zur iatrogenen Freisetzung von Tumorzellen führen. ${ }^{40,41,42}$

Bei der Therapiemethode der Leberresektion wurde bereits eine Erhöhung der CTC-Anzahl im Blut der Patienten nach dem Eingriff nachgewiesen. ${ }^{87,88}$ Es ist anzunehmen, dass es deshalb nach einer Resektion zu einer hohen Inzidenz von intrahepatischen und extrahepatischen Metastasen sowie zu Rezidivraten von mehr als $50 \%$ nach Therapie kommt. ${ }^{87,88}$

Sowohl bei der Therapie der TACE als auch bei der MWA wird die Freisetzung von Tumorzellen ebenso als potenzielle Komplikation diskutiert. ${ }^{89}$ 
Bis dato bestehen keine aussagekräftigen Studien zur Tumorzell-Freisetzung bei HCC-Patienten nach einer MWA. Es wird dennoch versucht einer solchen potenziellen Tumorzellfreisetzung entgegenzuwirken, zum Beispiel indem der Punktionskanal bei einer MWA beim Herausziehen der Sonde mit Mikrowellen bestrahlt wird, um geschädigte Gefäße zu veröden und mitgeschleppte Tumorzellen zu zerstören. ${ }^{89}$ Dies könnte ein Grund für das stärkere Absinken der CTC-Anzahl bei einer MWA- (0,4 CTCs pro ml Blut) im Vergleich zu einer TACE-Therapie $(0,2$ CTCs pro ml Blut) sein.

Untersuchungen zur Tumorzell-Freisetzung bei HCC nach einer TACE wurden zum derzeitigen Zeitpunkt mittels des epithelialen Zelladhäsionsmoleküls (epithelial cell adhesion molecule, Ep-CAM), einem Standard-Karzinomzellen-Marker, durchgeführt. ${ }^{90}$ In diesen Studien war die Anzahl der CTCs im Blut der untersuchten Patienten nach TACE nicht signifikant erhöht. ${ }^{90} \mathrm{Im}$ Unterschied dazu basiert die in dieser Arbeit vorliegende Studie zu TACE und MWA auf der CTC-Detektion mithilfe eines anderen Markers mit dem, ohne Ep-CAM, bislang keine Studie zur CTC-Freisetzung bei HCC-Patienten nach TACE durchgeführt wurde. Die Ergebnisse der durchgeführten Arbeit mit dem CD146-Antikörper und ohne den Ep-CAM-Marker zeigen das Absinken der CTC-Anzahl nach durchgeführter radiologischer Intervention. Die Wahrscheinlichkeit, dass das Ergebnis ein reiner Zufallsbefund ist, beträgt lediglich $0,8 \%(p=0,08)$. Deshalb ist davon auszugehen, dass es rentabel wäre weitere Studien mit dem CD146 Marker in diesem Gebiet anzuschließen.

\subsubsection{Gefäßarchitektur in Tumoren}

Nach neuesten Studien besteht die Auskleidung der Blutgefäße in malignen Geweben, im Gegensatz zu normalen Blutgefäßen, durch die zwiebelschalenartige Architektur der Tumorzellen um eine Kapillare herum, oft aus 20-mal mehr Tumorzellen als Endothelzellen. ${ }^{91}$ Dabei kann jedoch nicht differenziert werden, ob die Tumorzellen tatsächlich strukturelle Elemente vaskulärer Kanäle darstellen oder ob es sich um Tumorzellen handelt, die sich gerade im Durchgang in das Gefäß hinein oder aus dem Gefäß heraus befinden. ${ }^{91}$ Die direkte Manipulation solcher Tumorgefäße könnte daher, vor allem bei einer TACE, eine Tumorzellfreisetzung und damit einen Anstieg der CTC-Anzahl im Blut des Patienten, bedingen. Auch dies ist eine Erklärung für das stärkere Absinken der CTC-Anzahl bei einer MWA, 
bei der eine direkte Gefäßmanipulation in geringerem Ausmaß als bei der TACE stattfindet.

\subsubsection{Metastasierung durch CTCs}

Die Folgen des Absinkens der CTC-Anzahl nach durchgeführter radiologischer Intervention senkt auch die Wahrscheinlichkeit einer Metastasierung des Tumors.

Eine Metastasierung kann nämlich zum einen durch direkte Gewebeinvasion oder aber durch lymphatische oder hämatogene Streuung stattfinden. ${ }^{92}$ Das HCC metastasiert hauptsächlich durch die hämatogene Streuung, es breitet sich also vor allem über den Blut-Weg aus. ${ }^{93}$ Weiterhin ist bekannt, dass bei vaskulärer Tumorinvasion, das Risiko einer extrahepatischen Ausbreitung erhöht ist. ${ }^{94}$

Eine geringere Anzahl von CTCs geht daher mit einem niedrigeren Metastasierungsrisiko einher. Ob jedoch eine Metastasierung, eventuell durch freigesetzte Tumorzellen bei radiologischer Intervention, stattgefunden hat, kann durch die Untersuchung der Kurzzeitdynamik von CTCs nicht gänzlich ausgeschlossen werden. Für die vorliegende Studie wurden die Blutproben nach der TACE bzw. MWA direkt bis zu maximal fünf Minuten nach der Therapie abgenommen. Um eine Metastasierung feststellen zu können, müssten CTC-Anzahlen im Blut der Patienten zu einem späteren Zeitpunkt erneut bestimmt werden. Es war in der Arbeitsgruppe geplant für die Langzeitdynamik von CTCs nach TACE bzw. MWA jeweils erneut Blutproben der HCC-Patienten sechs und zwölf Monate nach Therapie zu untersuchen.

Könnte man das Absinken der Tumorzellanzahl im Blut nach einer radiologischen Intervention als signifikant nachweisen, würde das bedeuten, dass die diskutierten theoretischen Risiken einer Tumorzellfreisetzung bei TACE und MWA praktisch nicht gegeben sind. Im Gegenteil, der Nutzen der TACE und MWA wäre dann nicht nur ein direkter Versuch der Elimination des lokalen Tumors in der Leber, sondern auch ein Verringern der CTC-Anzahl im Blut der Patienten und damit ein niedrigeres Metastasierungsrisiko nach der Therapie. Dies würde ein deutlich besseres klinisches Outcome für HCC-Patienten nach einer solchen radiologischen Intervention bedeuten. 
Insgesamt hatte die Studie jedoch zu wenig „power“, um die Ergebnisse als signifikant auszuweisen.

Daher bleiben weitere Studien mit einem größeren Patientenkollektiv abzuwarten.

\subsection{Unterschied der Anzahl zirkulierender Tumorzellen zwischen gesunden Probanden und hepatozellulären Karzinompatienten}

Ein Unterschied der CTC-Anzahlen zwischen Gesunden und an HCC erkrankten Personen hätte die verwendete Methode als potenzielles Mittel zur Diagnostik oder Überwachung von HCC-Patienten herausstellen können.

Die statistische Auswertung der Ergebnisse ergab einen Wert des Mann-WhitneySchätzers aus gesunden und erkrankten Personen von 0,56-0,62. Dieser Wert zeigt, dass mit etablierter Methode nur ein geringer Unterschied zwischen gesunden Probanden und erkrankten HCC-Patienten (vor der Therapie) feststellbar ist.

Bislang wird bei Verdacht auf ein HCC meist eine Gewebebiopsie entnommen, um das suspekte Gewebe auf Pathologien zu untersuchen. ${ }^{95}$ Allerdings handelt es sich dabei um einen invasiven Eingriff, der zusätzlich das Risiko der Tumorzellfreisetzung birgt. ${ }^{95}$

Des Weiteren ist die Effektivität der HCC-Überwachung insgesamt sowohl mittels AFP-Wert als auch durch die Sonografie in der gegenwärtigen klinischen Praxis als eher unbefriedigend einzuschätzen, da angesichts dieser, nach aktuellen Studien aus den USA, kaum Verringerungen der HCC-bezogenen Mortalität beobachtet werden konnten. ${ }^{96}$

Es ist daher wünschenswert den Nutzen der Diagnostik zu maximieren und dabei die Invasivität zu minimieren. Aus diesen Gründen ist diese Doktorarbeit als Teil in einem Projekt der Allgemeinchirurgischen Klinik eingeschlossen, dessen Rahmen einerseits weitere Therapiemethoden und andererseits weitere Diagnosen von früheren sowie künftigen Patienten umfasst und umfassen wird. Ein Ziel des Projektes ist die Untersuchung der "Liquid Biopsy“ (dt. „flüssige Biopsie“), die in folgendem Kapitel näher erläutert werden soll. 


\subsubsection{Liquid Biopsy}

Die Methode der Liquid Biopsy wurde erstmals 1948 beschrieben. ${ }^{97}$ Die Liquid Biopsy bezeichnet eine Diagnostik bei der v.a. zellfreie Nukleinsäuren aus Körperflüssigkeiten, in der Regel CTCs oder zirkulierende freie Desoxyribonukleinsäuren („cirulating free“ DNA, cfDNA) aus dem Blut, angereichert und anschließend untersucht werden. ${ }^{98}$

Ein Vorteil der Liquid Biopsy ist die minimale Invasivität, da dem Patienten lediglich Blut entnommen werden muss. Es findet somit keine direkte Manipulation mit erhöhtem Risiko der Tumoraussaat statt. In diesem Zuge könnten CTCs dabei nicht nur detektiert, sondern anhand der Expression von speziellen Oberflächenmarkern näher charakterisiert werden. Zudem kann die CTC-Bestimmung im Laufe eines Behandlungszyklus als Indikator für die Effizienz der gewählten Therapie dienen, wodurch sich ggfs. die Prognose genauer vorhersagen lässt. ${ }^{99} \mathrm{CTC}$ s sind, aufgrund der durch den wachsenden Tumor verursachten Erosionen, auch schon in frühen Stadien der Karzinogenese nachweisbar. ${ }^{100}$ Die Liquid Biopsy wäre dazu leicht in den klinischen Alltag zu integrieren und bietet gleichzeitig den Vorteil jederzeit wiederholt werden zu können. In Abgrenzung zur normalen Biopsie, die lediglich Auskunft über den Zustand des Tumors zum Entnahmezeitpunkt gibt, spiegelt die Liquid Biopsy den Status der Erkrankung zum Zeitpunkt der Blutentnahme wider. Aufgrund der Wiederholbarkeit dieser Methode lässt sich so der Verlauf der Tumorerkrankung beurteilen.

Würde die in dieser Studie angewandte Methode zur CTC-Isolation und Detektion als Screeningverfahren für HCC-Patienten angewendet werden, zeigte sich eine Sensitivität von 0,78 und eine Spezifität von 0,38 . Dies bedeutete, dass $78 \%$ der tatsächlichen HCC-Patienten als solche erkannt würden und $38 \%$ der gesunden Patienten als gesund erkannt würden. Dies ist hinsichtlich eines Einsatzes als Screening-Methode in der Klinik als nicht ausreichend zu beurteilen, da sich die falsch-positiven Ergebnisse auf ca. $62 \%$ belaufen würden. Im Vergleich zum Screening mittels AFP-Wert-Bestimmung, die eine Sensitivität von 25 - $65 \%$ aufweist, liegt die hier erforschte Methode darüber. Bei der Spezifität von 80 - $94 \%$ zeigt sich der AFP-Wert in deutlichem Vorteil. 
Es bleiben also weitere Studien und Verfahren zur CTC-Detektion abzuwarten. Wünschenswert wäre eine Etablierung einer Liquid Biopsy Methode mit höchstmöglicher Sensitivität und Spezifität, die in den klinischen Alltag sowohl als Screening als auch zur Überwachung von Tumorpatienten einsetzbar wäre. Dies betrifft nicht nur das HCC, sondern wäre fachübergreifend für alle Tumorarten erstrebenswert. 


\subsection{Korrelation zwischen der Kurzzeitdynamik der CTCs und der des} AFP- Wertes als anerkannter klinischer Tumormarker

Zur Überprüfung der Funktionalität der vorliegenden Studie und der Methodik sollte die Kurzzeitdynamik der CTC-Anzahlen mit der Kurzzeitdynamik des AFP-Wertes auf eine Korrelation hin untersucht werden, da das AFP ein anerkannter klinischer Tumormarker für das HCC ist. ${ }^{16}$

Die Ergebnisse zeigen, dass die CTC-Anzahlen insgesamt gesunken sind. Jedoch war dies bei den AFP-Werten nicht der Fall. Ein negatives rho bedeutet eine negative Korrelation der Differenzen. D.h. wenn ein Wert steigt, sinkt der andere. Das Ergebnis hat in diesem Fall medizinisch keine Relevanz, da der p-Wert mit 0.901814 deutlich zeigt, dass dieser Test keine Signifikanz aufweist. Somit kann zu der Korrelation der Differenzen der CTC Anzahlen und der AFP-Werte bislang keine Aussage getroffen werden.

Die Gründe für das unterschiedliche Verhalten der CTC-Anzahlen und AFP-Werte müssen jedoch nicht an der Methodik dieser Arbeit liegen, sondern könnten an den Ungenauigkeiten des AFP-Wertes liegen.

Die Spezifität und Sensitivität von Tumormarkern sind bekanntlich oft nicht hoch genug als dass sie sich für ein Tumorscreening eignen. ${ }^{101}$ Dies bestätigt sich auch im Falle des AFP-Wertes. AFP weist als Screening-Test erhebliche Einschränkungen auf: In einem Drittel bis zur Hälfte der HCC-Fälle ist AFP nicht signifikant erhöht. ${ }^{102},{ }^{103}, 104,105$ Dies kann daran liegen, dass nahezu ein Drittel der Patienten mit radiologisch sichtbarem HCC nicht-AFP-produzierende Tumore tragen. ${ }^{102}$ Diese Fakten betreffen sicherlich auch das Patientenkollektiv in vorliegender Arbeit. Nur vier von 18 Patienten mit diagnostiziertem HCC wiesen pathologisch erhöhte AFP-Werte auf.

Auch umgekehrt kann AFP bei Menschen ohne HCC-Erkrankung erhöht sein. ${ }^{105},{ }^{16}$ Aus oben genannten Gründen ist es erstrebenswert, dass in Zukunft präzisere Marker die Tumorscreenings unterstützen können. ${ }^{101}$ Zum Beispiel könnte dies durch die Bestimmung von CTC-Anzahlen, im Sinne einer Liquid Biopsy (s.o.) erfolgen. 
Der Hauptnutzen von Tumormarkern liegt eher in Therapieverlaufskontrollen bzw. in der Nachsorge von Tumoren. ${ }^{101}$ AFP ist der am häufigsten verwendete Tumormarker zur HCC-Verlaufskontrolle und wurde bis vor kurzem in internationale Richtlinien für die HCC-Überwachung aufgenommen. ${ }^{7},{ }^{106}, 107$ Aktuell wird jedoch der Nutzen der AFP-Bestimmung stark diskutiert. ${ }^{108,}$ 109, 110 Diese Verlaufskontrolle bedeutet allerdings ein erneutes Überprüfen des Wertes nach Monaten. Doch in vorliegender Studie wurden die AFP-Werte direkt vor und direkt nach der Therapie bestimmt. Es ist zu vermuten, dass auch deshalb keine Aussage zu einer Korrelation der Werte gemacht werden konnte. Insgesamt ist davon auszugehen, dass die Effektivität der HCC-Überwachung sowohl mittels AFP als auch mittels Sonografie in der gegenwärtigen klinischen Praxis nicht optimal ist, da kaum Verringerungen der HCC-bezogenen Mortalität beobachtet werden können. ${ }^{96}$ Deshalb könnte auch zur Überwachung der HCC-Patienten eine Bestimmung der CTC-Anzahlen mit ausreichend sensitiver und spezifischer Methode hilfreich sein.

Es bleiben weitere Studien zur Entwicklung einer sichereren Screening- und Überwachungsmethode für das HCC abzuwarten. 


\subsection{Korrelation zwischen der Kurzzeitdynamik der CTCs und der des IL-6- Werts als neu diskutierter Tumormarker}

Als zweiter Tumormarker sollte in dieser Studie kein klinisch etablierter, sondern ein neuer, noch weitgehend unerforschter Marker, das IL-6, zum Einsatz kommen.

Das Ergebnis des Spearman's Korrelationskoeffizienten rho von +0.032361 zeigt eine sehr schwache Korrelation zwischen den Differenzen der CTCs und der der IL-6-Werte. (Effektstärke $<0,2=$ schwach). Der p-Wert von 0.901814 zeigt keine Signifikanz des Ergebnisses.

Die CTC-Anzahlen als auch die IL-6-Werte waren beide insgesamt gesunken. Ein positives rho bedeutet eine Korrelation der Differenzen. D.h. wenn ein Wert sinkt bzw. steigt, sinkt bzw. steigt auch der andere. In diesem Falle könnte der geringe Stichprobenumfang von $n=18$ den niedrigen $p$-Wert verschulden.

Es kann also zur Korrelation der Differenzen der CTC Anzahlen und der IL-6-Werte bislang keine statistisch signifikante Aussage getroffen werden. Allerdings geben die Ergebnisse einen Hinweis auf eine mögliche Korrelation. Daher bleiben Studien zur IL-6-Verwendung als Tumormarker bei HCC mit größerem Stichprobenumfang abzuwarten. 


\subsection{Limitationen}

\subsubsection{Blutproben-Gewinnung und Lagerung}

Die Gewinnung der Blutproben der HCC-Patienten stellt den ersten kritischen Punkt des Ablaufs der Methodik dar. In einer Studie aus dem Jahr 2014, die die CTC-Freisetzung bei HCC nach TACE untersuchte, waren signifikant mehr CTCs in Proben des zentralen Blutes als im peripheren Blut von Patienten mit HCC zu finden. ${ }^{90}$ Daher ist es zu erwägen nachfolgende Studien mit Blutproben, die zentral gewonnen wurden, durchzuführen. Dies führt jedoch zu dem Problem der Invasivität. Bei der TACE und der MWA ist kein Legen eines zentralen Venenkatheters notwendig. Wenn die Forschung invasiver als die Therapie ist, kommt die ethische Frage des Nutzens für das Individuum auf.

Das Blut der Patienten lagerte, wie in der Methodik beschrieben, in den „Cellsave Preservative Tubes“. Laut Produktdatenblatt der Firma CellSearch ${ }^{\circledR}$ können CTCs bis zu 10 Tage in diesen Röhrchen bei Raumtemperatur gelagert werden, ohne beschädigt zu werden. Bislang gibt es jedoch keine veröffentlichte wissenschaftliche Studie zur Stabilität von CTCs in diesen Röhrchen. Um diese Fehlerquelle zu eliminieren sollte in nachfolgenden Versuchen frisches Blut ohne den Zwischenschritt der Cellsave Preservative Tubes untersucht werden.

\subsubsection{Isolation mit OncoQuick}

Das OncoQuick Röhrchen zur Isolation von CTCs fand bereits in vielen Studien Verwendung. ${ }^{111-113}$ Wenngleich das OncoQuick Röhrchen in den durchgeführten Vorversuchen das Verfahren zur Isolation von CTCs mit der größten Ausbeute war, zeigte eine Studie, dass es die CTCs nur in $23 \%$ der Patienten mit Tumoren wieder finden ließ. ${ }^{114}$ In dieser Studie wurde das OncoQuick mit einer weiteren IsolationsMethode, die in vorliegender Arbeit nicht in Betracht gezogen wurde, verglichen. Bei dieser Vergleichsmethode wurden CTCs beispielsweise bei 54\% der Patienten wiedergefunden. ${ }^{114}$ Des Weiteren konnten bei der Vergleichsmethode $20 \mathrm{CTCs}$ pro ml Blut wieder gefunden werden, während man mit Hilfe des OncoQuick-Röhrchens nur 3 CTCs pro ml Blut detektieren konnte. ${ }^{114}$ Diese Vergleichsmethode hatte also die bessere Ausbeute. Was sie, so wie viele weitere Verfahren, jedoch vom OncoQuick unterscheidet, ist die Isolation mit Hilfe von Ep-CAM. ${ }^{115}$ Während das OncoQuick Röhrchen rein auf physikalischen Mechanismen beruht, basieren viele 
andere Isolationsmethoden auf der Bindung an den Ep-CAM-Rezeptor. ${ }^{115} \mathrm{Da}$ auf diesen Marker in vorliegender Studie verzichtet wurde, fiel die Entscheidung auf das verwendete OncoQuick Röhrchen.

Eine weitere Fehlerquelle, die durch das OncoQuick Röhrchen entstanden sein könnte, stellt die notwendige Verdünnung der FACS-Proben vor Detektion mit dem Durchflusszytometer da, weil die im OncoQuick Röhrchen gewonnenen FACS-Proben offenbar viele Zellen enthielten, die keine CTCs waren.

\subsubsection{Detektion zirkulierender Tumorzellen}

Die Auswahl der eingesetzten Antikörper und die Kriterien der detektierten Tumorzellen sind eindeutig kritische Punkte bei der Detektion von CTCs.

Bis dato war keine Studie zur CTC-Detektion mit den für diese wissenschaftliche Arbeit verwendeten Antikörpern und CTC-Kriterien aufzufinden.

Aus den Vorversuchen war ersichtlich, dass die reinen HepG2-Zellen mit angewendeter Methode zu 91,5 \% sowohl CD45 negativ als auch ASGPR-1 und CD146 positiv waren. Auch dies hätte theoretisch gereicht, um eine gefundene Zelle als CTC zu kategorisieren. Die im Rahmen dieser Studie detektierten CTCs haben zudem zusätzlich sowohl Tumorstammzell-Eigenschaften als auch Eigenschaften von aggressiven Tumorzellen. Es ist aus den Ergebnissen anzunehmen, dass ca. lediglich 7,4\% der HCC-Zellen allen diesen Merkmalen nachkommen. Daher ist davon auszugehen, dass ein Großteil der CTCs im Blut der Patienten nicht erfasst werden konnte.

Ebenso kritisch zu beurteilen sind die unterschiedlichen Blutmengen der Proben von 2,5 bis $21,5 \mathrm{ml}$, in denen unterschiedlich große Anzahlen an CTCs enthalten sein können, allein aufgrund des unterschiedlichen Volumens.

Außerdem ist die Verdünnung der FACS-Proben (s. 4.1), die aus technischen Gründen erforderlich war, ein limitierender Faktor dieser Arbeit. 


\subsection{Ausblick}

Es ist unbestreitbar, dass die frühzeitige Erkennung von Tumoren und Metastasen in der Medizin dringend benötigt wird und neue Techniken und Erkenntnisse den derzeitigen Standpunkt verbessern können. ${ }^{95}$ In der Zukunft könnte die CTC-Detektion ein wichtiges diagnostisches Werkzeug sein und eventuell sogar neue und genauere Klassifizierungen des HCCs ermöglichen. ${ }^{95}$

Die Forschung an einer Liquid Biopsy-Methode läuft glücklicherweise weiter fort. Aktuellste Studien (03/2019) konnten beispielsweise einen vielversprechenden Fortschritt in der Liquid-Biopsy-Methode verzeichnen. In dieser Studie war es möglich durch den Nachweis von cfDNA und Proteinen mit einer Sensitivität von 85\% und einer Spezifität von 93\% ein HCC im Frühstadium von asymptomatischen Populationen mit unbekanntem HCC-Status zu identifizieren. ${ }^{116}$

Wenngleich diese experimentelle, wissenschaftliche Arbeit noch keine Methode zur Isolation und Detektion von CTCs bei HCC-Patienten hervorbrachte, die signifikante Ergebnisse zeigen kann, sind die Auswertungen dennoch ein vielversprechender Hinweis auf zukünftige Studien der radiologischen Interventionen. 


\section{Publikation dieser Arbeit}

Teile der Forschungsergebnisse dieser Dissertation werden aktuell als wissenschaftliches Paper in der internationalen Online-Fachzeitschrift der Public Library of Science, PLOS ONE veröffentlicht.

Der Titel der Publikation lautet: „Early dynamic changes in circulating tumor cells and prognostic relevance following interventional radiological treatment in patients with hepatocellular carcinoma"

Die Autoren mit zugehörigen Institutionen der Publikation lauten:

Thomas J. Vogl 1, Linda J. Riegelbauer 2, Elsie Oppermann 2, Michel Kostantin 2, Hanns Ackermann 3, Annette Trzmiel 4, Stefan Stein 4, Katrin Eichler 1, Vladimir P. Zharov 5, Dhruvajyoti Roy 6, Andreas A. Schnitzbauer 2, Benjamin Strücker 7, Andreas Pascher 7, Wolf O. Bechstein 2, Mazen A. Juratli 2,7

1 Institute of Diagnostic and Interventional Radiology, Frankfurt University Hospital, Goethe University, Frankfurt, Germany

2 Department of General, Visceral and Transplant Surgery, Frankfurt University Hospital, Goethe University, Frankfurt, Germany

3 Department of Biomedical Statistics, Frankfurt University Hospital, Frankfurt am Main, Germany.

4 Flow Core Unit, Georg-Speyer-Haus, Frankfurt, Germany

5 Arkansas Nanomedicine Center, University of Arkansas for Medical Sciences, USA

6 Laboratory for Advanced Medicine, Inc., Irvine, CA, USA

7 Department of General, Visceral and Transplant Surgery, Muenster University Hospital, Muenster, Germany 
Das Ziel des Papers war es, gleichsam dieser Dissertation, die Veränderungen von CTC Anzahlen bei Patienten mit HCC vor und unmittelbar nach der Durchführung einer MWA und einer TACE zu untersuchen. Zusätzlich wurde die CTC Kurzzeitdynamik mit dem klinischen Verlauf der HCC-Patienten verglichen. Blutproben von 17 Patienten mit HCC, die sich einer MWA $(n=10)$ oder C-TACE $(n=7)$ unterzogen hatten, wurden analysiert. (Im Vergleich zu dieser Dissertation wurde ein TACE Patient ausgeschlossen, da er eine starke Abweichung aufzeigte).

Venöses Blut wurde vor und unmittelbar nach den radiologischen Eingriffen entnommen, um CTCs mittels Durchflusszytometrie zu isolieren und zu quantifizieren. CTCs wurden als DAPI+/CD45- identifiziert und positiv für die Marker ASGPR, CD146 und CD274 (PD-L1). (Im Vergleich zu dieser Dissertation wurde der Marker CD90 ausgeschlossen, da er die gefundenen CTCs zu sehr minimiert haben könnte).

Der klinische Verlauf der Patienten wurde bis zu 2,2 Jahre nach der radiologischen Intervention verfolgt. CTCs wurden bei 13 HCC-Patienten nachgewiesen (76\%) und vor den radiologischen Eingriffen entdeckt. Die Rate der CTCs war nach der Intervention bei den mit MWA behandelten Patienten signifikant verringert $(0,4 \mathrm{CTCs} / \mathrm{mL}$ Blut, $\mathrm{p}=0,031)$. (Im Vergleich zu dieser Dissertation wurde für die statistische Auswertung hier mit dem Programm Prism 7 für Windows (Version 7.04) GraphPad Software, Inc, San Jose, gearbeitet. Die Ergebnisse der Kurzzeitdynamik der MWA-Patienten konnten, im Gegensatz zu dieser Dissertation, als signifikant betrachtet werden.

Es wurden jedoch keine signifikanten Unterschiede bei Patienten beobachtet, die eine TACE erhielten ( $0,3 \mathrm{CTCs} / \mathrm{ml}$ Blut, $\mathrm{p}=0,3)$.

Insgesamt wurde keine Korrelation zwischen der CTC-Rate vor und nach der radiologischen Intervention und der Rezidivrate des HCCs gefunden. Diese vorläufigen Daten konnten jedoch, die tumorabtötende Wirkung der MWA bei Patienten mit HCC durch eine signifikante Senkung der CTC-Rate bestätigen. Die MWA scheint eine wirksame und vielversprechende Methode zu sein für HCCPatienten. Jedoch bleiben groß angelegte, randomisierte klinische Studien sind 
erforderlich, um die zukünftige Rolle und die prognostische Relevanz von CTCs nach dieser Behandlung zu bestimmen. 


\section{Literaturverzeichnis}

1. Severi $T$, van Malenstein $H$, Verslype $C$, van Pelt JF. Tumor initiation and progression in hepatocellular carcinoma. Risk factors, classification, and therapeutic targets. Acta Pharmacol Sin. 2010;31(11):1409-1420. doi:10.1038/aps.2010.142.

2. Jemal A, Bray F, Center MM, Ferlay J, Ward E, Forman D. Global cancer statistics. CA Cancer J Clin. 2011;61(2):69-90. doi:10.3322/caac.20107.

3. Manns MP, Schneidewind S, eds. Praxis der Hepatologie. Berlin, Heidelberg: Springer Berlin Heidelberg; 2016.

4. Robert Koch-Institut (Hrsg) und die Gesellschaft. Krebs in Deutschland für 2013/2014, 11. Ausgabe. Berlin.

5. Koch-Institut R. Leber (C22) „Krebs in Deutschland für 2013/2014. 11. Ausgabe. Robert Koch-Institut (Hrsg) und die Gesellschaft der epidemiologischen Krebsregister in Deutschland e.V. (Hrsg). Berlin, 2017.

6. Pachmann K. Die Bedeutung der im Blut zirkulierenden Tumorzellen in der Metastasierungskaskade. DZO. 2012;44(01):11-16. doi:10.1055/s-00311298684.

7. Bruix J, Sherman M. Management of hepatocellular carcinoma. An update. Hepatology. 2011;53(3):1020-1022. doi:10.1002/hep.24199.

8. Gerd Herold, ed. Innere Medizin. Köln: Herold, Gerd; 2018.

9. Llovet JM, Burroughs A, Bruix J. Hepatocellular carcinoma. The Lancet. 2003;362(9399):1907-1917. doi:10.1016/S0140-6736(03)14964-1.

10. Leitlinienprogramm Onkologie (Deutsche Krebsgesellschaft, Deutsche Krebshilfe, AWMF): Diagnostik und Therapie des hepatozellulären Karzinoms, Langversion 1.0, AWMF Registrierungsnummer: 032-053OL; Mai 2013.

11. Gassmann D, Schmid S, Hofer S. Wie sinnvoll sind Tumormarker im klinischen Altag? Praxis (Bern 1994). 2017;106(25):1383-1389. doi:10.1024/16618157/a002853.

12. Lou J, Zhang L, Lv S, Zhang C, Jiang S. Biomarkers for Hepatocellular Carcinoma. Biomark Cancer. 2017;9:1-9. doi:10.1177/1179299X16684640.

13. Alotaibi H, Atabey N, Diril K, Erdal E, Ozturk M. Molecular Mechanisms of Hepatocellular Carcinoma. In: Carr BI, ed. Hepatocellular carcinoma. 
Diagnosis and treatment. [Place of publication not identified]: Springer; 2016:43-63.

14. Amit S, Jorge A. M. Screening for Hepatocellular Carcinoma. Gastroenterol Hepatol (N Y). 2008;4(3):201-208.

15. Trevisani F, Garuti F, Neri A. Alpha-fetoprotein for Diagnosis, Prognosis, and Transplant Selection. Semin Liver Dis. 2019. doi:10.1055/s-0039-1677768.

16. Biselli M, Conti F, Gramenzi A, et al. A new approach to the use of $\alpha-$ fetoprotein as surveillance test for hepatocellular carcinoma in patients with cirrhosis. Br J Cancer. 2015;112(1):69-76. doi:10.1038/bjc.2014.536.

17. Cedrone A, Covino M, Caturelli E, et al. Utility of alpha-fetoprotein (AFP) in the screening of patients with virus-related chronic liver disease: does different viral etiology influence AFP levels in HCC? A study in 350 western patients. Hepatogastroenterology. 2000;47(36):1654-1658.

18. Trevisani F, D'Intino PE, Morselli-Labate AM, et al. Serum a-fetoprotein for diagnosis of hepatocellular carcinoma in patients with chronic liver disease. Influence of HBsAg and anti-HCV status. Journal of Hepatology. 2001;34(4):570-575. doi:10.1016/S0168-8278(00)00053-2.

19. Debruyne EN, Delanghe JR. Diagnosing and monitoring hepatocellular carcinoma with alpha-fetoprotein: new aspects and applications. Clin Chim Acta. 2008;395(1-2):19-26. doi:10.1016/j.cca.2008.05.010.

20. Gosain R, Anwar S, Miller A, lyer R, Mukherjee S. Interleukin-6 as a biomarker in patients with hepatobiliary cancers. J Gastrointest Oncol. 2019;10(3):537545. doi:10.21037/jgo.2019.01.09.

21. Bergmann J, Müller M, Baumann N, et al. IL-6 trans-signaling is essential for the development of hepatocellular carcinoma in mice. Hepatology. 2017;65(1):89-103. doi:10.1002/hep.28874.

22. Wang C-Q, Sun H-T, Gao X-M, et al. Interleukin-6 enhances cancer stemness and promotes metastasis of hepatocellular carcinoma via up-regulating osteopontin expression. Am J Cancer Res. 2016;6(9):1873-1889.

23. Kong L, Zhou Y, Bu H, Lv T, Shi Y, Yang J. Deletion of interleukin-6 in monocytes/macrophages suppresses the initiation of hepatocellular carcinoma in mice. J Exp Clin Cancer Res. 2016;35(1):131. doi:10.1186/s13046-0160412-1. 
24. Hassan EA, Ahmed EH, Nafee AM, El-Gafary N, Hetta HF, El-Mokhtar MA. Regulatory T Cells, IL10 and IL6 in HCV Related Hepatocellular Carcinoma after Transarterial Chemoembolization (TACE). Egypt J Immunol. 2019;26(1):69-78.

25. Suttorp N, Möckel M, Siegmund B, Dietel M, eds. Harrisons Innere Medizin. 19th ed.: ABW Wissenschaftsverlag; 2016.

26. Forner A, Reig ME, Lope CR de, Bruix J. Current strategy for staging and treatment. The BCLC update and future prospects. Semin Liver Dis. 2010;30(1):61-74. doi:10.1055/s-0030-1247133.

27. Raschzok N, Schmelzle M, Pratschke J. Leberresektion vs. Lebertransplantation bei HCC. Gastroenterologe. 2016;11(5):383-390. doi:10.1007/s11377-016-0095-3.

28. Bruix J, Gores GJ, Mazzaferro V. Hepatocellular carcinoma. Clinical frontiers and perspectives. Gut. 2014;63(5):844-855. doi:10.1136/gutjnl-2013-306627.

29. Schneider F, DeGIR. Minimal-invasive Gefäßeingriffe unter Röntgenkontrolle: Radiologische Interventionen gehören in die Radiologie! Stellungnahme der Fachgesellschaften und Berufsverbände der Radiologie und der Neuroradiologie zur aktuellen Diskussion der MWBO. Fortschr Röntgenstr. 2017;189(03):268-270. doi:10.1055/s-0043-102926 .

30. Vogl TJ, Panahi B, Fischer S, et al. Interventionelle Therapie von Lungen- und Lebermetastasen. Onkologe. 2014;20(8):746-756. doi:10.1007/s00761-0142669-3.

31. Forner A, Gilabert M, Bruix J, Raoul J-L. Treatment of intermediate-stage hepatocellular carcinoma. Nat Rev Clin Oncol. 2014;11(9):525-535. doi:10.1038/nrclinonc.2014.122.

32. Davis $C R$. Interventional radiological treatment of hepatocellular carcinoma. Cancer Control. 2010;17(2):87-99. doi:10.1177/107327481001700204.

33. Vogl TJ, Zangos S, Balzer JO, et al. Transarterielle Chemoembolisation (TACE) des hepatozellulären Karzinoms. Technik, Indikationsstellung und Ergebnisse. Rofo. 2007;179(11):1113-1126. doi:10.1055/s-2007-963285.

34. Simon CJ, Dupuy DE, Mayo-Smith WW. Microwave ablation. Principles and applications. Radiographics. 2005;25 Suppl 1:S69-83. doi:10.1148/rg.25si055501. 
35. Brace CL. Microwave ablation technology. What every user should know. Curr Probl Diagn Radiol. 2009;38(2):61-67. doi:10.1067/j.cpradiol.2007.08.011.

36. AUTHOR U. Physical Properties of Tissues: A Comprehensive Reference Book. Burlington: Elsevier Science; 1990.

37. Dr. rer. nat. Tobias M. Gorges, Prof. Dr. med. Klaus Pantel. Ist die Metastasierung bald vorhersagbar? Deutsches Ärzteblatt. 2016;2016(2):8-10.

38. Ashworth T. A case of cancer in which cells similar to those in the tumors were seen in the blood after death. Aust Med J 14. 1869(14):146-149.

39. Liotta LA, Saidel MG, Kleinerman J. The significance of hematogenous tumor cell clumps in the metastatic process. Cancer Res. 1976;36(3):889-894.

40. Demicheli R, Retsky MW, Hrushesky WJM, Baum M, Gukas ID. The effects of surgery on tumor growth. A century of investigations. Ann Oncol. 2008;19(11):1821-1828. doi:10.1093/annonc/mdn386.

41. Juratli MA, Siegel ER, Nedosekin DA, et al. In Vivo Long-Term Monitoring of Circulating Tumor Cells Fluctuation during Medical Interventions. PLOS ONE. 2015;10(9):e0137613. doi:10.1371/journal.pone.0137613.

42. Koonce NA, Juratli MA, Cai C, et al. Real-time monitoring of circulating tumor cell (CTC) release after nanodrug or tumor radiotherapy using in vivo flow cytometry. Biochem Biophys Res Commun. 2017;492(3):507-512. doi:10.1016/j.bbrc.2017.08.053.

43. Alix-Panabières $C$, Pantel K. Challenges in circulating tumour cell research. Nat Rev Cancer. 2014;14(9):623-631. doi:10.1038/nrc3820.

44. Cohen SJ, Punt CJA, lannotti N, et al. Relationship of circulating tumor cells to tumor response, progression-free survival, and overall survival in patients with metastatic colorectal cancer. J Clin Oncol. 2008;26(19):3213-3221. doi:10.1200/JCO.2007.15.8923.

45. US National Library of Medicine, National Institutes of Health. https://www.ncbi.nlm.nih.gov/pubmed?term=circulating+tumor+cells\&cmd=Det ailsSearch. Accessed December 29, 2018.

46. Nieto MA. Epithelial plasticity. A common theme in embryonic and cancer cells. Science. 2013;342(6159):1234850. doi:10.1126/science.1234850.

47. Giannelli G, Koudelkova P, Dituri F, Mikulits W. Role of epithelial to mesenchymal transition in hepatocellular carcinoma. Journal of Hepatology. 2016;65(4):798-808. doi:10.1016/j.jhep.2016.05.007. 
48. Yu J-M, Sun W, Hua F, et al. BCL6 induces EMT by promoting the ZEB1mediated transcription repression of E-cadherin in breast cancer cells. Cancer Lett. 2015;365(2):190-200. doi:10.1016/j.canlet.2015.05.029.

49. Zasadkevich YM, Sazonov SV. The role of E-cadherin cell adhesion molecule in human ontogenesis in norm and pathology. Morfologiia. 2014;146(5):78-82.

50. Kalluri R, Weinberg RA. The basics of epithelial-mesenchymal transition. J Clin Invest. 2009;119(6):1420-1428. doi:10.1172/JCI39104.

51. Wu S, Liu S, Liu Z, et al. Classification of Circulating Tumor Cells by EpithelialMesenchymal Transition Markers. PLOS ONE. 2015;10(4). doi:10.1371/journal.pone.0123976.

52. Friedmann-Morvinski D, Verma IM. Dedifferentiation and reprogramming. Origins of cancer stem cells. EMBO Rep. 2014;15(3):244-253. doi:10.1002/embr.201338254.

53. Zhu L, Zhang W, Wang J, Liu R. Evidence of CD90+CXCR4+ cells as circulating tumor stem cells in hepatocellular carcinoma. Tumour Biol. 2015;36(7):5353-5360. doi:10.1007/s13277-015-3196-6.

54. Dan L. Longo. Krebszellbiologie und Angiogenese. Für die deutsche Ausgabe Thomas Böhm. In: Suttorp N, Möckel M, Siegmund B, Dietel M, eds. Harrisons Innere Medizin: ABW Wissenschaftsverlag; 2016:719-736.

55. Visvader JE. Cells of origin in cancer. Nature. 2011;469(7330):314-322. doi:10.1038/nature09781.

56. Chaffer CL, Brueckmann I, Scheel C, et al. Normal and neoplastic nonstem cells can spontaneously convert to a stem-like state. Proc Natl Acad Sci U S A. 2011;108(19):7950-7955. doi:10.1073/pnas.1102454108.

57. Alison MR, Islam S, Wright NA. Stem cells in cancer: instigators and propagators? J Cell Sci. 2010;123(Pt 14):2357-2368. doi:10.1242/jcs.054296.

58. Ailles LE, Weissman IL. Cancer stem cells in solid tumors. Curr Opin Biotechnol. 2007;18(5):460-466. doi:10.1016/j.copbio.2007.10.007.

59. Chen W-C, Hsu H-P, Li C-Y, et al. Cancer stem cell marker CD90 inhibits ovarian cancer formation via $\beta 3$ integrin. Int J Oncol. 2016;49(5):1881-1889. doi:10.3892/ijo.2016.3691.

60. Yang ZF, Ho DW, Ng MN, et al. Significance of CD90+ cancer stem cells in human liver cancer. Cancer Cell. 2008;13(2):153-166. doi:10.1016/j.ccr.2008.01.013. 
61. Rege TA, Hagood JS. Thy-1 as a regulator of cell-cell and cell-matrix interactions in axon regeneration, apoptosis, adhesion, migration, cancer, and fibrosis. FASEB J. 2006;20(8):1045-1054. doi:10.1096/fj.05-5460rev.

62. Dennis JE, Esterly K, Awadallah A, Parrish CR, Poynter GM, Goltry KL. Clinical-scale expansion of a mixed population of bone-marrow-derived stem and progenitor cells for potential use in bone-tissue regeneration. Stem Cells. 2007;25(10):2575-2582. doi:10.1634/stemcells.2007-0204.

63. Lázaro CA, Croager EJ, Mitchell C, et al. Establishment, characterization, and long-term maintenance of cultures of human fetal hepatocytes. Hepatology. 2003;38(5):1095-1106. doi:10.1053/jhep.2003.50448.

64. Lu J-W, Chang J-G, Yeh K-T, Chen R-M, Tsai JJP, Hu R-M. Overexpression of Thy $1 / C D 90$ in human hepatocellular carcinoma is associated with HBV infection and poor prognosis. Acta Histochem. 2011;113(8):833-838. doi:10.1016/j.acthis.2011.01.001.

65. Gao Q, Wang X-Y, Qiu S-J, et al. Overexpression of PD-L1 significantly associates with tumor aggressiveness and postoperative recurrence in human hepatocellular carcinoma. Clin Cancer Res. 2009;15(3):971-979. doi:10.1158/1078-0432.CCR-08-1608.

66. Sheng J, Fang W, Yu J, et al. Expression of programmed death ligand-1 on tumor cells varies pre and post chemotherapy in non-small cell lung cancer. Sci Rep. 2016;6:20090. doi:10.1038/srep20090.

67. Anantharaman A, Friedlander T, Lu D, et al. Programmed death-ligand 1 (PDL1) characterization of circulating tumor cells (CTCs) in muscle invasive and metastatic bladder cancer patients. BMC Cancer. 2016;16(1):744. doi:10.1186/s12885-016-2758-3.

68. Freeman GJ, Long AJ, Iwai Y, et al. Engagement of the PD-1 immunoinhibitory receptor by a novel $\mathrm{B} 7$ family member leads to negative regulation of lymphocyte activation. J Exp Med. 2000;192(7):1027-1034.

69. Wang X, Teng F, Kong L, Yu J. PD-L1 expression in human cancers and its association with clinical outcomes. Onco Targets Ther. 2016;9:5023-5039. doi:10.2147/OTT.S105862.

70. Long J, Qu T, Pan XF, et al. Expression of programmed death ligand-1 and programmed death 1 in hepatocellular carcinoma and its clinical significance. $J$ 
Cancer Res Ther. 2018;14(Supplement):S1188-S1192. doi:10.4103/09731482.204850.

71. Pantel K, Alix-Panabières $C$. Detection methods of circulating tumor cells. $J$ Thorac Dis. 2012;4(5):446-447. doi:10.3978/j.issn.2072-1439.2012.08.15.

72. Hong $B, Z u$ Y. Detecting circulating tumor cells: current challenges and new trends. Theranostics. 2013;3(6):377-394. doi:10.7150/thno.5195.

73. Basu S, Campbell HM, Dittel BN, Ray A. Purification of specific cell population by fluorescence activated cell sorting (FACS). J Vis Exp. 2010(41). doi:10.3791/1546.

74. Herzenberg LA, Rosa SC de. Monoclonal antibodies and the FACS: complementary tools for immunobiology and medicine. Immunol Today. 2000;21(8):383-390.

75. Givan AL. Flow cytometry: First principles. 2nd ed. New York: Wiley-Liss; 2010.

76. Mazen A. Juratli, Roxana Zokai, Linda Riegelbauer, Michel Konstantin, Philipp Stoffers, Elsie Oppermann, Wolf O. Bechstein, Andreas A. Schnitzbauer. 8th UCT Science Day abstract book: October 27, 2017, p84. Frankfurt am Main; 27.10.2017.

77. BioCision, LLC 12 E. Sir Francis Drake Boulevard, Unit B, Larkspur, CA 94939 USA. CoolCell囚 LX. http://www.biocision.com/uploads/docs/lit_CoolCell_Brochure.pdf. Updated May 15, 2018.

78. Prof. Dr. HP Seelig, Dr. CA Seelig. Asialoglykoproteinrezeptor-Autoantikörper. Updated September 23, 2012.

79. Jiang G, Zhang L, Zhu Q, Bai D, Zhang C, Wang X. CD146 promotes metastasis and predicts poor prognosis of hepatocellular carcinoma. J Exp Clin Cancer Res. 2016;35:38. doi:10.1186/s13046-016-0313-3.

80. Hoffbrand AV. Grundkurs Hämatologie: Blackwell-Verlag; 2003.

81. Schumacher M, Schulgen G. Methodik klinischer Studien: Methodische Grundlagen der Planung, Durchführung und Auswertung. 3rd ed. Berlin: Springer; 2009.

82. Bortz J, Lienert GA. Kurzgefasste Statistik für die klinische Forschung: Leitfaden für die verteilungsfreie Analyse kleiner Stichproben ; mit 13 
Abbildungen und 97 Tabellen sowie zahlreichen Formeln. 3rd ed. Berlin, Heidelberg: Springer; 2008.

83. Weiß C. Basiswissen Medizinische Statistik. 5th ed. Berlin: Springer; 2010.

84. Pospeschill M, Siegel R. Methoden für die klinische Forschung und diagnostische Praxis. Berlin, Heidelberg: Springer Berlin Heidelberg; 2018.

85. BD FACSAria ${ }^{\text {TM }}$ Fusion Cell Sorter. Technical Specifications.

86. Lenhard W. Psychometrica - Tools zur Berechnung von Sensitivität, Spezifität, positivem und negativem prädiktiven Wert, sowie dem relativen Anstieg der Trefferquote (RATZ-Index). https://www.psychometrica.de/testkennwerte.html. Updated August 25, 2018. Accessed August 17, 2019.

87. Cha C, Fong $Y$, Jarnagin WR, Blumgart LH, DeMatteo RP. Predictors and patterns of recurrence after resection of hepatocellular carcinoma. J Am Coll Surg. 2003;197(5):753-758. doi:10.1016/j.jamcollsurg.2003.07.003.

88. Felden $\mathrm{J}$ von, Schulze $\mathrm{K}, \mathrm{Krech} \mathrm{T}$, et al. Circulating tumor cells as liquid biomarker for high $\mathrm{HCC}$ recurrence risk after curative liver resection. Oncotarget. 2017;8(52):89978-89987. doi:10.18632/oncotarget.21208.

89. Liang $P$, Wang Y. Microwave ablation of hepatocellular carcinoma. Oncology. 2007;72 Suppl 1:124-131. doi:10.1159/000111718.

90. Fang Z-T, Zhang W, Wang G-Z, et al. Circulating tumor cells in the central and peripheral venous compartment - assessing hematogenous dissemination after transarterial chemoembolization of hepatocellular carcinoma. Onco Targets Ther. 2014;7:1311-1318. doi:10.2147/OTT.S62605.

91. Kelley RK, Magbanua MJM, Butler TM, et al. Circulating tumor cells in hepatocellular carcinoma. A pilot study of detection, enumeration, and nextgeneration sequencing in cases and controls. BMC Cancer. 2015;15:206. doi:10.1186/s12885-015-1195-z.

92. Becker AK, Tso DK, Harris AC, Malfair D, Chang SD. Extrahepatic metastases of hepatocellular carcinoma. A spectrum of imaging findings. Can Assoc Radiol J. 2014;65(1):60-66. doi:10.1016/j.carj.2013.05.004.

93. Poon RT-P, Ng IO-L, Lau C, et al. Tumor microvessel density as a predictor of recurrence after resection of hepatocellular carcinoma. A prospective study. $J$ Clin Oncol. 2002;20(7):1775-1785. doi:10.1200/JCO.2002.07.089. 
94. Kanda M, Tateishi R, Yoshida H, et al. Extrahepatic metastasis of hepatocellular carcinoma. Incidence and risk factors. Liver Int. 2008;28(9):1256-1263. doi:10.1111/j.1478-3231.2008.01864.x.

95. Chiappini F. Circulating tumor cells measurements in hepatocellular carcinoma. Int J Hepatol. 2012;2012:684802. doi:10.1155/2012/684802.

96. El-Serag HB, Kramer JR, Chen GJ, Duan Z, Richardson PA, Davila JA. Effectiveness of AFP and ultrasound tests on hepatocellular carcinoma mortality in HCV-infected patients in the USA. Gut. 2011;60(7):992-997. doi:10.1136/gut.2010.230508.

97. Mandel $P$, Metais $P$. Les acides nucléiques du plasma sanguin chez l'homme. C R Seances Soc Biol Fil. 1948;142(3-4):241-243.

98. Jung A, Kirchner T. Liquid Biopsy in Tumor Genetic Diagnosis. Dtsch Arzteb/ Int. 2018;115(10):169-174. doi:10.3238/arztebl.2018.0169.

99. Qiao Y, Li J, Shi C, et al. Prognostic value of circulating tumor cells in the peripheral blood of patients with esophageal squamous cell carcinoma. Onco Targets Ther. 2017;10:1363-1373. doi:10.2147/OTT.S129004.

100. Juratli MA, Sarimollaoglu M, Nedosekin DA, Melerzanov AV, Zharov VP, Galanzha El. Dynamic Fluctuation of Circulating Tumor Cells during Cancer Progression. Cancers (Basel). 2014;6(1):128-142. doi:10.3390/cancers6010128.

101. Gassmann D, Schmid S, Hofer S. Wie sinnvoll sind Tumormarker im klinischen Alltag? https://econtent.hogrefe.com/doi/abs/10.1024/16618157/a002853?rfr_dat=cr_pub\%3Dpubmed\&url_ver=Z39.882003\&rfr_id=ori\%3Arid\%3Acrossref.org\&journalCode=prx. Updated December 12, 2017. Accessed March 17, 2019.

102. Agopian VG, Harlander-Locke MP, Markovic D, et al. Evaluation of Patients With Hepatocellular Carcinomas That Do Not Produce a-Fetoprotein. JAMA Surg. 2017;152(1):55-64. doi:10.1001/jamasurg.2016.3310.

103. Colli A, Fraquelli M, Casazza G, et al. Accuracy of ultrasonography, spiral $\mathrm{CT}$, magnetic resonance, and alpha-fetoprotein in diagnosing hepatocellular carcinoma: a systematic review. Am J Gastroenterol. 2006;101(3):513-523. doi:10.1111/j.1572-0241.2006.00467.x.

104. Giannini EG, Marenco S, Borgonovo G, et al. Alpha-fetoprotein has no prognostic role in small hepatocellular carcinoma identified during surveillance 
in compensated cirrhosis. Hepatology. 2012;56(4):1371-1379.

doi:10.1002/hep.25814.

105. Lok AS, Sterling RK, Everhart JE, et al. Des-gamma-carboxy prothrombin and alpha-fetoprotein as biomarkers for the early detection of hepatocellular carcinoma. Gastroenterology. 2010;138(2):493-502. doi:10.1053/j.gastro.2009.10.031.

106. EASL-EORTC clinical practice guidelines: management of hepatocellular carcinoma. Journal of Hepatology. 2012;56(4):908-943. doi:10.1016/j.jhep.2011.12.001.

107. Bruix J, Sherman M. Management of hepatocellular carcinoma. Hepatology. 2005;42(5):1208-1236. doi:10.1002/hep.20933.

108. Lee E, Edward S, Singal AG, Lavieri MS, Volk M. Improving screening for hepatocellular carcinoma by incorporating data on levels of $\alpha$-fetoprotein, over time. Clin Gastroenterol Hepatol. 2013;11(4):437-440. doi:10.1016/j.cgh.2012.11.029.

109. El-Serag HB, Kanwal F. a-Fetoprotein in hepatocellular carcinoma surveillance: mend it but do not end it. Clin Gastroenterol Hepatol. 2013;11(4):441-443. doi:10.1016/j.cgh.2012.12.046.

110. Yao M, Zhao J, Lu F. Alpha-fetoprotein still is a valuable diagnostic and prognosis predicting biomarker in hepatitis $B$ virus infection-related hepatocellular carcinoma. Oncotarget. 2016;7(4):3702-3708. doi:10.18632/oncotarget.6913.

111. Clawson GA, Kimchi E, Patrick SD, et al. Circulating tumor cells in melanoma patients. PLOS ONE. 2012;7(7):e41052. doi:10.1371/journal.pone.0041052.

112. Obermayr E, Sanchez-Cabo F, Tea M-KM, et al. Assessment of a six gene panel for the molecular detection of circulating tumor cells in the blood of female cancer patients. BMC Cancer. 2010;10:666. doi:10.1186/1471-240710-666.

113. Müller V, Stahmann N, Riethdorf S, et al. Circulating tumor cells in breast cancer: correlation to bone marrow micrometastases, heterogeneous response to systemic therapy and low proliferative activity. Clin Cancer Res. 2005;11(10):3678-3685. doi:10.1158/1078-0432.CCR-04-2469. 
114. Balic M, Dandachi N, Hofmann G, et al. Comparison of two methods for enumerating circulating tumor cells in carcinoma patients. Cytometry $B$ Clin Cytom. 2005;68(1):25-30. doi:10.1002/cyto.b.20065.

115. Königsberg R, Obermayr E, Bises $G$, et al. Detection of EpCAM positive and negative circulating tumor cells in metastatic breast cancer patients. Acta Oncol. 2011;50(5):700-710. doi:10.3109/0284186X.2010.549151.

116. Qu C, Wang $\mathrm{Y}$, Wang $\mathrm{P}$, et al. Detection of early-stage hepatocellular carcinoma in asymptomatic HBsAg-seropositive individuals by liquid biopsy. Proc Natl Acad Sci U S A. 2019. doi:10.1073/pnas.1819799116.

117. CLS Cell Lines Service GmbH. CLS Product Information: HepG2. https://clsgmbh.de/pdf/hepg2.pdf. Updated May 14, 2018. 


\section{Abbildungsverzeichnis}

Abbildung 1 - Erkrankungsrate Deutschland 1999 - 2015 ............................. 11

Abbildung 2 - BCLC-Klassifizierung des HCCs ........................................... 14

Abbildung 3 - Therapievefahren der Transarteriellen Chemoembolisation........... 17

Abbildung 4 - Prinzip der Mikrowellenablation.................................................. 18

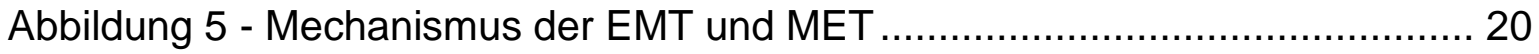

Abbildung 6 - Durchflusszytometer.................................................... 23

Abbildung 7 - Prinzip der Anfärbung mit fluoreszenzmarkierten Antikörpern ....... 24

Abbildung 8 - Prinzip der CTC-Isolation mit Oncoquick Röhrchen ....................... 30

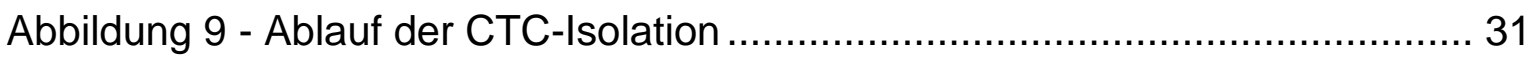

Abbildung 10- Ablauf der CTC-Anfärbung mit fluoreszenzmarkierten Antikörpern33

Abbildung 11 - CTCs im Immunfluoreszenz-Mikroskop.................................. 38

Abbildung 12 - Ergebnisse der Durchflusszytometrie: HepG2-Zellen mit Antikörper-

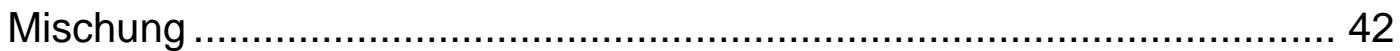

Abbildung 13 - Ergebnisse der CTC-Anzahlen bei TACE im Vergleich............... 55

Abbildung 14 - Ergebnisse der CTC-Anzahlen bei MWA im Vergleich................. 56

Abbildung 15 - Ergebnisse der CTC-Anzahlen bei TACE und MWA.................. 57

Abbildung 16 - HDs vs. TACE-Patienten ............................................... 58

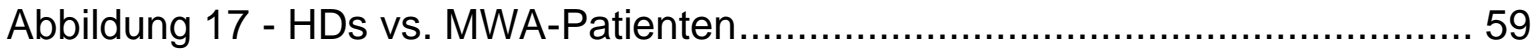

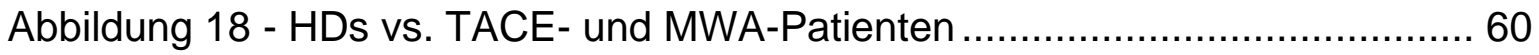

Abbildung 19 - FACS-Auswertung, zweites Gate ......................................... 61

Abbildung 20 - FACS-Auswertung, drittes Gate ............................................ 62

Abbildung 21 - FACS-Auswertung Tabelle TACE5 prä-op ............................... 63 


\section{Tabellenverzeichnis}

Tabelle 1 - Behandlungstechniken interventioneller Radiologie .......................... 16

Tabelle 2 - Ein- und Ausschlusskriterien der Studienpopulation........................... 27

Tabelle 3 - Ergebnisse des Vorversuchs 1 .................................................. 39

Tabelle 4 - verwendete Antikörper-Zusammensetzung ..................................... 41

Tabelle 5 - Kollektiv A - Patienten, die eine TACE erhielten................................. 48

Tabelle 6 - Kollektiv B - Patienten, die eine MWA erhielten ............................... 49

Tabelle 7 - Kollektiv $C$ - gesunde Probanden ................................................ 50

Tabelle 8 - Ergebnisse prä-op ................................................................ 52

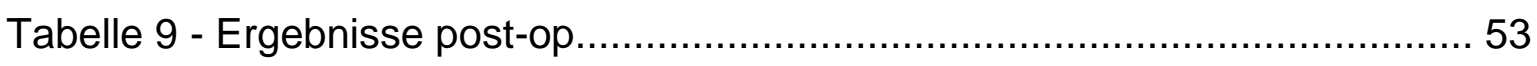

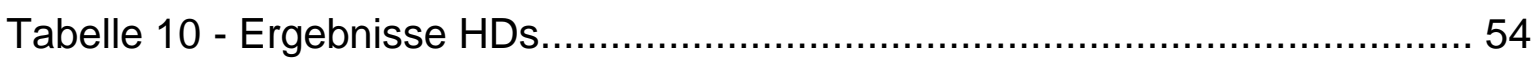

Tabelle 11 - AFP-Werte und Differenzen der AFP-Werte und CTC-Anzahlen ..... 64

Tabelle 12 - IL-6-Werte und Differenzen der IL-6-Werte und CTC-Anzahlen ....... 66

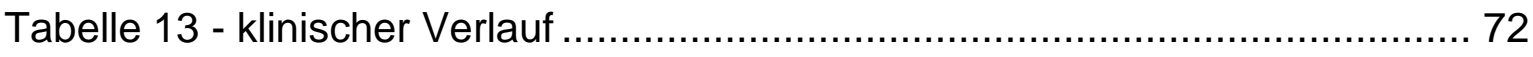

Tabelle 13 - verwendete Geräte mit Hersteller ............................................. 107

Tabelle 14 - verwendete Verbrauchsmaterialien mit Herstellern ....................... 108

Tabelle 15 - Chemikalien, Lösungen und Puffer........................................... 109

Tabelle 16 - Zusammensetzung des Zellmediums für die HepG2-Zellen ............ 112

Tabelle 17 - Zusammensetzung des Einfriermediums für die HepG2-Zellen ..... 112 


\section{Abkürzungsverzeichnis}

\begin{tabular}{|c|c|}
\hline Abkürzung & Bedeutung \\
\hline A. & Arteria (dt. Arterie) \\
\hline Abk. & Abkürzung \\
\hline AFP & Alpha-Fetoprotein \\
\hline Anm. & Anmerkung \\
\hline APC & Allophycocyanin \\
\hline ASGPR-1 & Asialoglykoproteinrezeptor \\
\hline BCLC & Barcelona Clinic Liver Cancer Klassifikation \\
\hline Begleiterkrank. & Begleiterkrankung/en \\
\hline ca. & circa \\
\hline CD & Cluster of Differentation \\
\hline cfDNA & Cell free DNA (dt. zellfreie Desoxyribunukleinsäure) \\
\hline $\csc (s)$ & Tumorstammzelle(n) \\
\hline CTC(s) & Zirkulierende Tumorzelle(n) \\
\hline Cy5.5 & Cyanin5.5-Molekül \\
\hline d.h. & das heißt \\
\hline DeGIR & $\begin{array}{l}\text { Deutsche Gesellschaft für internationale Radiologie und } \\
\text { minimalinvasive Therapie }\end{array}$ \\
\hline Dil.faktor & Verdünnungsfaktor \\
\hline Dr. & Doktor \\
\hline dt. & deutsch \\
\hline e.V. & Eingetragener Verein \\
\hline einges. & eingesetzt \\
\hline EMT & Epithelial-mesenchymale Transition \\
\hline engl. & englisch \\
\hline Ep-CAM & $\begin{array}{l}\text { Epithelial cell adhesion molecule (dt. epitheliales } \\
\text { Zelladhäsionsmolekül) }\end{array}$ \\
\hline FACS & Fluorescence activated Cell Sorting \\
\hline FCU & Flow Core Unit \\
\hline
\end{tabular}


Abkürzungsverzeichnis

\begin{tabular}{|c|c|}
\hline Abkürzung & Bedeutung \\
\hline FITC & Fluoresceinisothiocyanat \\
\hline HBsAg & $\begin{array}{l}\text { Hepatitis B Virus surface antigen (dt. Hepatitis B Virus } \\
\text { Oberflächen Antigen) }\end{array}$ \\
\hline HCC & Hepatozelluläres Karzinom \\
\hline HD & Healthy Donor (dt. gesunder Spender/Proband) \\
\hline insb. & insbesondere \\
\hline IRE & Elektroporation \\
\hline LITT & Laserablation \\
\hline LTX & Lebertransplantation \\
\hline $\mathbf{m}$ & männlich \\
\hline MCAM & $\begin{array}{l}\text { Melanoma cell adhesion molecule (dt. Melanomzellen } \\
\text { Adhäsions Molekül) }\end{array}$ \\
\hline MET & Mesenchymal-epitheliale Transition \\
\hline MWA & Mikrowellenablation \\
\hline 0. & oder \\
\hline PBS & $\begin{array}{l}\text { Phosphate buffered Saline (dt. phosphatgepufferte } \\
\text { Salzlösung) }\end{array}$ \\
\hline PD-L1 & Programmed-Death Ligand1 \\
\hline PE & Phycoerythrin \\
\hline PerCP & Peridinin-Chlorophyll-Protein \\
\hline post & nach \\
\hline post-op & nach Therapie \\
\hline prä & vor \\
\hline prä-op & vor Therapie \\
\hline Prof. & Professor \\
\hline RFA & Radiofrequenzablation \\
\hline s. & siehe \\
\hline S. & Seite \\
\hline SIRT & Selektive interne Radiotherapie \\
\hline sog. & sogenannt \\
\hline
\end{tabular}


Abkürzungsverzeichnis

\begin{tabular}{|l|l|}
\hline Abkürzung & Bedeutung \\
\hline TACE & Transarterielle Chemoembolisation \\
\hline TACP & Transarterielle Chemoperfusion \\
\hline TIK & Tumor Isolation Kit \\
\hline u. & und \\
\hline u.A. & unter anderem \\
\hline UCT & Universitäres Centrum für Tumorerkrankungen \\
\hline vgl. & vergleiche \\
\hline w & weiblich \\
\hline z.B. & Zum Beispiel \\
\hline
\end{tabular}




\section{Anhang}

\subsection{Materialien}

Tabelle 13 verwendete Geräte mit Hersteller

\begin{tabular}{|c|c|}
\hline Material & Name, Firma (Standort) \\
\hline Automatisierter Färbeautomat & $\begin{array}{l}\text { Mirastainer II, VWR International } \\
\text { (Radnor, PA, USA) }\end{array}$ \\
\hline Cell Imaging System & $\begin{array}{l}\text { EVOS XL Core, Thermo Scientific } \\
\text { (Waltham, MA, USA) }\end{array}$ \\
\hline Zentrifugen & $\begin{array}{l}\text { Rotanta AP, Hettich (Tuttlingen, } \\
\text { Deutschland) } \\
\text { Heraeus Multifuge X3 FR, Thermo } \\
\text { Scientific (Waltham, MA, USA) }\end{array}$ \\
\hline \multirow[t]{2}{*}{ Durchflusszytometer/ Sorter } & $\begin{array}{l}\text { FACSAria }^{\mathrm{TM}} \text { Fusion, BD Biosciences } \\
\text { (San Jose, CA, USA) }\end{array}$ \\
\hline & $\begin{array}{l}\text { FACS Canto II, BD Biosciences (San } \\
\text { Jose, CA, USA) }\end{array}$ \\
\hline Lichtmikroskop & $\begin{array}{l}\text { VisiScope BL 214, VWR International } \\
\text { (Radnor, PA, USA) }\end{array}$ \\
\hline Plattformschüttler & $\begin{array}{l}\text { UNIMAX 1010, Heidolph (Schwabach, } \\
\text { Deutschland) }\end{array}$ \\
\hline MACS MultiStand & $\begin{array}{l}\text { Miltenyi Biotec GmbH (Bergisch } \\
\text { Gladbach, Deutschland) }\end{array}$ \\
\hline QuadroMACS Seperator & $\begin{array}{l}\text { Miltenyi Biotec GmbH (Bergisch } \\
\text { Gladbach, Deutschland) }\end{array}$ \\
\hline Sterile Werkbank & Antair BSK 6, Mc Labor oHG (Albstadt) \\
\hline Wasserbad & $\begin{array}{l}\text { 1003, Gesellschaft für Labortechnik } \\
\text { (Burgwedel) }\end{array}$ \\
\hline Brutschrank & $\begin{array}{l}\text { HERA cell, Thermo Scientific (Waltham, } \\
\text { Massachusetts, USA) }\end{array}$ \\
\hline
\end{tabular}


Einfrierbox

\subsubsection{Verbrauchsmaterialien}

Tabelle 14 verwendete Verbrauchsmaterialien mit Herstellern

\begin{tabular}{|l|l|}
\hline Material & Name, Firma (Standort) \\
\hline C-chips & NanoEnTek (Seoul, Korea) \\
\hline Zellkulturflaschen & Sarstedt (Nümbrecht, Deutschland) \\
\hline Combitips & $\begin{array}{l}\text { biopur 10 ml, Eppendorf (Hamburg, } \\
\text { Deutschland) }\end{array}$ \\
\hline Reagiergefäß & $\begin{array}{l}2.0 \text { ml, braun, Sarstedt (Nümbrecht, } \\
\text { Deutschland) }\end{array}$ \\
\hline Eppendorf cups & Eppendorf (Hamburg, Deutschland) \\
\hline FACS tubes & Falcon (Heidelberg, Deutschland) \\
\hline Cellstar Tubes & $\begin{array}{l}\text { PP 50 ml und 15 ml, Greiner bio-one } \\
\text { (Kremsmünster, Österreich) }\end{array}$ \\
\hline Filter Units & $\begin{array}{l}\text { Stericup \& Steritop, Sigma-Aldrich } \\
\text { (St. Louis, MO, USA) }\end{array}$ \\
\hline Pipette & $\begin{array}{l}\text { Mirco One, Starlab (Hamburg, } \\
\text { Deutschland) }\end{array}$ \\
\hline Pipette Tips & $\begin{array}{l}\text { Tip One, Starlab (Hamburg, } \\
\text { Deutschland) }\end{array}$ \\
\hline Pipettor & $\begin{array}{l}\text { Pipetus, Hirschmann-Laborgeräte } \\
\text { (Eberstadt, Deutschland) }\end{array}$ \\
\hline Serological Pipette & $\begin{array}{l}\text { Costar Stripette, Sigma-Aldrich (St. } \\
\text { Louis, MO, USA) }\end{array}$ \\
\hline CellSave Preservative Tubes & $\begin{array}{l}\text { Cellsearch, Menarini Silicon } \\
\text { Biosystems, (San Diego, CA, USA) }\end{array}$ \\
\hline Tumor Isolation Kit & $\begin{array}{l}\text { Miltenyi Biotec GmbH (Bergisch } \\
\text { Gladbach, Deutschland) }\end{array}$ \\
\hline & (I) \\
\hline
\end{tabular}




\begin{tabular}{|l|l|}
\hline $\begin{array}{l}\text { RosetteSep } \\
\text { Containing Anti-CD36 }\end{array}$ & $\begin{array}{l}\text { Stemcell Technologies (Vancouver, } \\
\text { BC, Kanada) }\end{array}$ \\
\hline EasySep $^{\mathrm{TM}}$ Human CD45 Depletion Kit & $\begin{array}{l}\text { Stemcell Technologies (Vancouver, } \\
\text { BC, Kanada) }\end{array}$ \\
\hline OncoQuick & $\begin{array}{l}\text { Greiner Bio One (Kremsmünster, } \\
\text { Österreich) }\end{array}$ \\
\hline MycoProbeTM - Mycoplasma Detection Kit & $\begin{array}{l}\text { R\&D Systems, Inc. (Minneapolis, } \\
\text { USA) }\end{array}$ \\
\hline
\end{tabular}

\subsubsection{Chemikalien, Lösungen und Puffer}

Tabelle 15 - Chemikalien, Lösungen und Puffer

\begin{tabular}{|l|l|}
\hline Material & Name, Firma (Standort) \\
\hline Destilliertes Wasser & $\begin{array}{l}\text { Fresenius Kabi (Bad Homburg v.d. } \\
\text { Höhe, Deutschland) }\end{array}$ \\
\hline Gentamicin Sulfate & Lonza (Walkersville, USA) \\
\hline Dulbecco's Modified Eagle Medium & $\begin{array}{l}\text { + L-Glutamin, Gibco/Invitrogen } \\
\text { (Karlsruhe) }\end{array}$ \\
\hline Hepes Buffer (1M) & Gibco/Invitrogen (Karlsruhe) \\
\hline PBS (ohne CaCl ${ }_{2}$ und MgCl ${ }_{2}$ ) & $\begin{array}{l}\text { Dulbeccos Phosphate Buffered } \\
\text { Saline, Sigma-Aldrich (St. Louis, MO, }\end{array}$ \\
\hline Bovines Serum Albumin (BSA) & Sigma-Aldrich (St. Louis, MO, USA) \\
\hline Fetal Bovine Serum (FBS) & $\begin{array}{l}\text { Gibco/Invitrogen (Karlsruhe, } \\
\text { Deutschland) }\end{array}$ \\
\hline Accutase & $\begin{array}{l}\text { Sigma-Aldrich (St. Louis, MO, USA) } \\
\text { FcR Blocking Reagent }\end{array}$ \\
\hline Trypanblau & $\begin{array}{l}\text { Gibco/Invitrogen (Karlsruhe, } \\
\text { Deutschland) }\end{array}$ \\
\hline Sigma-Aldrich (St. Louis, MO, USA) \\
\hline Gmonium Chlorid (NH4CI)
\end{tabular}




\begin{tabular}{|c|c|}
\hline APC Conjugation Kit & $\begin{array}{l}\text { Lightning-link APC Conjugation Kit, } \\
\text { Innova Bioscience (Cambridge, UK) }\end{array}$ \\
\hline ASGPR Antikörper & $\begin{array}{l}\text { Mouse anti-human, BD Biosciences } \\
\text { (San Jose, CA, USA) }\end{array}$ \\
\hline Anti-ASGPR1 FITC Antikörper & $\begin{array}{l}\text { Mouse anti-human, Hycult Biotech } \\
\text { (Plymouth, PA, USA) }\end{array}$ \\
\hline Anti-ASGPR1 PE Antikörper & $\begin{array}{l}\text { Mouse anti-human, BD Biosciences } \\
\text { (San Jose, CA, USA) }\end{array}$ \\
\hline Anti-CD146 PE Antikörper & $\begin{array}{l}\text { Mouse anti-human, Biolegend (San } \\
\text { Diego, CA, USA) }\end{array}$ \\
\hline Anti-CD146 APC Antikörper & Biolegend (San Diego, CA, USA) \\
\hline Anti-CD274 FITC Antikörper & $\begin{array}{l}\text { Mouse anti-human, BD Biosciences } \\
\text { (San Jose, CA, USA) }\end{array}$ \\
\hline Anti-CD274 BV421 Antikörper & $\begin{array}{l}\text { Mouse anti-human, Biolegend (San } \\
\text { Diego, CA, USA) }\end{array}$ \\
\hline Anti-CD326 PE Antikörper & $\begin{array}{l}\text { Mouse anti-human, Biolegend (San } \\
\text { Diego, CA, USA) }\end{array}$ \\
\hline Anti-CD45 FITC Antikörper & $\begin{array}{l}\text { Mouse anti-human, Biolegend (San } \\
\text { Diego, CA, USA) }\end{array}$ \\
\hline Anti-CD45 PE Antikörper & $\begin{array}{l}\text { Mouse anti-human, Biolegend (San } \\
\text { Diego, CA, USA) }\end{array}$ \\
\hline Anti-CD90 PE Antikörper & $\begin{array}{l}\text { Mouse anti-human, Santa Cruz } \\
\text { Biotechnology (Dallas, TX, USA) }\end{array}$ \\
\hline Anti-CD90 PerCp/Cy5.5 Antikörper & $\begin{array}{l}\text { Mouse anti-human, Biolegend (San } \\
\text { Diego, CA, USA) }\end{array}$ \\
\hline Dimethylsulfoxide (DMSO) & Sigma-Aldrich (St. Louis, MO, USA) \\
\hline Ethanol & Sigma-Aldrich (St. Louis, MO, USA) \\
\hline Ethylenediaminetetraacetic acid (EDTA) & Sigma-Aldrich (St. Louis, MO, USA) \\
\hline
\end{tabular}




\begin{tabular}{|c|c|}
\hline Sodium bicarbonate (NaHCO3) & Sigma-Aldrich (St. Louis, MO, USA) \\
\hline Ammoniumchlorid (NH4Cl2) & Sigma-Aldrich (St. Louis, MO, USA) \\
\hline Tumor Cell Isolation Kit & $\begin{array}{l}\text { Miltenyi Biotec } \mathrm{GmbH} \text { (Bergisch } \\
\text { Gladbach, Deutschland) }\end{array}$ \\
\hline $\begin{array}{l}\text { RosetteSep }{ }^{\mathrm{TM}} \text { CTC Enrichment Cocktail } \\
\text { Containing Anti-CD36 }\end{array}$ & $\begin{array}{l}\text { Stemcell Technologies (Vancouver, } \\
\text { BC, Kanada) }\end{array}$ \\
\hline EasySep $^{\mathrm{TM}}$ Human CD45 Depletion Kit & $\begin{array}{l}\text { Stemcell Technologies (Vancouver, } \\
\text { BC, Kanada) }\end{array}$ \\
\hline OncoQuick & $\begin{array}{l}\text { Greiner Bio One (Kremsmünster, } \\
\text { Österreich) }\end{array}$ \\
\hline MACS-Puffer & PBS + 0,5\% BSA + 2 mM EDTA \\
\hline FACS-Puffer & PBS + 0,5\% BSA \\
\hline Lyse-Puffer & $\begin{array}{l}\text { Destilliertes Wasser + } \\
\text { Ethylenediaminetetraacetic acid } \\
\text { (EDTA) \%? } \\
\text { Sodium bicarbonate (NaHCO3) \% }\end{array}$ \\
\hline PBS + 5mM EDTA & $500 \mathrm{ml}+950 \mathrm{mg}$ EDTA \% \\
\hline
\end{tabular}




\subsubsection{HCC-Zelllinie HepG2}

Die verwendete HepG2-Zelllinie stammt von der Firma CLS Cell Lines Service $\mathrm{GmbH}$ aus Heidelberg. Laut Herstellerangaben stammen die Zellen von einem hochdifferenziertem hepatozellulärem Karzinom eines männlichen, 15-jährigen Kaukasiers. ${ }^{117}$

\subsubsection{Zellmedium zur Kultivierung der HCC-Zelllinie HepG2}

Tabelle 16 Zusammensetzung des Zellmediums für die HepG2-Zellen

\begin{tabular}{cc}
\hline Chemikalie & Menge [\%] \\
\hline DMEM/F-12 Medium & 88,3 \\
Hepes Buffer (1M) & 1,8 \\
Gentamicin & 0,2 \\
\hline
\end{tabular}

\subsubsection{Einfriermedium zur Konservierung der HCC-Zelllinie HepG2}

Tabelle 17 Zusammensetzung des Einfriermediums für die HepG2-Zellen

\begin{tabular}{cc}
\hline Menge [\%] & Chemikalie \\
\hline 70 & Zellmedium (s.o.) \\
20 & FBS \\
10 & DMSO \\
\hline
\end{tabular}

